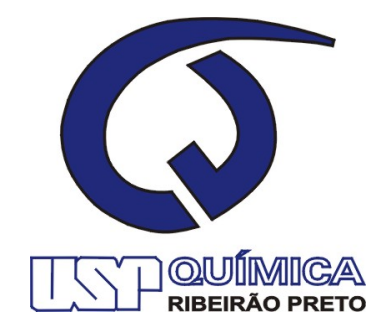

\author{
Universidade de São Paulo \\ Faculdade de Filosofia, Ciências e Letras de Ribeirão Preto \\ Departamento de Química \\ Programa de Pós-Graduação em Química
}

\title{
Avaliação de fungos na obtenção do metabólito quiral e ativo 0 -desmetilvenlafaxina.
}

\author{
Marcela Armelim Bortoleto
}

Dissertação apresentada à Faculdade de Filosofia, Ciências e Letras de Ribeirão Preto da Universidade de São Paulo, como parte das exigências para a obtenção do título de Mestre em Ciências.

Área: Química

RIBEIRÃO PRETO - SP 


\title{
Universidade de São Paulo \\ Faculdade de Filosofia, Ciências e Letras de Ribeirão Preto Departamento de Química \\ Programa de Pós-Graduação em Química
}

\section{Avaliação de fungos na obtenção do metabólito quiral e ativo 0 -desmetilvenlafaxina.}

\author{
Marcela Armelim Bortoleto
}

Prof. Dr. Anderson R. M. de Oliveira

Orientador

Dissertação apresentada à Faculdade de Filosofia, Ciências e Letras de Ribeirão Preto da Universidade de São Paulo, como parte das exigências para a obtenção do título de Mestre em Ciências.

Área: Química

RIBEIRÃO PRETO - SP 


\begin{abstract}
AUTORIZO A REPRODUÇÃO E DIVULGAÇÃO TOTAL OU PARCIAL DESTE TRABALHO, POR QUALQUER MEIO CONVENCIONAL OU ELETRÔNICO, PARA FINS DE ESTUDO E PESQUISA, DESDE QUE CITADA A FONTE.
\end{abstract}

\title{
FICHA CATALOGRÁFICA
}

Bortoleto, Marcela Armelim

Avaliação de fungos na obtenção do metabólito quiral e ativo O-desmetilvenlafaxina 100 p.; $30 \mathrm{~cm}$

Dissertação de Mestrado, apresentada à Faculdade de Filosofia, Ciências e Letras de Ribeirão Preto/USP - Área de concentração: Química.

Orientador: De Oliveira, Anderson Rodrigo Moraes

1. Venlafaxina. 2. DLLME.

3. Biotransformação por fungos. 4. Enantiosseparação 


\section{FOLHA DE APROVAÇÃO}

Marcela Armelim Bortoleto

Avaliação de fungos na obtenção do metabólito quiral e ativo O-desmetilvenlafaxina.

Dissertação de mestrado apresentada ao Programa de Pós-Graduação em Química para obtenção do título de Mestre em Ciências

Área de concentração: Química

Orientador: Prof. Dr. Anderson R. M. de Oliveira

Aprovada em:

\section{Banca Examinadora}

Prof. Dr.

Instituição: Assinatura:

Prof. Dr. Instituição: Assinatura:

Prof. Dr. Instituição: Assinatura:

Prof. Dr. Instituição: Assinatura:

Prof. Dr. Instituição: Assinatura: 


\section{DEDICATÓRIA}

Dedico este trabalho aos meus pais

Antônio Luiz e Gabriela. 


\section{AGRADECIMENTOS}

\section{A Deus.}

Ao Professor Anderson pela orientação exemplar e disponibilidade; pelo apoio e confiança depositados em mim;

Agradeço imensamente aos meus pais, Antônio Luiz e Gabriela, pelo abrigo e apoio incondicional e aos meus irmãos, Daniel e Andréa, pelo exemplo e amizade;

Ao meu namorado, Ricardo, pela paciência, carinho e compreensão;

Aos amigos do LABMETS pelo auxílio, companheirismo e bons momentos compartilhados;

À Mariana pelos ensinamentos e toda a ajuda;

Às agências de fomento CAPES, CNPq e FAPESP pelo auxílio financeiro;

A todos que contribuíram, direta ou indiretamente, para a conclusão desse trabalho, 


\section{"Talvez não tenhamos conseguido fazer o melhor, mas lutamos para que o melhor fosse feito."}

(Martin Luther King) 


\section{RESUMO}

BORTOLETO, M. A. Avaliação de fungos na obtenção do metabólito quiral e ativo Odesmetilvenlafaxina. 2014. Dissertação (Mestrado). Faculdade de Filosofia, Ciências e Letras de Ribeirão Preto - Universidade de São Paulo, Ribeirão Preto, 2014.

A venlafaxina é um fármaco quiral utilizado no tratamento da depressão e da ansiedade associada à depressão. A ação farmacológica desse fármaco está associada principalmente ao enantiômero (+)-(S)-venlafaxina, que inibe a recaptação da serotonina enantiosseletivamente. Quando metabolizada pelas enzimas da citocromo P450 dois metabólitos são produzidos, também quirais, a $\mathrm{O}$ desmetilvenlafaxina (ODV) e a $N$-desmetilvenlafaxina (NDV). O estudos mostram que o metabólito ODV é farmacologicamente ativo, apresentando ação farmacológica semelhante a venlafaxina. Fungos são micro-organismos capazes de mimetizar o metabolismo de mamíferos, produzindo, muitas vezes, os mesmos metabólitos. Além disso, esse processo pode ser enantiosseletivo. Dessa forma, o objetivo desse trabalho foi avaliar a capacidade de fungos em biotransformar a venlafaxina em seus metabólitos ODV e NDV de uma maneira enantiosseletiva. A separação quiral dos analitos foi realizada por cromatografia liquida de alta eficiência (CLAE) e eletroforese capilar (CE). Como técnica de preparação de amostra foi empregada a microextração liquido-liquido dispersiva (DLLME). Essa técnica recente de preparação de amostra possui alta eficiência na extração, permitindo a obtenção de altos valores de recuperação e um consumo mínimo de solvente orgânico. Anterior aos estudos de biotransformação, o método foi validado para análise por CLAE e CE, empregando, em ambos os casos, a DLLME como técnica de preparação de amostras. A validação foi realizada de acordo com as recomendações da ANVISA para análise de fármacos em material biológico. Todos os parâmetros avaliados (linearidade, precisão, exatidão, estabilidade, seletividade e limite de quantificação) apresentaram valores dentro das exigências da ANVISA. Os estudos de biotransformação foram realizados empregando os seguintes fungos: Mucor rouxii, Cunninghamella echinulata ATCC 8688A, Cunninghamella elegans 10028B, Beuveria bassiana ATCC 7159, Phomopsis sp (TD2), Chaetomiun globosun (VR10) e Glomerela cingulata (VA1). Entre esses, o fungo Cunninghamella elegans mostrou-se promissor na biotransformação da venlafaxina. Dessa forma, diversos fatores foram avaliados na tentativa de melhorar a biotransformação, sendo esses: troca de fonte de carbono do meio de cultura, alteração de meios de biotransformação e adição de cofatores ao meio de cultura. Os resultados mostraram fortes indícios de biotransformação enantiosseletiva da venlafaxina em seu metabólito (+)-(S)- $N$-desmetilvenlafaxina.

Palavras chave: venlafaxina, DLLME, biotransformação por fungos, enantioseparação. 


\begin{abstract}
BORTOLETO, M. A. Evaluation of fungi in obtaining the chiral and active metabolite O-desmethylvenlafaxine. 2014. Dissertação (Mestrado). Faculdade de Filosofia, Ciências e Letras de Ribeirão Preto - Universidade de São Paulo, Ribeirão Preto, 2014.

Venlafaxine is a chiral drug used in the treatment of depression and anxiety associated with depression. The pharmacological activity of this drug is mainly associated to the enantiomer (+)-(S)-venlafaxine, which inhibits the reuptake of serotonin with enantioselectivity. When metabolized by the cytochrome P450 enzymes, two metabolites, also chiral, are produced, O-desmethylvenlafaxine (ODV) and $\mathrm{N}$-desmethylvenlafaxine (NDV). The studies have demonstrated that the ODV metabolite is pharmacologically active, with similar pharmacological activity of venlafaxine. Fungal are microorganisms capable of mimicking the mammalian metabolism, often producing the same metabolites. Moreover, this process can be enantioselective. Thus, the aim of this study was to evaluate the ability of fungi to biotransform, with enantioselectivity, the venlafaxine in its metabolites ODV and NDV. The chiral separation of the analytes was performed by high performance liquid chromatography (HPLC) and capillary electrophoresis (CE). As sample preparation was employed the dispersive liquid-liquid microextraction (DLLME). This recent technique of sample preparation has high extraction efficiency, allowing obtaining high values of recovery and minimal consumption of organic solvent. Before the biotransformation studies, the method was validated employing CE and HPLC with the DLLME technique as sample preparation. The validation was performed according to ANVISA recommendations. All parameters (linearity, precision, accuracy, stability, selectivity and limit of quantification) were acceptable as required by ANVISA. The biotransformation studies were conducted using the following fungal: Mucor rouxii, Cunninghamella echinulata ATCC 8688A, Cunninghamella elegans 10028B, Beuveria bassiana ATCC 7159, Phomopsis sp (TD2), Chaetomiun globosun (VR10) and Glomerela cingulata (VA1). Among these, the fungus Cunninghamella elegans was promising in the biotransformation of venlafaxine. Thus, several factors were evaluated in an attempt to improve the biotransformation: carbon source exchange in the liquid culture medium, changes of the biotransformation medium and addition of cofators in the culture medium. The results provides strong evidences of enantioselective biotransformation of venlafaxine in its metabolite $(+)-(\mathrm{S})-\mathrm{N}$-desmethylvenlafaxine.
\end{abstract}

Keywords: venlafaxine, DLLME, fungal biotransformation, enantioseparation. 


\section{LISTA DE FIGURAS}

Figura 1 - Estrutura química da venlafaxina e seus metabólitos Odesmetilvenlafaxina e $N$-desmetilvenlafaxina.

Figura 2 - Estrutura química do tris (3,5-dimetilfenilcarbamato) de amilose e suas possíveis interações.

Figura 3 - Esquemas representativos do fluxo eletrodinânimo e do fluxo eletroosmótico.

Figura 4 - Estrutura molecular e esquema representativo da organização em cone truncado da $\alpha-C D$.

Figura 5 - Esquema representativo da microextração líquido-líquido dispersiva (DLLME)

Figura 6 - Esquema representativo do procedimento de biotransformação de fungos.

Figura 7 - Cromatogramas da separação quiral da Vx e metabólitos. (A)coluna Chiralpak AD-RH ${ }^{\circledR}$; (B)-coluna Chiralpak $A D^{\circledR}$ acoplada a uma coluna aquiral C18. (1)-(2) enantiômeros da ODV; (3)-(4)enantiômeros da NDV; (5)-(6) enantiômeros da Vx. Fase móvel: metanol: acetonitrila: água (80: 13: $7 \mathrm{v} / \mathrm{v} / \mathrm{v}$ ) com 0,15\% de trietilamina, temperatura de análise $23 \pm 2^{\circ} \mathrm{C}$ e vazão de $0,3 \mathrm{~mL}$ $\min ^{-1}$

Figura 8 - Gráfico de Ohm. Condições de análise: solução tampão fosfato $50 \mathrm{mmol} \mathrm{L}{ }^{-1} \mathrm{pH} 2,0$ contendo CM- $\beta-C D(1 \%)$ e $\alpha-C D(10 \mathrm{mmol}$ $\mathrm{L}^{-1}$ ), temperatura de análise $20^{\circ} \mathrm{C}$ 
Figura 9 - Eletroferograma da separação enantiosseletiva da venlafaxina e seus metabólitos. (1)-(2)-enantiômeros da $V x$; (3)-(4)enantiômeros da NDV; (5)-(6)-enantiômeros da ODV. Condições de análise: solução tampão fosfato de sódio 50 mmol L-1 $\mathrm{pH}^{2,0}$ contendo CM- $\beta$-CD (1\%) e $\alpha-\mathrm{CD}\left(8 \mathrm{mmol} \mathrm{L}^{-1}\right)$, tensão aplicada $+20 \mathrm{kV}$ e temperatura de análise $20^{\circ} \mathrm{C}$

Figura 10 - Cromatogramas referentes a análise dos enantiômeros (-)-R-Vx e (+)-S-Vx puros e fortificados em uma mistura racêmica. Condições cromatográficas: coluna Chiralpak $A D-R H^{\circledR}$, fase móvel: metanol: acetonitrila: água (80: $13: 7 \mathrm{v} / \mathrm{v} / \mathrm{v})+0,15 \%$ de trietilamina, temperatura de análise $23 \pm 2^{\circ} \mathrm{C}$ e vazão de $0,3 \mathrm{~mL}$ $\min ^{-1}$

Figura 11 - Cromatogramas referentes a análise dos enantiômeros (-)-RNDV e (+)-S-NDV puros e fortificados em uma mistura racêmica. Condições cromatográficas: coluna Chiralpak AD$\mathrm{RH}^{\circledR}$, fase móvel: metanol:acetonitrila:água $(80: 13: 7 \mathrm{~V} / \mathrm{V} / \mathrm{V})+$ $0,15 \%$ de trietilamina temperatura de análise $23 \pm 2^{\circ} \mathrm{C}$ e vazão de $0,3 \mathrm{~mL} \mathrm{~min}^{-1}$

Figura 12 - Cromatogramas referentes a análise dos enantiômeros (-)-RODV e (+)-S-ODV puros e fortificados em uma mistura racêmica. Condições cromatográficas: coluna Chiralpak AD$\mathrm{RH}^{\circledR}$, fase móvel: metanol: acetonitrila: água (80: 13: $\left.7 \mathrm{v} / \mathrm{V} / \mathrm{V}\right)+$ $0,15 \%$ de trietilamina, temperatura de análise $23 \pm 2^{\circ} \mathrm{C}$ e vazão de $0,3 \mathrm{~mL} \mathrm{~min}^{-1}$

Figura 13 - Eletroferogramas referentes a análise dos enantiômeros (+)-SVx e (-)-R-Vx puros e fortificados em uma mistura racêmica. Condições de análise: solução tampão fosfato de sódio 50 mmol L-1 $\mathrm{pH}^{2,0}$ contendo CM- $\beta-\mathrm{CD}(1 \%)$ e $\alpha$-CD $\left(8 \mathrm{mmol} \mathrm{L}^{-1}\right)$, tensão aplicada $+20 \mathrm{kV}$, temperatura do capilar $20^{\circ} \mathrm{C}$ 
Figura 14 - Eletroferogramas referentes a análise dos enantiômeros (+)-SNDV e (-)-NDV puros e fortificados em uma mistura racêmica. Condições de análise: solução tampão fosfato de sódio 50 mmol L-1 pH 2,0 contendo CM- $\beta-C D(1 \%)$ e $\alpha-C D\left(8 \mathrm{mmol} \mathrm{L}^{-1}\right)$, tensão aplicada $+20 \mathrm{kV}$, temperatura do capilar $20^{\circ} \mathrm{C}$

Figura 15 - Eletroferogramas referentes a análise dos enantiômeros (+)-SODV e (-)-R-ODV puros e fortificados em uma mistura racêmica. Condições de análise: solução tampão fosfato de sódio $50 \mathrm{mmol} \mathrm{L}^{-1} \mathrm{pH} \mathrm{2,0}$ contendo CM- $\beta$-CD (1\%) e $\alpha-C D(8$ $\left.\mathrm{mmol} \mathrm{L}{ }^{-1}\right)$, tensão aplicada $+20 \mathrm{kV}$, temperatura do capilar $20^{\circ} \mathrm{C}$.

Figura 16 - Otimização do tipo de solvente dispersor. Condições extração: $100 \mu \mathrm{L}$ de clorofórmio e $500 \mu \mathrm{L}$ de solvente dispersor. Amostra: $2 \mathrm{~mL}$ de meio de cultura liquido Czapek fortificado com $2 \mathrm{~mL}$ de solução tampão borato de sódio $100 \mathrm{mmol} \mathrm{L}^{-1} \mathrm{pH} 10$. Condições cromatográficas: coluna Chiralpak $\mathrm{AD}-\mathrm{RH}^{\circledR}$, fase móvel: metanol: acetonitrila: água (80: 13: $7 \mathrm{v} / \mathrm{v} / \mathrm{v})+0,15 \%$ de trietilamina, temperatura de análise $23 \pm 2^{\circ} \mathrm{C}$ e vazão de $0,3 \mathrm{~mL}$ $\min ^{-1}$

Figura 17 - Otimização do tipo de solvente extrator. Condições extração: $100 \mu \mathrm{L}$ de solvente extrator e $500 \mu \mathrm{L}$ de isopropanol. Amostra: 2 $\mathrm{mL}$ de meio de cultura liquido Czapek fortificado com $2 \mathrm{~mL}$ de solução tampão borato de sódio $100 \mathrm{mmol} \mathrm{L}^{-1} \mathrm{pH} 10$. Condições cromatográficas: coluna Chiralpak $A D-\mathrm{RH}^{\circledR}$, fase móvel: metanol: acetonitrila: água (80: $13: 7 \mathrm{v} / \mathrm{v} / \mathrm{v})+0,15 \%$ de trietilamina, temperatura de análise $23 \pm 2^{\circ} \mathrm{C}$ e vazão de $0,3 \mathrm{~mL}$ $\min ^{-1}$ 
Figura 18 - Otimização do volume de solvente dispersor. Condições extração: $100 \mu \mathrm{L}$ de solvente clorofórmio e volume de solvente extrator variável. Amostra: $2 \mathrm{~mL}$ de meio de cultura liquido Czapek fortificado com $2 \mathrm{~mL}$ de solução tampão borato de sódio $100 \mathrm{mmol} \mathrm{L} \mathrm{L}^{-1}, \mathrm{pH}$ 10. Condições cromatográficas: coluna Chiralpak $\mathrm{AD}-\mathrm{RH}^{\circledR}$, fase móvel: metanol: acetonitrila: água (80: 13: $7 v / v / v)+0,15 \%$ de trietilamina, temperatura de análise $23 \pm$ $2^{\circ} \mathrm{C}$ e vazão de $0,3 \mathrm{~mL} \mathrm{~min}^{-1}$

Figura 19 - Otimização do volume de solvente extrator. Condições extração: $300 \mu \mathrm{L}$ de solvente de isopropanol e volume de solvente extrator variável. Amostra: $2 \mathrm{~mL}$ de meio de cultura liquido Czapek fortificado com $2 \mathrm{~mL}$ de solução tampão borato de sódio $100 \mathrm{mmol} \mathrm{L}^{-1}, \mathrm{pH}$ 10. Condições cromatográficas: coluna Chiralpak $A D-R H^{\circledR}$, fase móvel: metanol: acetonitrila: água (80: $13: 7 \mathrm{v} / \mathrm{v} / \mathrm{V})+0,15 \%$ de trietilamina, temperatura de análise $23 \pm 2^{\circ} \mathrm{C}$ e vazão de $0,3 \mathrm{~mL} \mathrm{~min}{ }^{-1}$

Figura 20 - Otimização do tempo de agitação das amostras. Condições de extração: $200 \mu \mathrm{L}$ de clorofórmio e $300 \mu \mathrm{L}$ de isopropanol. Amostra: $2 \mathrm{~mL}$ de meio de cultura liquido Czapek fortificado com $2 \mathrm{~mL}$ de solução tampão borato de sódio $100 \mathrm{mmol} \mathrm{L}^{-1} \mathrm{pH}$ 10. Condições cromatográficas: coluna Chiralpak $A D-R H^{\circledR}$, fase móvel: metanol: acetonitrila: água (80: 13: $7 \mathrm{v} / \mathrm{v} / \mathrm{V})+0,15 \%$ de trietilamina, temperatura de análise $23 \pm 2^{\circ} \mathrm{C}$ e vazão de $0,3 \mathrm{~mL}$ $\min ^{-1}$

Figura 21 - Estrutura química do cetoconazol

Figura 22 - Estrutura química da risperidona 
Figura 23 - A- Cromatograma referente a biotransformação da venlafaxina pelo fungo Cunninghamella elegans após 480 horas de incubação. B- Amostra controle "branco do fungo" Cunninghamella elegans. C- Cromatograma referente a injeção das soluções padrão da venlafaxina e seus metabólitos. Condições cromatográficas: coluna Chiralpak $A D-\mathrm{RH}^{\circ}$, fase móvel: metanol: acetonitrila: água (80: 13: $7 \mathrm{v} / \mathrm{v} / \mathrm{v})+0,15 \%$ de trietilamina e vazão de $0,3 \mathrm{~mL} \mathrm{~min}^{-1}$. (1)- (+)-(S)- ODV; (2)- (-)(R)-ODV; (3)-(+)-(S)-NDV; (4)-(-)-(R)-NDV; (5)-(+)-(S)-Vx (6)$(-)(\mathrm{R})-\mathrm{Vx} ;(7)-(8)$-produtos de biotransformação do fungo. (PI)Padrão interno cetoconazol

Figura 24- Espectros de absorção dos picos 8 (produto de biotransformação) e $3 \quad(+)(S)-N$-desmetilvenlafaxina representados na figura 23 .

Figura 25 - A-Eletroferograma referente a biotransformação da venlafaxina pelo fungo Cunninghamella elegans após 480 horas de biotransformação. B- Amostra controle "branco do fungo" Cunninghamella elegans. C- Eletroferograma referente a análise dos padrões de venlafaxina e seus metabólitos. Condições de análise: solução tampão fosfato de sódio 50 mmol L-1 pH 2,0 contendo CM- $\beta$-CD (1\%) e $\alpha$-CD $\left(8 \mathrm{mmol} \mathrm{L}^{-1}\right)$, tensão aplicada $+20 \mathrm{kV}$, temperatura de análise $20^{\circ} \mathrm{C}$. (1)-(+)(S)-Vx; (2)-(-)-(R)-Vx; (3)-(+)-(S)-NDV; (4)-(-)-(R)-NDV; (5)-(+)(S)-ODV (6)-(-)-(R)-ODV; (7), (8)-produtos de biotransformação do fungo. (PI)-Padrão interno risperidona.

Figura 26 - Eletroferograma referente a biotransformação da venlafaxina pelo fungo Cunninghamella elegans em meio de cultura liquido Czapek contendo glicose como fonte de carbono. Aeletroferograma referente a biotransformação da venlafaxina após 480 horas de incubação; B- Amostra controle "branco de 
fungo". Condições de análise: solução tampão fosfato de sódio $50 \mathrm{mmol} \mathrm{L}^{-1} \mathrm{pH} 2,0$ contendo CM- $\beta$-CD (1\%) e $\alpha-\mathrm{CD}\left(8 \mathrm{mmol} \mathrm{L}^{-}\right.$ $\left.{ }^{1}\right)$, tensão aplicada $+20 \mathrm{kV}$, temperatura de análise $20^{\circ} \mathrm{C} \ldots \ldots \ldots \ldots . . .$.

Figura 27 - Eletroferograma referente a biotransformação da venlafaxina pelo fungo Cunninghamella elegans em meio de cultura liquido Czapek na ausência de fonte de carbono. A- eletroferograma referente a biotransformação da venlafaxina após 480 horas de incubação; B- Amostra controle "branco de fungo". Condições de análise: solução tampão fosfato de sódio $50 \mathrm{mmol} \mathrm{L}^{-1} \mathrm{pH}$ 2,0 contendo CM- $\beta-C D(1 \%)$ e $\alpha-C D\left(8 \mathrm{mmol} \mathrm{L}^{-1}\right)$, tensão aplicada $+20 \mathrm{kV}$, temperatura de análise $20^{\circ} \mathrm{C}$

Figura 28 - Eletroferograma referente a biotransformação da venlafaxina pelo fungo Cunninghamella elegans em meio de cultura liquido Czapek sem a etapa de pré-fermentação. A- eletroferograma referente a biotransformação da venlafaxina após 480 horas de incubação; B- Amostra controle "branco de fungo". Condições de análise: solução tampão fosfato $50 \mathrm{mmol} \mathrm{L}^{-1} \mathrm{pH} \mathrm{2,0}$ contendo $C M-\beta-C D(1 \%)$ e $\alpha-C D\left(8 \mathrm{mmol} \mathrm{L}^{-1}\right)$, tensão aplicada $+20 \mathrm{kV}$, temperatura de análise $20^{\circ} \mathrm{C}$

Figura 29 - Eletroferograma referente a biotransformação da venlafaxina pelo fungo Cunninghamella elegans em meio de cultura préfermentativo malte. A- eletroferograma referente a biotransformação da venlafaxina após 480 horas de incubação; B- Amostra controle "branco de fungo". Condições de análise: solução tampão fosfato $50 \mathrm{mmol} \mathrm{L}^{-1} \mathrm{pH} 2,0$ contendo CM- $\beta-C D$ (1\%) e $\alpha-C D\left(8 \mathrm{mmol} \mathrm{L}^{-1}\right)$, tensão aplicada $+20 \mathrm{kV}$, temperatura de análise $20^{\circ} \mathrm{C}$. 


\section{LISTA DE TABELAS}

Tabela 1 - Efeitos adversos comuns aos fármacos antidepressivos

Tabela 2 - Algumas ações estereosseletivas de fármacos no organismo

Tabela 3 - Fases estacionárias baseadas em polissacarídeos.

Tabela 4 - Tipos de seletores quirais utilizados em eletroforese capilar e seus mecanismos de separação

Tabela 5 - Valores de resolução obtidos com diferentes concentrações de solução tampão fosfato de sódio

Tabela 6 - Valores de resolução obtidos após aplicação de diferentes valores de tensão aplicada.

Tabela 7 - Valores de resolução obtidos empregando diferentes temperaturas do capilar.

Tabela 8 - Valores de resolução obtidos com diferentes concentrações aCD

Tabela 9 - Valores de resolução obtidos com diferentes concentrações CM$\beta-C D$

Tabela 10 - Linearidade do método para análise dos enantiômeros da $V x$ e ODV.

Tabela 11 - Análise de variância e falta de ajuste (ANOVA) para análise dos enantiômeros da Vx e ODV.

Tabela 12 - Limite de quantificação para análise dos enantiômeros da Vx e ODV 
Tabela 13 - Precisão e exatidão inter-dia para análise dos enantiômeros da Vx e ODV.

Tabela 14 - Precisão e exatidão intradia para análise dos enantiômeros da $V x$ e ODV

Tabela 15 - Estabilidade de bancada e ciclos de congelamento e descongelamento para análise dos enantiômeros da Vx e ODV....

Tabela 16 - Linearidade do método para análise dos enantiômeros da Vx e seus metabólitos

Tabela 17 - Análise de variância e falta de ajuste (ANOVA) para análise dos enantiômeros da $\mathrm{Vx}$ e seus metabólitos.

Tabela 18 - Limite de quantificação do método para análise dos enantiômeros da $V x$ e seus metabólitos.

Tabela 19 - Precisão e exatidão inter-dia para análise dos enantiômeros da Vx e seus metabólitos.

Tabela 20 - Precisão e exatidão intradia para análise dos enantiômeros da $V x$ e seus metabólitos.

Tabela 21 - Estabilidade de bancada e ciclos de congelamento e descongelamento para análise dos enantiômeros da $\mathrm{Vx}$ e seus metabólitos. 


\section{LISTA DE ABREVIATURAS E SIGLAS}

$\begin{array}{ll}\text { ANOVA } & \text { Análise de variância } \\ \text { ANVISA } & \text { Agência Nacional de Vigilância Sanitária } \\ \text { ATCC } & \text { American Type Culture Collection } \\ \text { CE } & \text { Eletroforese capilar } \\ \text { CDs } & \text { Ciclodextrinas } \\ \text { CM- } \beta-C D & \text { Carboxi-metil- } \beta \text {-ciclodextrina } \\ \text { CYP } & \text { Citocromo } \\ \text { DLLME } & \text { Microextração líquido-líquido dispersiva } \\ \text { DPR } & \text { Desvio Padrão Relativo } \\ \text { E\% } & \text { Erro Relatvo } \\ \text { EOF } & \text { Fluxo eletroosmótico } \\ \text { FDA } & \text { Food and Drug Administration } \\ \text { HF-LPME } & \text { Microextração em fase líquida por membrana cilíndrica oca } \\ \text { HPLC } & \text { Cromatografia líquida de alta eficiência } \\ \text { Log P } & \text { Coeficiente de partição } \\ \text { LOQ } & \text { Limite de quantificação } \\ \bar{M} & \text { Média } \\ \text { NDV } & \text { N-desmetilvenlafaxina } \\ \text { ODV } & \text { O-desmetilvenlafaxina } \\ \text { PDA } & \text { Potato Dextrose Agar } \\ \text { PI } & \text { Padrão interno } \\ \text { Rs } & \text { Resolução } \\ \text { Vx } & \text { Venlafaxina } \\ \alpha-C D & \alpha \text {-ciclodextrina } \\ \text { UV } & \text { Ultravioleta }\end{array}$




\section{SUMÁRIO}

1. INTRODUÇÃO

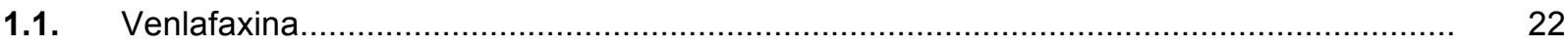

1.2. Análise enantiosseletiva de fármacos quirais........................................................... 24

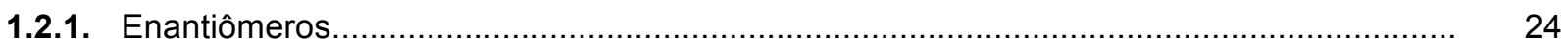

1.2.2. Estudo do metabolismo de fármacos quirais ............................................................. 25

1.3. Análise enantiosseletiva por cromatografia líquida de alta eficiência (CLAE).................... 26

1.3.1. Fases estacionárias quirais baseadas em polissacarídeos............................................ 26

1.3.2. Análise enantiosseletiva da venlafaxina em matrizes biológicas por CLAE - Revisão da literatura.

1.4. Análise enantiosseletiva por eletroforese capilar (CE) ............................................... 29

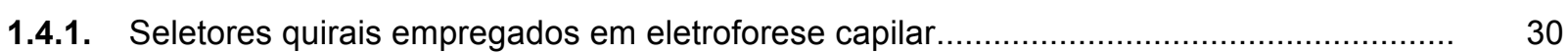

1.4.2. Análise enantiosseletiva da venlafaxina em matrizes biológicas por CE - Revisão da

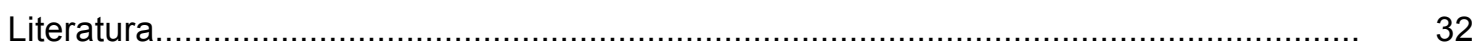

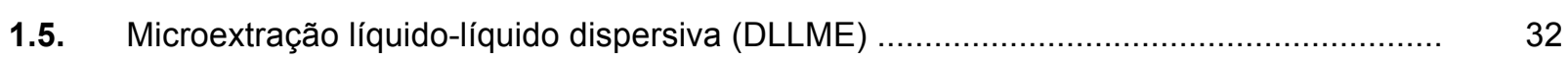

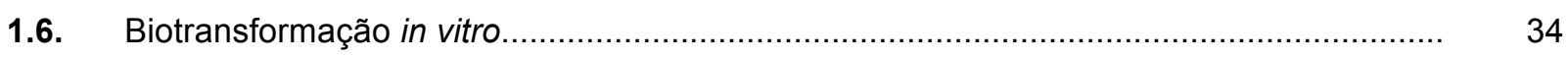

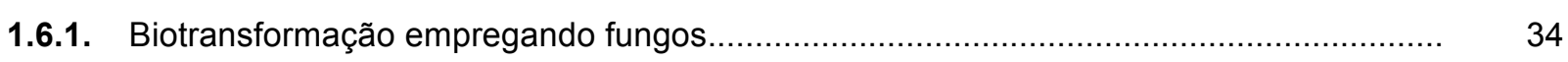

1.6.2. Estudos de biotransformação enantiosseletiva empregando fungos - Revisão da

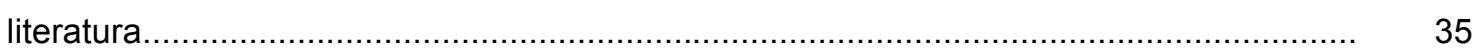

2. OBJETIVOS.

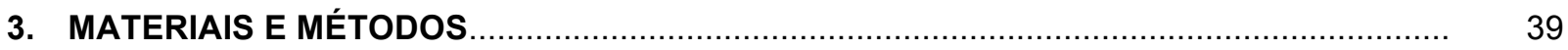

3.1. Separação enantiosseletiva da venlafaxina e seus metabólitos........................................ 40

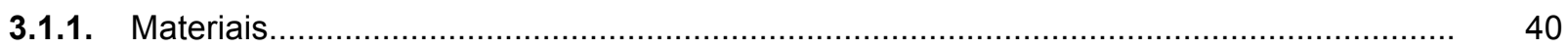

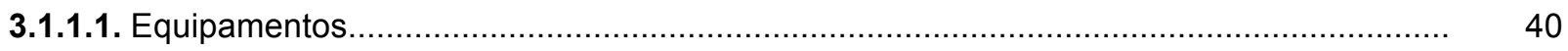

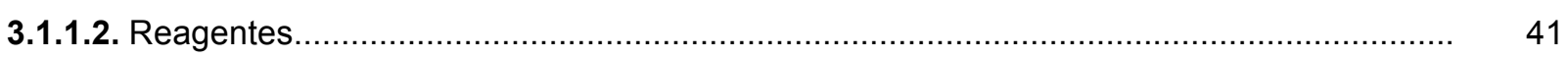

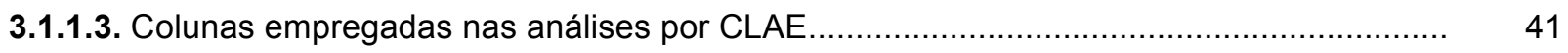

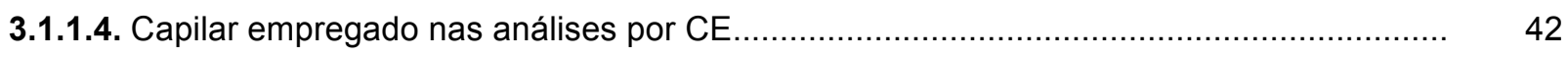

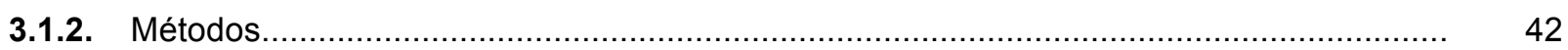

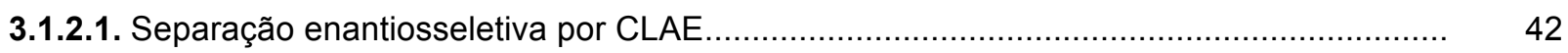

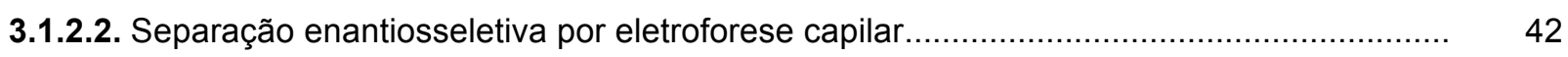

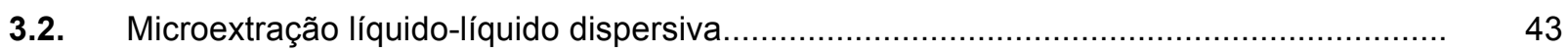

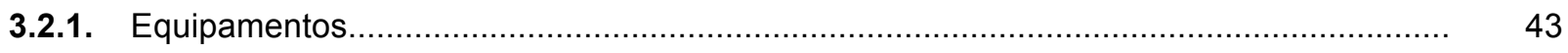

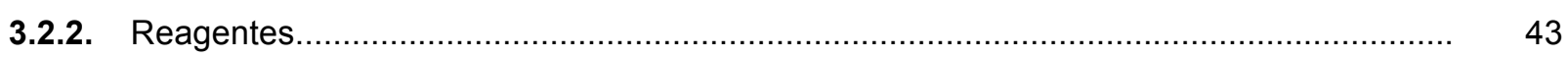

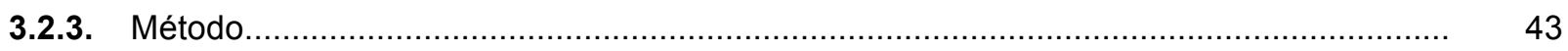

3.2.3.1. Otimização do tipo e volume dos solventes dispersor e extrator.......................................... 44

3.2.3.2. Otimização do tempo de agitação das amostras (DLLME assistida)................................... 44

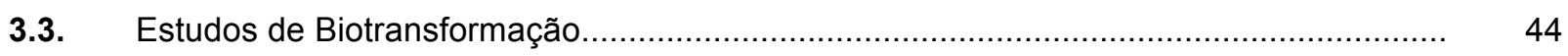

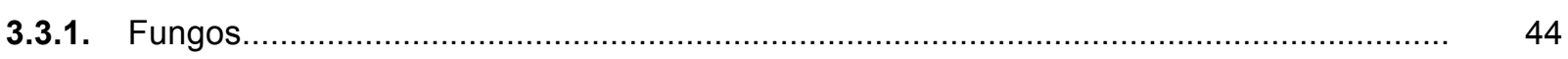

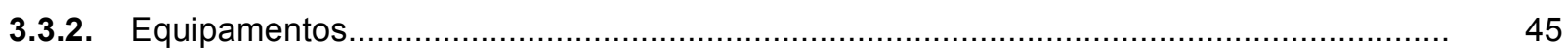


3.3.3. Reagentes.

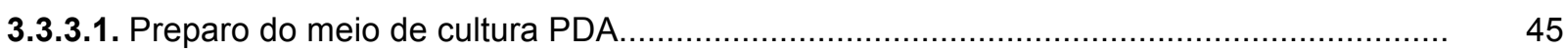

3.3.3.2. Preparo do meio de cultura pré-fermentativo Malte...................................................... 46

3.3.3.3. Preparo do meio de cultura Czapek modificado.......................................................... 46

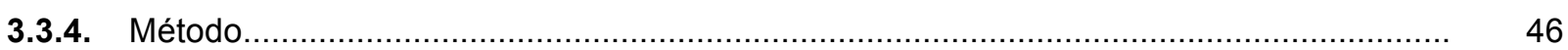

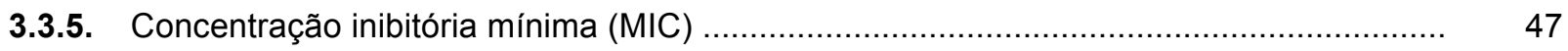

3.3.6. Otimização do procedimento de biotransformação................................................... 48

3.3.6.1. Substituição da fonte de carbono do meio de cultura líquido Czapek (a sacarose foi substituída pela glicose)

3.3.6.2. Eliminação da fonte de carbono do meio de cultura líquido Czapek deixando apenas a venlafaxina como fonte de carbono.

3.3.6.3. Eliminação da etapa de pré-fermentação em meio Malte.

3.3.6.4. Adição da venlafaxina diretamente na etapa de pré-fermentação em meio de cultura líquido Malte

3.3.6.5. Adição de cofator NADPH no meio de cultura líquido Czapek........................................ 50

3.4. Validação Analítica............................................................................................... 50

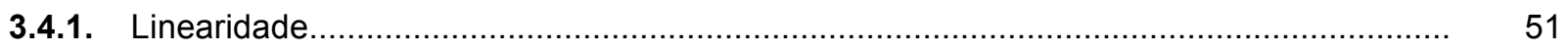

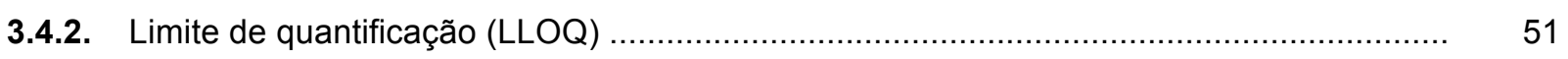

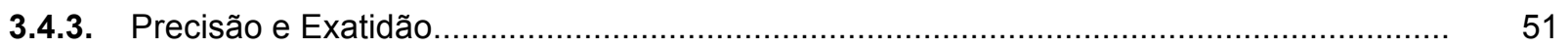

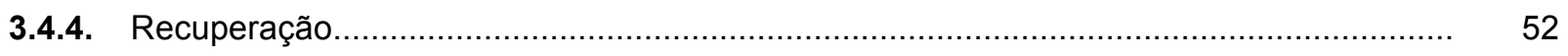

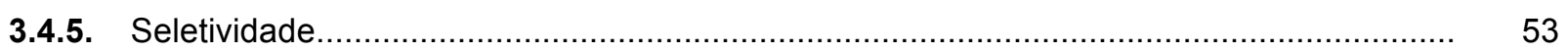

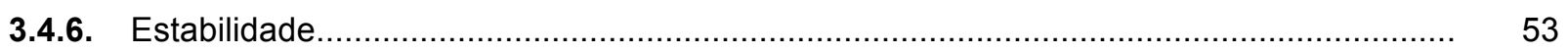

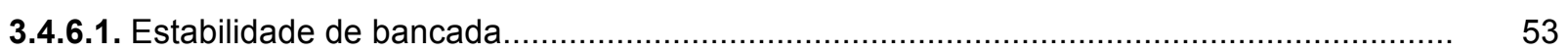

3.4.6.2. Estabilidade de ciclos de congelamento e descongelamento......................................... 54

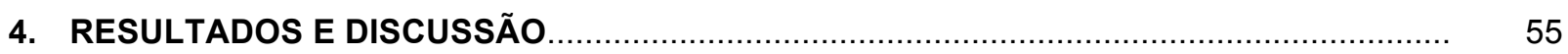

4.1. Separação Enantiosseletiva da venlafaxina e seus metabólitos...................................... 56

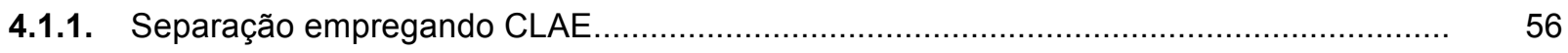

4.1.2. Separação empregando eletroforese capilar.............................................................. 58

4.1.2.1. Otimização da concentração e pH da solução tampão de análise.................................... 59

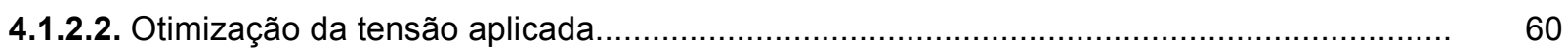

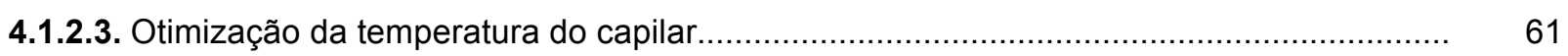

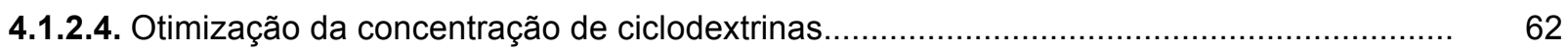

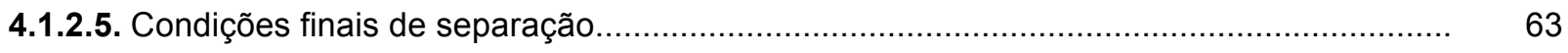

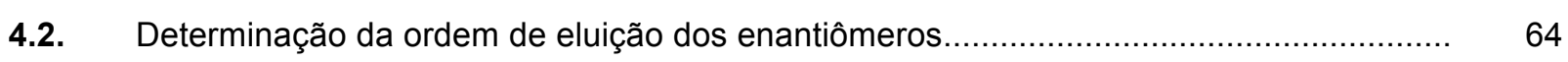

4.2.1. Determinação da ordem de eluição dos enantiômeros por CLAE ....................................... 65

4.2.2. Determinação da ordem de migração dos enantiômeros por EC.................................... 66

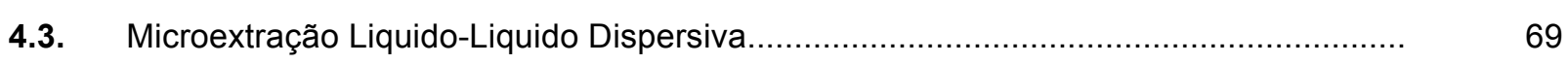

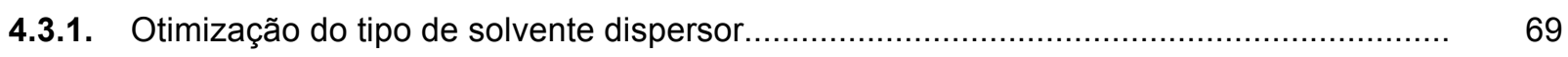

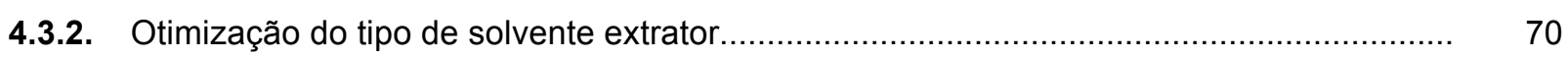

4.3.3. Otimização dos volumes de solventes dispersor e extrator................................................ 71 
4.3.4. Otimização do tempo de agitação das amostras (DLLME assistida).

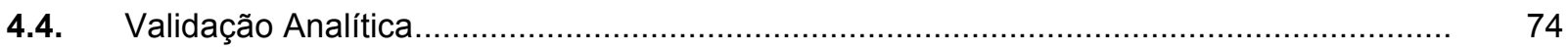

4.4.1. Validação do método analítico empregando CLAE.................................................... 74

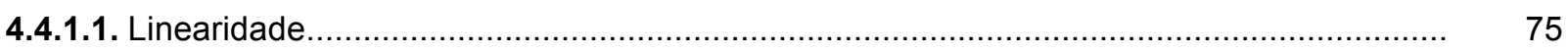

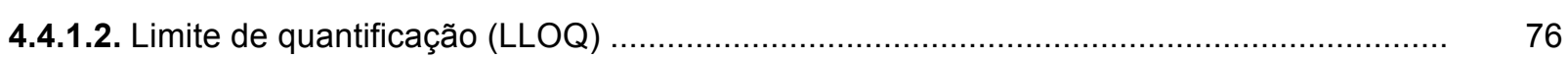

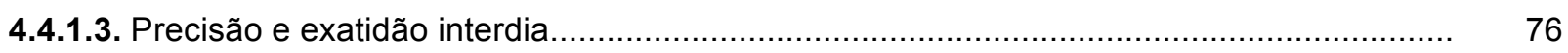

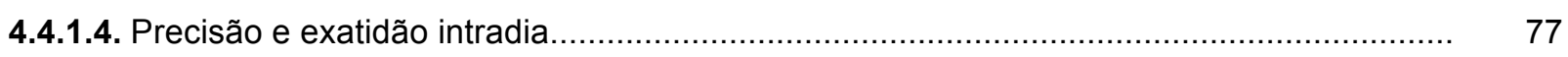

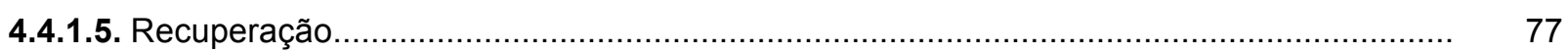

4.4.1.6. Estabilidade de bancada e ciclos de congelamento e descongelamento dos enantiômeros da Vx e ODV .........................................................................................

4.4.2. Validação do método analítico empregando eletroforese capilar...................................... 78

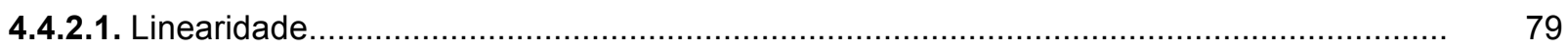

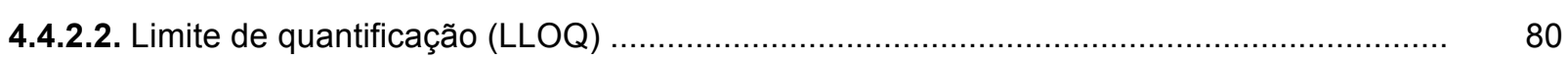

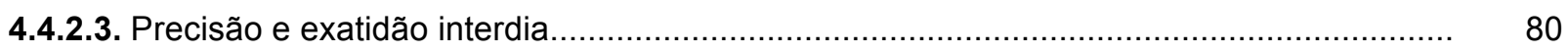

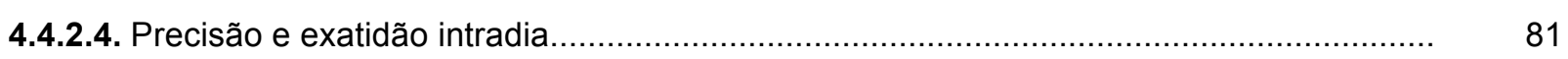

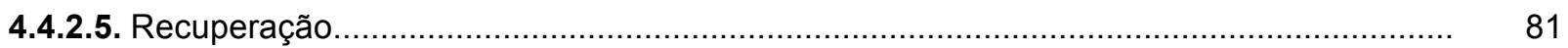

4.4.2.6. Estabilidade de bancada e ciclos de congelamento e descongelamento dos enantiômeros da $V x$ e metabólitos.................................................................................... 82

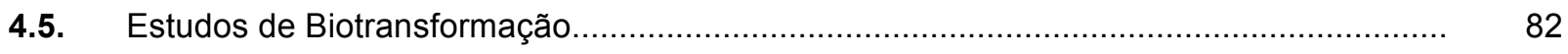

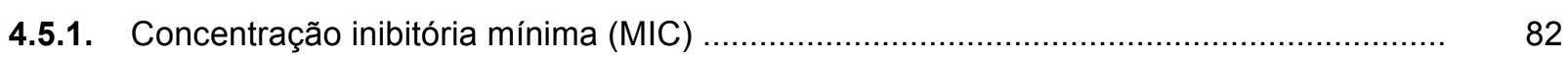

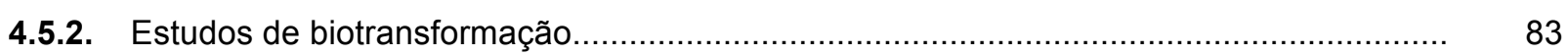

4.5.2.1. Biotransformação pelo fungo Cunninghamella elegans e análise por CLAE..................... 83

4.5.2.2. Biotransformação pelo fungo Cunninghamella elegans e análise por EC .......................... 85

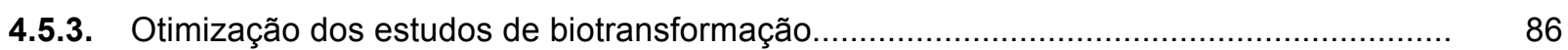

4.5.3.1. Substituição da fonte de carbono do meio de cultura líquido Czapek (a sacarose foi substituída pela glicose)

4.5.3.2. Eliminação da fonte de carbono do meio de cultura líquido Czapek deixando apenas a venlafaxina como fonte de carbono.......................................................................... 87

4.5.3.3. Eliminação da etapa de pré-fermentação em meio de cultura líquido Malte....................... 88

4.5.3.4. Adição da venlafaxina diretamente na etapa de pré-fermentação em meio de cultura líquido Malte (troca de meio de biotransformação)........................................................ 89

4.5.3.5. Adição de cofator NADPH no meio de cultura líquido Czapek........................................ 90

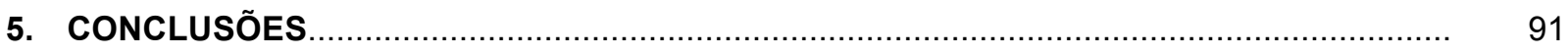

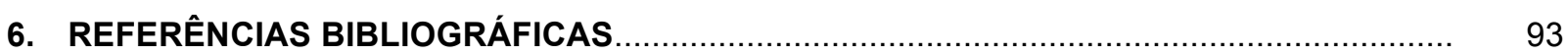


INTRODUÇÃO 


\section{INTRODUÇÃO}

\subsection{VENLAFAXINA}

A venlafaxina (Vx) ((R/S)-1-[(2-dimetilamina)-1-(4- metoxifenil) etil] ciclohexano) é um fármaco quiral, da classe dos antidepressivos de segunda geração, utilizado no tratamento de depressão e ansiedade associada a depressão. Seu mecanismo de ação consiste na inibição da recaptação de aminas biogênicas como a serotonina e a norepinefrina nas fendas sinápticas (HOLLIDAY; BENFIELD, 1995). A venlafaxina apresenta-se como um fármaco seguro, por possuir ampla janela terapêutica. Isso porque não há interação com receptores não relacionados à atividade neuronal, como os receptores colinérgicos muscarínicos e histaminérgicos H1 que são responsáveis pelos efeitos indesejáveis dos antidepressivos (Tabela 1). Estudos terapêuticos indicaram atividade estereosseletiva na ação farmacológica da venlafaxina. O enantiômero (-)-(R)-venlafaxina apresenta capacidade de inibir a recaptação de norepinefrina e de serotonina enquanto o enantiômero (+)-(S)venlafaxina apresenta seletividade para inibição da recaptação apenas da serotonina (HOLLIDAY; BENFIELD, 1995).

Tabela 1- Efeitos adversos comuns aos fármacos antidepressivos.

Ação

\begin{tabular}{cc}
\hline Antagonismo de receptores $\alpha$-adrenérgicos & Sedação \\
& Hipotensão Ortostática (tontura) \\
Interações farmacodinâmicas com alguns anti & hipertensivos \\
Antagonismo de receptores colinérgicos & Boca seca \\
muscarínicos & Retenção urinária \\
& Visão borrada \\
Constipação \\
Antagonismo de receptores histamínicos $\mathrm{H} 1$ & Taquicardia \\
& Déficit de memória \\
Interações farmacodinâmicas com agentes & Sedação \\
& depressores centrais \\
\end{tabular}


Após administração oral, a venlafaxina é metabolizada pelas enzimas hepáticas da superfamília P450 produzindo dois metabólitos principais, também quirais: $N$-desmetilvenlafaxina (NDV), metabolizada principalmente pela enzima CYP2D6 e O-desmetilvenlafaxina (ODV), metabolizada principalmente pela enzima CYP3A4 (Figura 1).

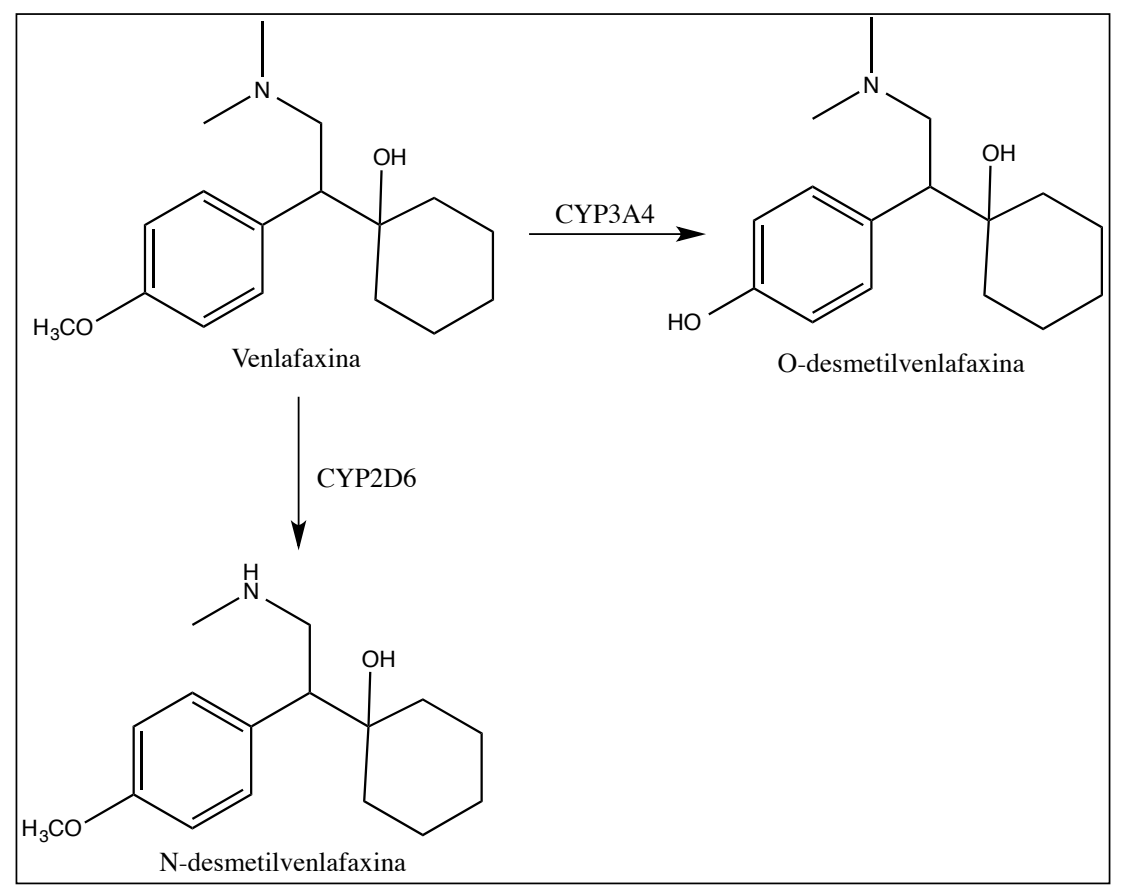

Figura 1- Estrutura química da venlafaxina e seus metabólitos O-desmetilvenlafaxina e $N$ desmetilvenlafaxina.

A biotransformação da venlafaxina em seus metabólitos $N$ desmetilvenlafaxina e O-desmetilvenlafaxina ocorre por desalquilação oxidativa realizada pelas enzimas do complexo P450. Produzido em maior proporção, a ODV é o metabólito ativo e apresenta atividade farmacológica semelhante à venlafaxina (SPINA; SANTORO; D'ARRIGO, 2008). O metabólito ODV foi aprovado pelo FDA (Food and Drug Administration) em Fevereiro de 2008 para o tratamento da desordem depressiva em adultos (PERRY; CASSAGNOL, 2009). A administração de O-desmetilvenlafaxina apresenta algumas vantagens em relação à administração de venlafaxina (ambos em sua forma racêmica) como uma maior potência, visto que $50 \mathrm{mg}$ de ODV possui a mesma eficácia que $150 \mathrm{mg}$ de venlafaxina, acarretando menores efeitos adversos. Além disso, como a ODV é metabolizada principalmente pela enzima CYP3A4, apresenta menor susceptibilidade às variações individuais 
(polimorfismos) quando comparada à venlafaxina que é substrato das enzimas CYP3A4 e CYP2D6.

\subsection{ANÁLISE ENANTIOSSELETIVA DE FÁRMACOS QUIRAIS}

\subsubsection{Enantiômeros}

Enantiômeros são estereoisômeros que se diferem nos arranjos espaciais de seus átomos. Essas moléculas apresentam uma imagem especular não sobreponível uma da outra e, portanto, possuem quiralidade. O principal elemento de quiralidade é o centro quiral, representado por um átomo $(\mathrm{C}, \mathrm{Si}, \mathrm{S}, \mathrm{P}, \mathrm{N})$ contendo todos os ligantes diferentes. Os enantiômeros apresentam as mesmas características físico-químicas em meio aquiral. Porém, em meio quiral, como o organismo biológico, os enantiômeros podem apresentar diferenças significativas em suas características, como diferentes afinidades na ligação com receptores endógenos, proteínas e enzimas (EECKHAUT; MICHOTTE, 2009).

A configuração, ou arranjo, dos átomos ao redor do centro quiral é denominada de acordo com a nomenclatura $R, S$. Nesse sistema, os grupos ligados ao centro quiral recebem graus de prioridade e a ordem é verificada. Se os grupos tiverem sentido horário, o enantiômero é denominado $R$ e se o sentido for antihorário, é denominado $S$. Essa denominação não tem relação com a atividade óptica (BRUICE, 2006). Enantiômeros apresentam atividade óptica, ou seja, a capacidade de desviar o plano da luz polarizada. Se o desvio da luz polarizada ocorrer para a direita, o enantiômero é denominado de dextrógiro e recebe o símbolo (+). Se o desvio ocorrer para a esquerda, o enantiômero é denominado levógiro e recebe o símbolo (-) (BRUICE, 2006). Misturas racêmicas, que contêm quantidades equivalentes dos enantiômeros são opticamente inativas. Isso ocorre porque os enantiômeros desviam o plano da luz polarizada em iguais magnitudes porém, em direções contrárias, o que anula o resultado (BRUICE, 2006).

Moléculas que apresentam dois ou mais elementos de quiralidade são denominadas diasteroisômeros e não apresentam imagem especular não sobreponível. Esses compostos possuem diferentes características físicas e químicas, podendo ser facilmente identificados através de métodos convencionais (BRUICE, 2006). 


\subsubsection{Estudo do metabolismo de fármacos quirais}

Quando administrados, fármacos sofrem metabolização que consiste em diversas transformações enzimáticas. O metabolismo de fase I consiste em reações de oxidação, redução e hidrólise com o objetivo de transformar o fármaco em um metabólito mais polar. Essa etapa envolve principalmente as enzimas do complexo enzimático P450. O metabolismo de fase II envolve reações de glicuronidação, sulfatação, acilação, metilação e formação de adutos com glutationa. Nessa etapa há formação de moléculas altamente polares capazes de serem eliminadas pela via renal (ELIEZER; FRAGA, 2008). O estudo de metabolismo de fármacos permite estabelecer a cinética de formação e as estruturas químicas de seus metabólitos, determinar a velocidade de metabolismo, compreender interações metabólicas assim como determinar sua toxicidade (ELIEZER; FRAGA, 2008).

Ao ingressarem no sistema biológico, os fármacos passam por etapas farmacocinéticas como absorção, distribuição, metabolismo e excreção; e farmacodinâmicas como a interação com os receptores biológicos. Em todas essas etapas pode haver enantiosseletividade quando se trata de um fármaco quiral. Isso porque os seres vivos são formados por moléculas quirais que podem interagir diferentemente com cada enantiômero. A Tabela 2 apresenta algumas ações estereosseletivas que os fármacos quirais podem sofrer no organismo.

Tabela 2- Algumas ações estereosseletivas de fármacos no organismo.

\begin{tabular}{ccc}
\hline Substância quiral & Função & Ação estereosseletiva \\
\hline Glicoproteínas de membrana & $\begin{array}{c}\text { Transporte ativo de substâncias } \\
\text { para interior da célula }\end{array}$ & $\begin{array}{c}\text { Diferenças na intensidade de } \\
\text { absorção }\end{array}$ \\
Enzimas & Metabolismo de fármacos & Diferenças na intensidade de \\
& & metabolização (t 1/2)
\end{tabular}


A obtenção de fármacos enantiomericamente puros é de grande importância uma vez que podem apresentam maior potência, menor toxicidade e menores efeitos adversos quando comparado à sua administração na forma racêmica. Como exemplo vale citar o propranolol, fármaco anti-hipertensivo, que interage com os receptores $\beta$-adrenérgicos de forma enantiosseletiva. O enantiômero (S)-propranolol interage com esses receptores através de interações hidrofóbicas, ligações de hidrogênio e interações íon-dipolo. Porém, o enantiômero (R)-propranolol possui uma menor afinidade pelos receptores por apresentar uma hidroxila da cadeia lateral em um arranjo espacial desfavorável à essas interações sendo, portanto, inativo (ELIEZER; FRAGA, 2008).

\subsection{ANÁLISE ENANTIOSSELETIVA POR CROMATOGRAFIA LIQUIDA DE ALTA EFICIÊNCIA (CLAE)}

A CLAE é uma das técnicas mais utilizadas em laboratórios e indústrias por estar muito bem estabelecida. Essa técnica apresenta diversas vantagens como tempo reduzido de análise, alto poder de resolução e versatilidade (COLLINS; BRAGA; BONATO, 2006). Normalmente, a separação de enantiômeros por CLAE é realizada empregando colunas constituídas por fases estacionárias quirais. Essas fases são formadas por moléculas opticamente ativas e as mais empregadas são as fases baseadas em polissacarídeos, antibióticos macrocíclicos e proteínas. Nesse trabalho, somente as fases baseadas em polissacarídeos foram empregadas. Dessa forma, somente esse tipo de fase será discutido.

\subsubsection{Fases estacionárias quirais baseadas em polissacarídeos}

Polissacarídeos, por si só, não apresentam boa capacidade de reconhecimento quiral. Porém, podem ser facilmente substituídos por grupamentos que apresentam características enantiosseletivas como tris-benzoatos e trisfenilcarbamatos (COLLINS; BRAGA; BONATO, 2006). Estudos indicam que os derivados de celulose e amilose apresentam estruturas em forma de uma "calha helicoidal" com os grupos carbamatos e benzoatos localizados em seu interior e os grupos aromáticos hidrofóbicos localizados na parte exterior. Essa estrutura 
determina a separação enantiomérica de acordo com as diferentes interações entre os enantiômeros. O mecanismo de separação enantiomérica dessas fases estacionárias não é totalmente conhecido, porém é possível deduzir os tipos de interações que os enantiômeros podem realizar com os substituintes do polissacarídeo. Os derivados tris-benzoatos podem interagir com os enantiômeros através de ligações de hidrogênio e ligações tipo dipolo-dipolo (grupamento carbonila do éster). Pode ocorrer aumento na capacidade de reconhecimento quiral quando o grupamento fenil do tris-benzoato é substituído com um grupo doador de elétrons, como o metil (LOURENÇO; CASSIANO; CASS, 2010; BONATO; JABOR, 2005). Nos derivados de tris-fenilcarbamato, os enantiômeros podem interagir por meio de ligações de hidrogênio (grupos amina e carbonila) e interações dipolo-dipolo (carbonila). As interações do tipo $\pi-\pi$ do grupo fenil da fase estacionária com o grupo aromático dos enantiômeros podem ser importantes no processo de separação enantiomérica principalmente quando há emprego de fase reversa. Substituintes no grupo fenil também irão influenciar a capacidade de reconhecimento quiral nos derivados tris-fenilcarbamato (Figura 2) (LOURENÇO; CASSIANO; CASS, 2010; BONATO; JABOR, 2005).
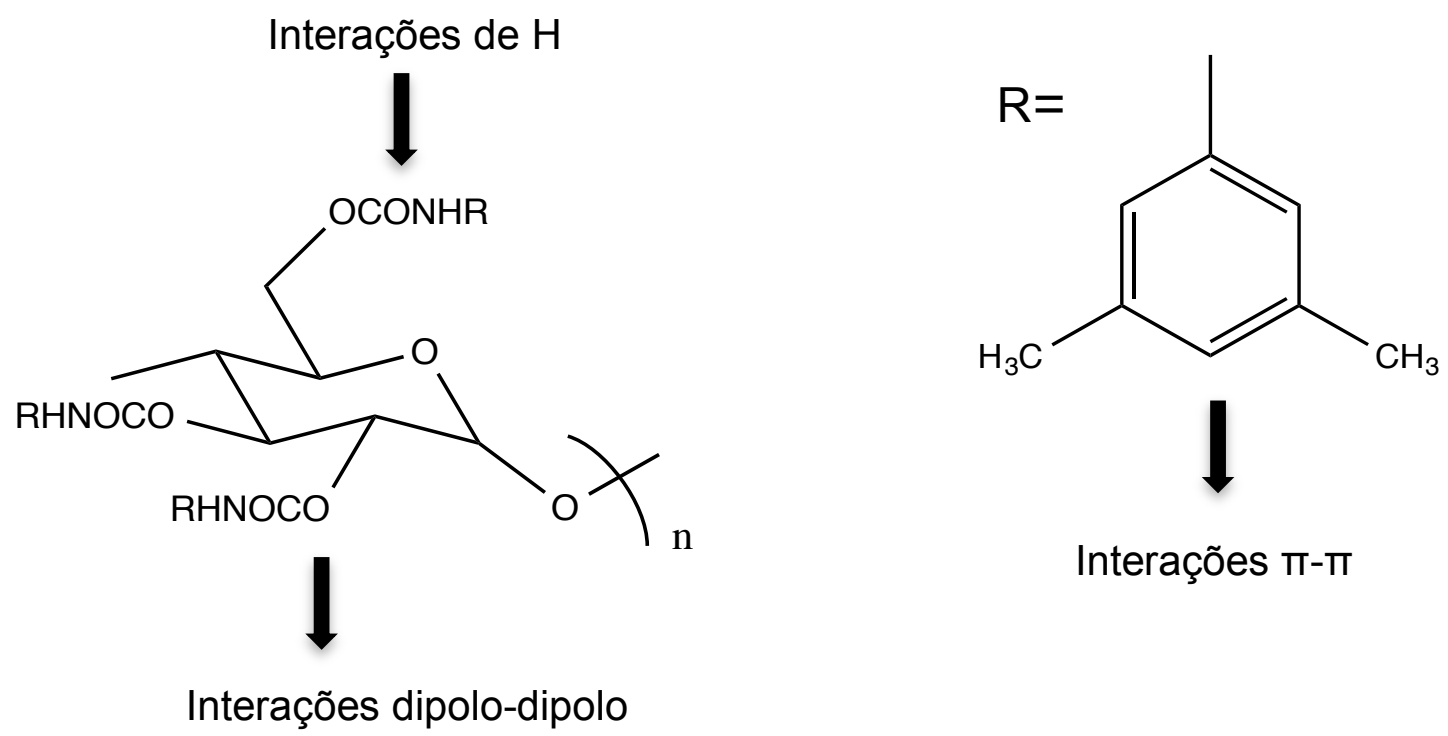

Figura 2- Estrutura química do tris (3,5-dimetilfenilcarbamato) de amilose e suas possíveis interações Fonte: LOURENÇO et al., 2010.

As fases estacionárias baseadas em polissacarídeos podem ser empregadas em fase normal, reversa ou polar orgânico. Abaixo, na Tabela 3, estão 
representadas algumas colunas quirais baseadas em polissacarídeos, seus substituintes e nomes comerciais.

Tabela 3: Fases estacionárias baseadas em polissacarídeos.

\begin{tabular}{lll} 
Polissacarídeo & \multicolumn{1}{c}{ Substituinte } & \multicolumn{1}{c}{ Nome comercial* $^{*}$} \\
& Benzoato & CHIRALCEL OB, CHIRALCEL OB-H \\
& 3,5-dimetilfenil carbamato & CHIRALCEL OD, CHIRALCEL OD-H \\
& 4-metilbenzoato & CHIRALCEL OJ, CHIRALCEL OJ-H \\
Celulose & 4-metilfenil carbamato & CHIRALCEL-OG \\
& 4-clorofenil carbamato & CHIRALCEL-OF \\
& Cinimato & \\
& Fenil carbamato & CHIRALCEL-OK \\
& 3,5-dimetilfenil carbamato & CHIRALPAK AD, CHIRALPAK AD-H \\
Amilose & & \\
& (S)-a-metilbenzil carbamato & CHIRALPAK AS, CHIRALPAK AS-H \\
\hline
\end{tabular}

*colunas fabricadas pela Diacel Technologies

\subsubsection{Análise enantiosseletiva da Venlafaxina em matrizes biológicas por CLAE - Revisão da literatura}

Alguns métodos têm sido descritos para a análise enantiosseletiva da venlafaxina e seus metabólitos em fluidos biológicos. Wen et al (2007), reportaram a separação quiral da venlafaxina e seu metabólito ODV em plasma utilizando a coluna Chirobiotic $\mathrm{V}^{\circledR}$ e fase móvel constituída de acetato de amônio $30 \mathrm{mmol} \mathrm{L}^{-1}$ : metanol (15: $85 \mathrm{v} / \mathrm{v}$ ) em pH 6,0 e vazão de $1 \mathrm{~mL} \mathrm{~min}^{-1}$. As resoluções obtidas foram de 2,7 para a venlafaxina e 2,17 para a ODV. Como técnica de preparo de amostra os autores empregaram a extração líquido-líquido. Fonseca e Bonato (2010) realizaram a separação quiral dos metabólitos da $\mathrm{Vx}$ por CLAE para estudar o metabolismo da Vx por microssomas hepático de ratos. A separação foi realizada empregando a coluna Chiralpak $A D^{\circledR}$ e fase móvel composta de hexano: 2-propanol 
$(95: 5 \mathrm{v} / \mathrm{v})+0,025 \%$ de dietilamina como modificador orgânico e vazão de 1,0 mL $\min ^{-1}$. As resoluções obtidas foram 1,5 para NDV e 2,5 para a ODV. Como técnica de preparo de amostra foi empregado a microextração em fase liquida empregando membranas cilíndricas ocas (HF-LPME). Kingback et al. (2010) desenvolveram um método para análise quiral da venlafaxina e seus metabólitos em plasma. A separação foi realizada empregando uma coluna Chirobiotic $V^{\circledR}$ e a fase móvel utilizada foi uma mistura de tetraidrofurano: acetato de amônio $10 \mathrm{mmol} \mathrm{L}^{-1} \mathrm{pH} 6,0$

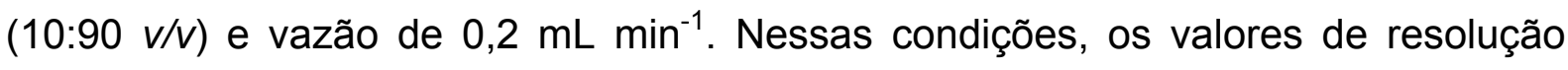
obtido para os enantiômeros da Vx, NDV e N,O-didesmetilvenlafaxina foram, respectivamente, de 1,79,1,25 e 1,13. O método de preparo de amostra empregado foi a extração em fase sólida.

\subsection{ANÁLISE ENANTIOSSELETIVA POR ELETROFORESE CAPILAR (CE)}

A separação empregando eletroforese capilar pode apresentar uma maior eficiência quando comparado a CLAE. Devido à ausência de uma fase estacionária, a resistência à transferência de massa presente é ausente. Além disso, em sistemas de pressão (como a CLAE) a fase móvel gera forças friccionais ao interagir com a fase estacionária ocasionando um gradiente de velocidade. Com isso, a velocidade do fluxo no meio da coluna é maior que a velocidade próxima às extremidades (fluxo parabólico), resultando assim em um fluxo laminar (Figura 3). Já em CE, o movimento eletroosmótico da solução gera um fluxo homogêneo em todo o comprimento do capilar ocasionando um fluxo radial, exceto muito próximo às paredes do capilar que a velocidade do fluxo aproxima-se a zero. Esse sistema ocasiona menos alargamento de bandas (WEINBERGER, 1999). 


\section{Fluxo Eletrodinâmico}

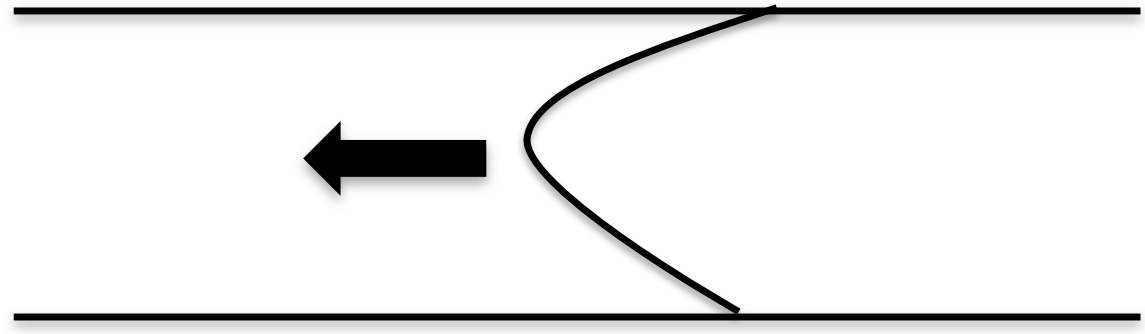

\section{Fluxo eletroosmótico}

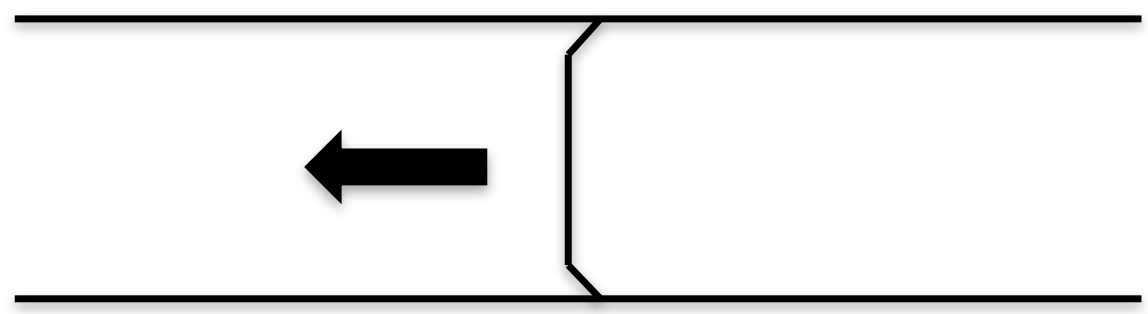

Figura 3- Esquemas representativos do fluxo eletrodinânimo e do fluxo eletroosmótico.

\subsubsection{Seletores Quirais empregados em eletroforese capilar}

A análise enantiosseletiva por eletroforese capilar é realizada, frequentemente, empregando seletores quirais no eletrólito de análise. Vários seletores quirais podem ser utilizados como éteres de coroa, proteínas, polissacarídeos lineares, antibióticos macrocíclicos, ciclodextrinas, surfactantes etc., sendo que cada um apresentará um mecanismo de reconhecimento quiral característico (Tabela 4). Os seletores quirais precisam apresentar algumas características para exercerem adequadamente sua função como: i) formar um complexo diasteroisomérico transitório com cada enantiômero de modo estereosseletivo; ii) deve ser compatível com a solução tampão de análise; iii) deve ser seletivo e iiii) possuir uma cinética de complexação relativamente alta (BLANCO; VALVERDE, 2003). 
Tabela 4- Tipos de seletores quirais utilizados em eletroforese capilar e seus mecanismos de separação.

\begin{tabular}{cc}
\hline Seletor Quiral & Mecanismo de Separação Quiral \\
\hline Surfactantes & Inclusão em micelas helicoidais. \\
Éteres de coroa & Complexos de inclusão com bases. \\
Antibióticos macrocíclicos & $\begin{array}{c}\text { Complexo de inclusão, interações dipolo-dipolo, } \\
\text { ligações de hidrogênio, interações m-m, ligações } \\
\text { estéricas e aniônicas. }\end{array}$ \\
Polissacarídeos lineares carregados & Interações com sua estrutura helicoidal e grupos \\
Polissacarídeos lineares neutros & carregados. \\
Proteínas & $\begin{array}{c}\text { Interações com sua estrutura helicoidal de bioafinidade entre a proteína e o } \\
\text { analito por interações dipolo-dipolo, ligações de } \\
\text { hidrogênio. }\end{array}$ \\
Calixarenos quirais & $\begin{array}{c}\text { Anéis benzênicos conectados por grupos metilenos } \\
\text { formam uma cavidade hidrofóbica que serve como } \\
\text { hospedeiro químico. }\end{array}$ \\
\hline
\end{tabular}

Os seletores mais empregados são as ciclodextrinas (CDs) e seus derivados. Esses seletores são oligossacarídeos cíclicos derivados da degradação enzimática do amido por enzimas glicosiltransferases ou ciclodextrinases. As CDs se organizam em forma de cone truncado (Figura 4) com os grupamentos polares localizados na região externa e os grupamentos hidrofóbicos na região interna (FANALI, 2000).

As ciclodextrinas nativas, de ocorrência natural, são representadas por $\alpha, \beta$, e $\mathrm{Y}-\mathrm{CD}$, sendo constituídas de seis, sete e oito unidades glicopiranosídeas respectivamente, apresentando a mesma profundidade, mas larguras diferentes. Essas ciclodextrinas neutras são utilizadas apenas em separações de fármacos ionizados, portanto, o desenvolvimento de seletores carregados foi necessário. Os grupos hidroxi nas posições 2, 3 e 6 das ciclodextrinas nativas, estão disponíveis para derivatização. Assim, podem ser produzidas ciclodextrinas carregadas negativamente (geralmente carboxiladas e sulfatadas) ou carregadas positivamente. As CDs carregadas podem ser utilizadas em análises de moléculas neutras, ácidas ou básicas. 

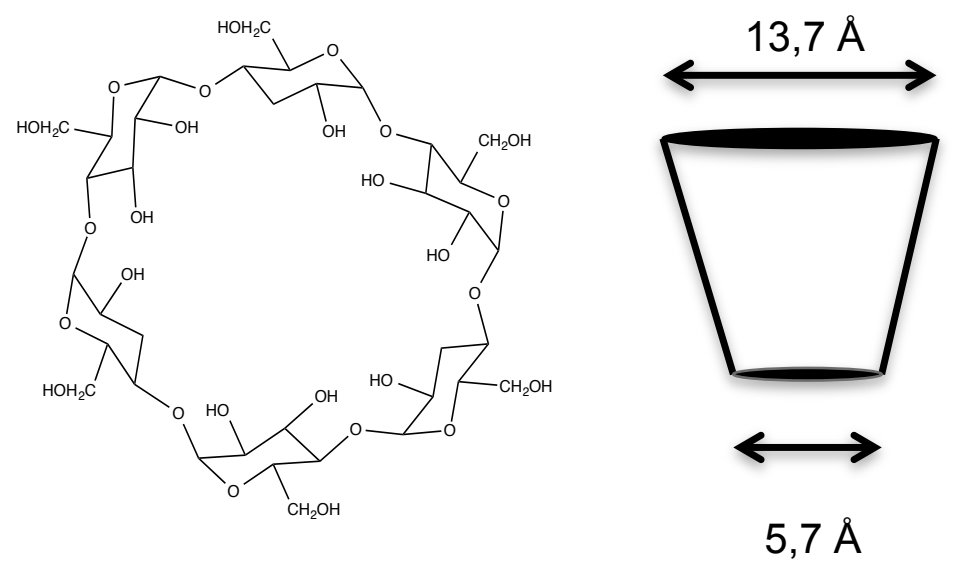

Figura 4- Estrutura molecular e esquema representativo da organização em cone truncado da $\alpha-C D$.

\subsubsection{Análise enantiosseletiva da venlafaxina em matrizes biológicas por CE - Revisão da Literatura}

A análise enantiosseletiva da venlafaxina e seus metabólitos por eletroforese capilar é pouco relatado na literatura. Rudaz et al. (2000) descreveram a separação enantiosseletiva da $\mathrm{Vx}$ e da ODV em amostras clínicas de soro por eletroforese capilar utilizando ciclodextrinas carregadas. As resoluções obtidas foram maiores que 1,5. Nesse trabalho os autores empregaram como eletrólito de análise uma solução tampão fosfato $50 \mathrm{mmol} \mathrm{L}^{-1} \mathrm{pH} 2,5$ contendo $20 \mathrm{mg} \mathrm{mL}^{-1}$ de ciclodextrina-Yfosfatada. Fanali et al (2001) obtiveram a separação enantiosseletiva desses analitos em plasma humano empregando a eletrocromatografia capilar. Nesse trabalho os autores empregaram uma fase estacionária baseada em vancomicina e fase móvel constituída por solução tampão acetato de amônio $100 \mathrm{mmol} \mathrm{L}^{-1} \mathrm{pH} 6,0$ : água: acetonitrila (5:5:90 $\mathrm{v} / \mathrm{V} / \mathrm{V})$; os valores de resolução obtidos foram de 1,68 para Vx e 1,57 para a ODV. Em ambos os trabalhos foi empregada a extração líquidolíquido como técnica de preparo de amostra.

\subsection{MICROEXTRAÇÃO LIQUIDO-LIQUIDO DISPERSIVA (DLLME)}

Em 2006, Rezaee e colaboradores desenvolveram uma nova técnica miniaturizada de preparação de amostra, a microextração liquido-liquido dispersiva (DLLME). Esse método é baseado na formação de uma solução turva (ponto nuvem) 
proveniente de uma mistura de solventes extrator e dispersor que é rapidamente injetada em uma fase aquosa contendo os analitos de interesse. A superfície de contato entre a fase extratora e a fase aquosa é infinitamente grande permitindo que o equilíbrio de extração seja atingido rapidamente. Após extração, a separação de fases ocorre, normalmente, por centrifugação e a fase sedimentada contendo os analitos é coletada e analisada por uma técnica adequada (Figura 5). As principais vantagens dessa técnica são sua simplicidade, rapidez, baixo custo e grande eficiência de extração (REZAEE et al., 2006; MENG et al., 2011; CALDAS; GONÇALVEZ; PRIMEL, 2011; ZGOTA-GRZESKOWIAK; GRZESKOWIAK, 2011; REZAEE; YAMINI; FARAJI, 2010; XIAO-HUAN et al., 2009). Recentemente, alguns métodos empregando a DLLME como técnica de preparo de amostra vem sendo desenvolvidos para análise de fármacos e seus metabólitos em diferentes matrizes biológicas, tais como urina e plasma (SUH et al., 2013; MASHAYEKHI; ABROOMAND-AZAR; SABER-TEHRANI; HUSAIN, 2010; GHAMBARI; HADJMOHAMMADI, 2012; KOHLER; SHAPPLERA; SIERROA; RUDAZ, 2013). Até o momento, apenas um método é descrito na literatura para análise de fármacos e metabólitos em meio de cultura empregando a DLLME (FORTES et al., 2013). Não há na literatura registro do uso da DLLME para extração da venlafaxina e seus metabólitos de matriz biológica ou meio de cultura. 


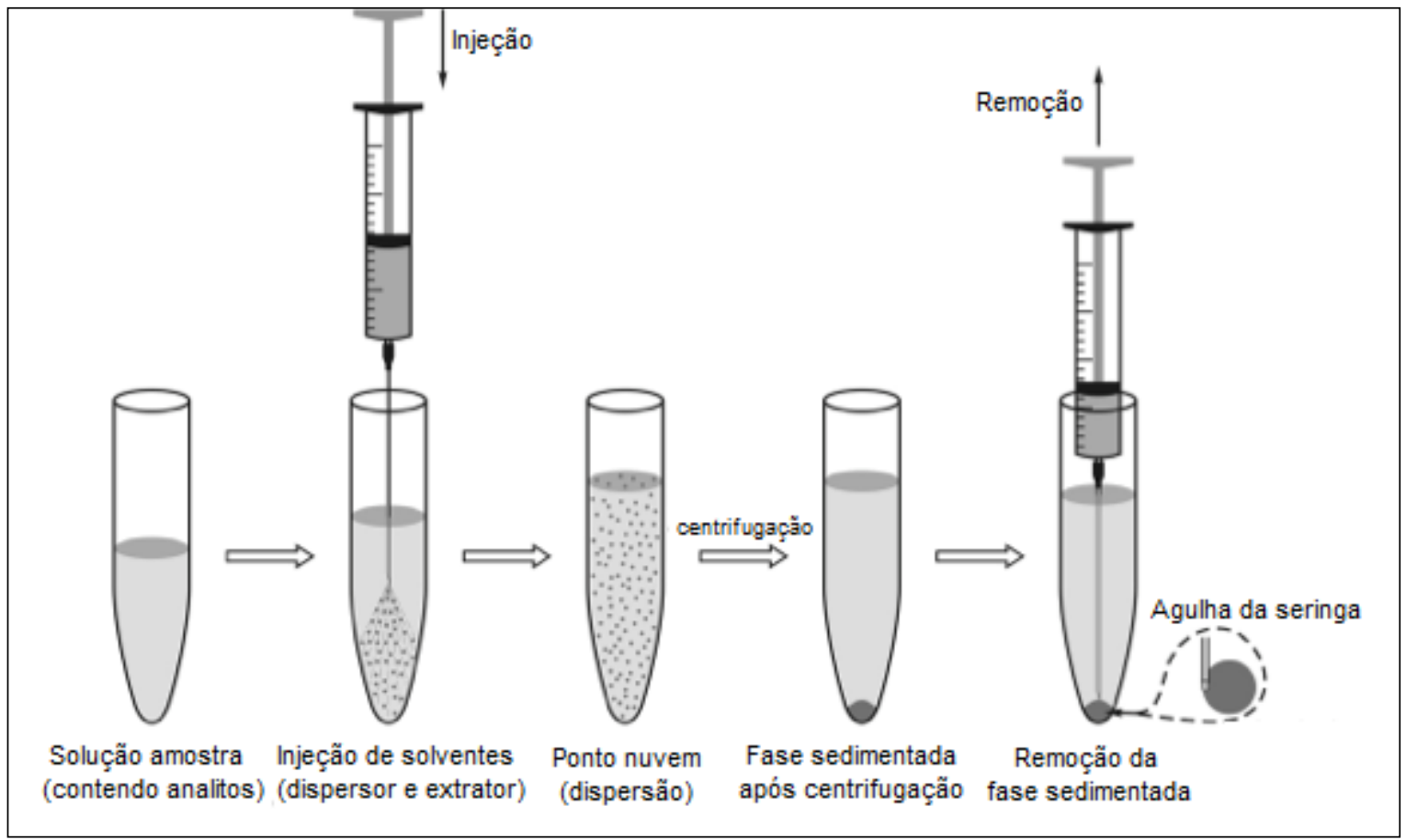

Figura 5- Esquema representativo da microextração líquido-líquido dispersiva (DLLME). Fonte: Trends in Analytical Chemistry, Vol. 30, No. 9, 2011 (adaptado).

\subsection{BIOTRANSFORMAÇÃO IN VITRO}

Processos de biotransformação in vitro se tornaram uma ferramenta muito importante para estudos de metabolismo. Estudos de biotransformação in vitro apresentam diversas vantagens sobre o uso de modelos in vivo ou processos químicos devido à sua baixa complexidade. $\mathrm{O}$ uso de micro-organismos permite $\mathrm{o}$ controle estrito das condições de análise; é um procedimento barato e, além disso, pode ser um processo enantiosseletivo (PUPO; BORGES; BORGES; BONATO, 2008; BORGES; BORGES; PUPO; BONATO, 2009). Os principais micro-organismos utilizados são bactérias, leveduras e fungos.

\subsubsection{Biotransformação empregando fungos}

Procedimentos de biotransformações empregando fungos são viáveis pois esses micro-organismos podem mimetizar as reações enzimáticas de mamíferos levando aos mesmos metabólitos. Diferentes micro-organismos podem ser utilizados em processos de biotransformação porém, os fungos apresentam algumas vantagens como resistência a vários substratos, exibem um rápido crescimento e 
propiciam grande quantidade de metabólitos. Além disso, podem apresentar quimiosseletividade, enantiosseletividade e também serem capazes de catalisar uma grande faixa de reações (PUPO; BORGES; BORGES; BONATO, 2008; BORGES; BORGES; PUPO; BONATO, 2009).

Os micro-organismos em geral apresentam um ciclo de crescimento exponencial contendo quatro fases. A fase lag equivale ao período de adaptação do micro-organismo ao meio em que se encontra. Essa adaptação pode incluir o preparo do sistema enzimático ou o reparo de células danificadas. A fase log, ou exponencial, é a fase de rápido crescimento do micro-organismo, em que todas as células estão se multiplicando. Há estudos indicando que nessa fase ocorre produção de enzimas que não são produzidas em outras etapas do ciclo (BORGES; BORGES; PUPO; BONATO, 2009). Na fase estacionária, o crescimento permanece constante até se esgotarem as fontes de nutrientes. Nessa etapa, a principio, ocorre o maior acúmulo de metabólitos. Com a depleção das fontes de nutrientes, o microorganismo entra na última fase, a morte, que é acompanhada geralmente de lise celular (PELCZAR; CHAN; KRIEG, 1996).

\subsubsection{Estudos de biotransformação enantiosseletiva utilizando fungos - Revisão da literatura}

Existem diversos estudos demonstrando a habilidade dos fungos de biotransformar de forma enantiosseletiva fármacos racêmicos. A biotransformação enantiosseletiva da tioridazina por oxidação do átomo de enxofre na cadeia lateral (posição 2) ou no anel fenotiazínico (posição 5) foi realizada pelos fungos Phomopsis sp (TD2), Glomerella cingutara (VA1), Penicillium crustosum (VR4) e Arpergillus fumigatus (VR12). Após 48 horas, o metabólito (R)-tioridazina-2-sulfóxido foi produzido com prioridade pelo fungo VR12 (34,4\% de eficiência) enquanto o metabólito (S)-tioridazina-2-sulfóxido foi produzido pelo fungo VR4 com $84,4 \%$ de eficiência. O fungo VA1 produziu ambos os enantiômeros na mesma proporção (10,5\% de eficiência) (BORGES; BORGES; PUPO; BONATO, 2008). Foi também reportada a biotransformação do pró-fármaco midodrina em seu metabólito ativo desglimidodrina pela hidrólise da ligação amida. Após 72 horas de incubação, o fungo TD2 foi capaz de converter a (-)-midodrina em (-)-desglimidodrina com 1,1\% de eficiência e (+)-midodrina em (+)-desglimidodrina com 6,1\% de eficiência 
(BARTH; PUPO; BORGES; BONATO, 2010). Estudos recentes de nosso grupo mostraram a biotransformação por fungos do albendazol em albendazol sulfóxido (ABZSOX). O fungo Mucor rouxii foi capaz de produzir enantiosseletivamente o (+)ABZSOX com cerca de $80 \%$ de excesso enantiomérico após 144 horas de incubação (HILARIO et al., 2012) e o fungo VR4 apresentou um excesso enantiomérico de 50,4\% para a formação do metabólito (-)-ABZSOX (CARRAO et al., 2011). A biotransformação da risperidona em seu metabólito ativo (-)-9hidroxirisperidona foi realizada pelo fungo Mucor rouxii com excesso enantiomérico de 79,6\% após 168 horas de incubação (De JESUS et al.; 2011). Os fungos Cunninghamella echinulara var. Elegans (ATCC 8688) e Cunninghamella elegans (ATCC 10028B) foram capazes de biotransformar a risperidona no metabólito (+)-9hidroxirisperidona com 100\% de excesso enantiomérico após 168 horas de incubação (BOCATO et al., 2012). 


\section{OBJETIVOS}




\section{OBJETIVOS}

O objetivo desse trabalho foi avaliar a capacidade de fungos em promover a biotransformação enantiosseletiva da venlafaxina em seus principais metabólitos, a O-desmetilvenlafaxina e a $\mathrm{N}$-desmetilvenlafaxina.

Para esse fim, foram desenvolvidas as seguintes etapas:

$\checkmark$ Desenvolvimento de um método de separação enantiosseletivo para análise da venlafaxina e seus metabólitos por CLAE;

$\checkmark$ Desenvolvimento de um método de separação enantiosseletivo para análise da venlafaxina e seus metabólitos por CE;

$\checkmark$ Otimização de uma técnica de preparo de amostra miniaturizada, a DLLME, para extração da venlafaxina e seus metabólitos do meio de cultura;

$\checkmark$ Validação dos métodos analíticos desenvolvidos. 
MATERIAIS E MÉTODOS 


\section{MATERIAIS E MÉTODOS}

\subsection{SEPARAÇÃO ENANTIOSSELETIVA DA VENLAFAXINA E SEUS METABÓLITOS}

\subsubsection{Materiais}

\subsubsection{Equipamentos}

O sistema para cromatografia liquida de alta eficiência utilizado para a otimização da separação enantiomérica da venlafaxina e metabólitos foi um equipamento da Shimadzu (Kyoto, Japão) constituído de duas bombas LC10AS, um detector UV-Vis SPD10A operando em $230 \mathrm{~nm}$ e um injetor Rheodyne modelo 7125 (Cotati, EUA) com uma alça de amostragem de $20 \mu \mathrm{L}$. Uma controladora modelo SCL10A (Shimadzu, Kyoto, Japão) foi empregada como interface entre o cromatógrafo e o computador e o software utilizado para aquisição dos dados foi o Class-VP (Shimadzu, Kyoto, Japão). Para a validação analítica e estudos de biotransformação foi utilizado um equipamento da Shimadzu (Kyoto, Japão) constituído de duas bombas LC20AT, um detector UV-Vis SPD M20A operando em $230 \mathrm{~nm}$ e um injetor automático modelo SIL 10AF. Os dados foram monitorados em uma controladora modelo CBM20A e o software utilizado para aquisição dos dados foi LC Solution (Shimadzu, Kyoto, Japão). Em ambos os casos, as análises foram realizadas em temperatura ambiente $\left(24 \pm 2^{\circ} \mathrm{C}\right)$.

A separação enantiomérica por eletroforese capilar foi realizada em um equipamento da Beckman Coulter Instruments, modelo P/ACE MDQ (Fullerton, CA, EUA), equipado com um amostrador automático com controle de temperatura e detector com absorção no UV-Vis com arranjo de diodos. O software utilizado para aquisição dos dados foi o $32 \mathrm{Karat}^{\circledR} \mathrm{e}$ o comprimento de onda monitorado durante as análises foi $204 \mathrm{~nm}$.

Para degaseificação e dissolução dos solutos das soluções empregadas na análise por eletroforese capilar foi empregado um equipamento de ultrassom da marca Thorton Unique, modelo USC1450 (Santo André, SP, Brasil). Um sistema de purificação de água, Milli-Q plus da Millipore Corporation (Bedford, MA, EUA) 
forneceu água livre de resíduos orgânicos e inorgânicos para preparação das soluções aquosas.

\subsubsection{Reagentes}

Os padrões de rac- $\mathrm{N}$-desmetilvenlafaxina, rac-O-desmetilvenlafaxina e racvenlafaxina foram obtidos da Toronto Reasearch Chemicals Inc. (Toronto, Canadá). As soluções foram preparadas em metanol na concentração de $100 \mu \mathrm{gL}^{-1} \mathrm{e}$ armazenadas em tubos âmbar a $-20^{\circ} \mathrm{C}$. Os solventes constituintes da fase móvel tais como metanol, acetonitrila e trietilamina, foram obtidos da J.T.Baker (Phillipsburg, NJ, EUA) e da Sigma-Aldrich (St. Louis, Missouri, EUA). Para preparo da solução tampão foi utilizado fosfato de sódio monobásico da Synth (Diadema, SP, Brasil) e ácido fosfórico da Qhemis (Indaiatuba, SP, Brasil). Hidróxido de sódio foi adquirido da Nuclear (Diadema, SP, Brasil). Foram utilizados como seletores quirais a carboximetil- $\beta-C D$ obtida da Sigma-Aldrich (St. Louis, Missouri, EUA) e $\alpha-C D$ obtida da Thermo Scientific (Waltham, MA, EUA). As soluções usadas como eletrólito de análise e nos ciclos de pré-condicionamento do capilar foram filtradas através de um filtro Millex-HA com poros de 0,45 $\mu \mathrm{m}$, obtido da Millipore (Bedford, MA, USA).

\subsubsection{Colunas empregadas nas análises por CLAE}

As colunas quirais avaliadas para na separação enantiomérica da venlafaxina e seus metabólitos foram a Chiralpak $A D \mathrm{RH}^{\circledR}(150 \mathrm{~mm} \times 4,6 \mathrm{~mm}, 5 \mu \mathrm{m}$ de partícula, Chiral Technologies, Exton, PA, EUA) e Chiralpak AD $^{\circledR}(250 \mathrm{~mm} \times$ 4,6 mm, $10 \mu \mathrm{m}$ de partícula, Chiral Technologies, Exton, PA, EUA) acoplada a uma coluna aquiral C18 (250 mm x 4,6 mm, $5 \mu \mathrm{m}$ de partícula, Agilent Technologies, CA, EUA). Foi utilizado também uma coluna de guarda C18 (4,6 mm x 12,5 mm, $5 \mu \mathrm{m}$ de partícula, Merck, Darmstadt, Alemanha) acoplada as colunas analíticas. 


\subsubsection{Capilar empregado nas análises por CE}

As análises foram realizadas em um capilar de sílica fundida de $75 \mu \mathrm{m}$ de diâmetro interno, com comprimento variável e revestimento externo de poliimida (Polymicro, Phoenix, AZ, EUA).

\subsubsection{Métodos}

\subsubsection{Separação enantiosseletiva por CLAE}

A separação enantiosseletiva da venlafaxina e seus metabólitos foi obtida empregando duas colunas quirais constituídas de amilose com substituinte 3,5dimetilfenilcarbamato. Primeiramente, a separação foi estabelecida com o uso da coluna Chiralpak $A D^{\circledR}$ acoplada a uma coluna $C 18$. Posteriormente a separação foi avaliada também na coluna Chiralpak $A D \mathrm{RH}^{\circledR}$. A fase móvel utilizada foi constituída de metanol: acetonitrila: água (80: 13: 7 v/v/v) com adição de 0,15\% de trietilamina como modificador orgânico.

\subsubsection{Separação enantiosseletiva por eletroforese capilar}

Antes do primeiro uso, os capilares novos foram condicionados por lavagem com solução de $\mathrm{NaOH} 1 \mathrm{~mol} \mathrm{~L}{ }^{-1}$ durante $10 \mathrm{~min}$, seguido de 10 min com $\mathrm{NaOH}$ 0,1 mol $\mathrm{L}^{-1}$ e finalizando com água ultrapura durante $10 \mathrm{~min}$. No início de cada dia, o

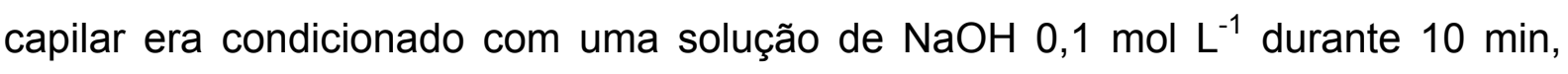
seguido de uma etapa de lavagem com água ultrapura por $10 \mathrm{~min}$.

Entre cada análise o capilar era condicionado por 2 min com $\mathrm{NaOH} \mathrm{0,1} \mathrm{mol} \mathrm{L'}$

1, 4 min com água ultrapura e 2 min com o eletrólito de análise. Ao final das análises, o capilar era lavado com uma solução de $\mathrm{NaOH} 0,1 \mathrm{~mol} \mathrm{~L}^{-1}$ durante $10 \mathrm{~min}$, seguido por uma etapa de lavagem com água ultrapura durante $10 \mathrm{~min}$. Durante o armazenamento, as extremidades do capilar permaneceram imersas em água ultrapura.

A resolução dos analitos por eletroforese capilar foi avaliada empregando alíquotas de $50 \mu \mathrm{L}$ das soluções-padrão dos analitos na concentração de $100 \mu \mathrm{g} \mathrm{mL}$ - 
1. Após evaporação do solvente sob fluxo de ar comprimido, os resíduos foram dissolvidos em $120 \mu \mathrm{L}$ de água ultrapura e analisados por CE. Nesta etapa foram otimizadas várias condições e parâmetros do método, sendo esses: tipo de seletor quiral, concentração e pH do eletrólito de análise, pré-condicionamento do capilar, temperatura do capilar, modo de injeção (tempo e pressão) e tensão aplicada.

\subsection{MICROEXTRAÇÃO LIQUIDO-LIQUIDO DISPERSIVA (DLLME)}

\subsubsection{Equipamentos}

Para o preparo da amostra empregando a DLLME foi utilizado uma microsseringa de $1 \mathrm{~mL}$ obtida da Hamilton ${ }^{\circledR}$ (Bonaduz, Suíça). As amostras foram agitadas em um vórtex da marca Phoenix (Araraquara, SP, Brasil) e centrifugadas em uma centrífuga Himac ${ }^{\circledR}$ CF16RXII (Tókio, Japão).

\subsubsection{Reagentes}

Os solventes utilizados na otimização do preparo de amostra empregando DLLME (grau HPLC) foram: acetonitrila, metanol, etanol, diclorometano e clorofórmio obtidos da J.T.Baker (Phillipsburg, NJ, EUA) e tetracloreto de carbono obtido da Sigma (St. Louis, Missouri, EUA) e 1,1-dicloroetano obtido da Fluka (Buchs, Suíça). Para preparo da solução tampão empregada na extração foi utilizado o ácido bórico e o borato de sódio da J.T.Baker (Phillipsburg, NJ, EUA).

\subsubsection{Método}

O preparo de amostra empregando a DLLME foi realizado empregando $2 \mathrm{~mL}$ de meio de cultura liquido Czapek acrescido de $2 \mathrm{~mL}$ de solução tampão borato de sódio $100 \mathrm{mmol} \mathrm{L}^{-1} \mathrm{pH} 10$. Os parâmetros otimizados foram tipo e volume de solvente extrator e dispersor e tempo de agitação (DLLME assistida). 
3.2.3.1. Otimização do tipo e volume dos solventes dispersor e extrator

$\mathrm{Na}$ otimização do tipo de solvente dispersor foram avaliados os seguintes solventes: metanol, etanol, acetonitrila, isopropanol e acetona. Após definir o melhor solvente, seu volume foi avaliado entre $300-700 \mu \mathrm{L}$. Na otimização do solvente extrator, os seguintes solventes foram avaliados: clorofórmio, diclorometano, tetracloreto de carbono e dicloroetano. Após definir o melhor solvente, seu volume foi variado entre 70 a $400 \mu \mathrm{L}$.

\subsubsection{Otimização do tempo de agitação das amostras (DLLME Assistida)}

Em DLLME o equilíbrio de extração é atingido rapidamente devido à enorme superfície de contato proporcionada pelo ponto nuvem, formado ao injetar a mistura de solventes extrator e dispersor, rapidamente em uma amostra aquosa. Essa superfície de contato geralmente acarreta altos valores de recuperação dos analitos. Porém, a agitação das amostras após formação do ponto nuvem e antes da centrifugação pode aumentar ainda mais a eficiência de extração e, portanto a recuperação (REZAEE et al., 2006; MENG et al., 2011; CALDAS; GONÇALVEZ; PRIMEL, 2011; ZGOTA-GRZESKOWIAK; GRZESKOWIAK, 2011; REZAEE; YAMINI; FARAJI, 2010; XIAO-HUAN et al., 2009). Para avaliar a influência desse parâmetro, foram avaliados os seguintes tempos de agitação das amostras: 0, 5, 10, 20 e 30 segundos após a formação do ponto nuvem.

\subsection{ESTUDOS DE BIOTRANSFORMAÇÃO}

\subsubsection{Fungos}

Os fungos utilizados nos experimentos de biotransformação foram Mucor rouxii NRRL 1894 obtido como uma cortesia do Dr. C.W. Hesseltine (Northern Utilization Research and Developmente Division, ARS, USDA, Peoria, IL, USA) e pertencente a coleção de culturas de fungos do Departamento de Biologia da Faculdade de Filosofia, Ciências e Letras de Ribeirão Preto da Universidade de São Paulo. 
Os fungos Cunninghamella echinulata var. elegans ATCC 8688A, Cunninghamella elegans ATCC 10028B e Beuveria bassiana ATCC 7159 foram adquiridos da American Type Culture Collection (ATCC) (Manassas, VA, USA).

Os fungo endofítico Phomopsis sp (TD2) foi previamente isolado da planta Tithonia diversifolia enquanto os fungos Chaetomiun globosun (VR10) e Glomerela cingulata (VA1) foram isolados da planta Viguiera robusta. Os fungos endofíticos e os fungos do gênero Cunninghamella são mantidos em discos de meio BDA, com $0,5 \mathrm{~cm}$ de diâmetro, imersos em solução estéril de glicerol $80 \%$ e armazenados a temperatura de $-20{ }^{\circ} \mathrm{C}$. Os fungos endofíticos estão estocados no Laboratório de Química de Micro-organismos-FCFRP/USP, Brasil.

\subsubsection{Equipamentos}

A esterilização dos instrumentos e meios de cultura foi realizada em uma autoclave vertical da marca Phoenix (Araraquara, SP, Brasil) modelo AV 75. A manipulação dos instrumentos, meios de cultura e fungos foi realizada em uma capela de fluxo laminar vertical modelo 310 da marca Pachane (Piracicaba, SP, Brasil). Os fungos foram incubados e permaneceram sob agitação em um shaker de bancada da marca Cientec (Piracicaba, SP, Brasil) modelo CT 712 RN.

\subsubsection{Reagentes}

\subsubsection{Preparo do meio de cultura PDA}

Para o preparo do meio de cultura PDA foi usado o reagente Potato Dextrose Agar da Acumedia (Lansing, Michigan, EUA) na concentração de $39 \mathrm{~g} \mathrm{~L}^{-1}$. e, após a pesagem, completa-se com quantidade necessária de água ultra-pura para tantos quantos forem o número de placas de Petri a serem utilizadas nesta primeira etapa. São necessários $15 \mathrm{~mL}$ de meio para cada placa de Petri. Por fim, essa mistura é esterilizada em autoclave por cerca de 30 minutos para posterior distribuição do meio em cada placa. 


\subsubsection{Preparo do meio de cultura pré-fermentativo Malte}

Para o meio pré-fermentativo Malte foram utilizados os reagentes triptona (5,0 $\left.\mathrm{g} \mathrm{L}^{-1}\right)$, extrato de levedura $\left(3,0 \mathrm{~g} \mathrm{~L}^{-1}\right)$ e extrato de malte $\left(10 \mathrm{~g} \mathrm{~L}^{-1}\right)$ todos da Acumedia (Lansing, Michigan, EUA) e dextrose $\left(10 \mathrm{~g} \mathrm{~L}^{-1}\right)$ da Mallinckrodt (Phillipsburg, NJ, EUA). Posteriormente é adicionado água ultrapura no volume desejado desde que as concentrações em massa permaneçam as mesmas. Tal mistura gera uma solução líquida de pH próximo de 7 que é corrigido para pH 6,2 utilizando-se ácido clorídrico $0,5 \mathrm{~mol} \mathrm{~L}^{-1}$. Em seguida, esse meio é também esterilizado em autoclave da mesma forma que para o meio PDA.

\subsubsection{Preparo do meio de cultura Czapek Modificado}

Para o preparo do meio de cultura líquido Czapek foram utilizados os reagentes sacarose (3\%) da Mallinckrodt (Phillipsburg, NJ, EUA); cloreto de potássio $(0,05 \%)$, sulfato de magnésio heptaidratado $(0,05 \%)$, fosfato de potássio $(0,1 \%)$, sulfato de ferro heptaidratado $(0,001 \%)$ todos da Merck (Darmstadt, Germany) e nitrato de sódio $(0,2 \%)$ da JT Baker (Phillipsburg, NJ, USA). Em seguida, adiciona-se água ultrapura no volume desejado desde que as concentrações em massa permaneçam as mesmas. A mistura gera uma solução liquida de $\mathrm{pH}$ próximo de 8

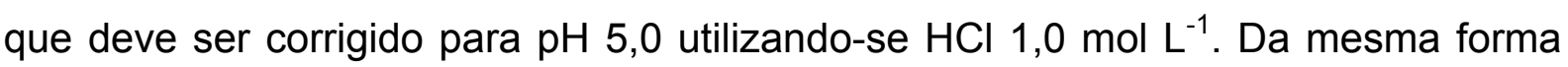
que para os outros meios de cultura, esta mistura é esterilizada em autoclave.

\subsubsection{Método}

Inicialmente os fungos filamentosos em estudo foram repicados, em duplicata, em placas de Petri contendo o meio de cultura PDA e incubados a $30^{\circ} \mathrm{C}$. Em seguida, após o crescimento dos fungos sobre a placa, três discos de $0,5 \mathrm{~cm}$ do meio de cultura com os fungos foram retirados com o "transfer tube" e inoculados assepticamente em $10 \mathrm{~mL}$ de meio pré-fermentativo de malte e colocados sob agitação de $120 \mathrm{rpm}$ a uma temperatura de $30^{\circ} \mathrm{C}$ por 10 dias para o crescimento dos fungos. Em seguida, a massa micelial formada foi transferida assepticamente para $100 \mathrm{~mL}$ de meio Czapek Modificado juntamente com a venlafaxina (3 mg). A 
incubação $\left(30^{\circ} \mathrm{C}, 120 \mathrm{rpm}\right)$ foi realizada por 20 dias sendo que a cada 5 dias foi coletada uma alíquota de $4 \mathrm{~mL}$ do fluído da cultura assepticamente e armazenado a $-20^{\circ} \mathrm{C}$ até o momento da análise (Figura 6). As alíquotas foram submetidas à extração e posteriormente analisadas. Paralelamente aos estudos de biotransformação foram realizados controles contendo: (i) somente o meio de cultura e o fármaco, (ii) somente o meio de cultura e o fungo sem o fármaco.

Alterações nas condições de biotransformação dos fungos foram realizadas para favorecer a biotransformação e/ou o excesso enantiomérico. $O$ excesso enantiomérico $(e e)$ foi avaliado de acordo com a seguinte equação: ee $=(A-B / A+B)$ x 100; onde $A$ é o enantiômero em maior concentração e $B$ o enantiômero em menor concentração.

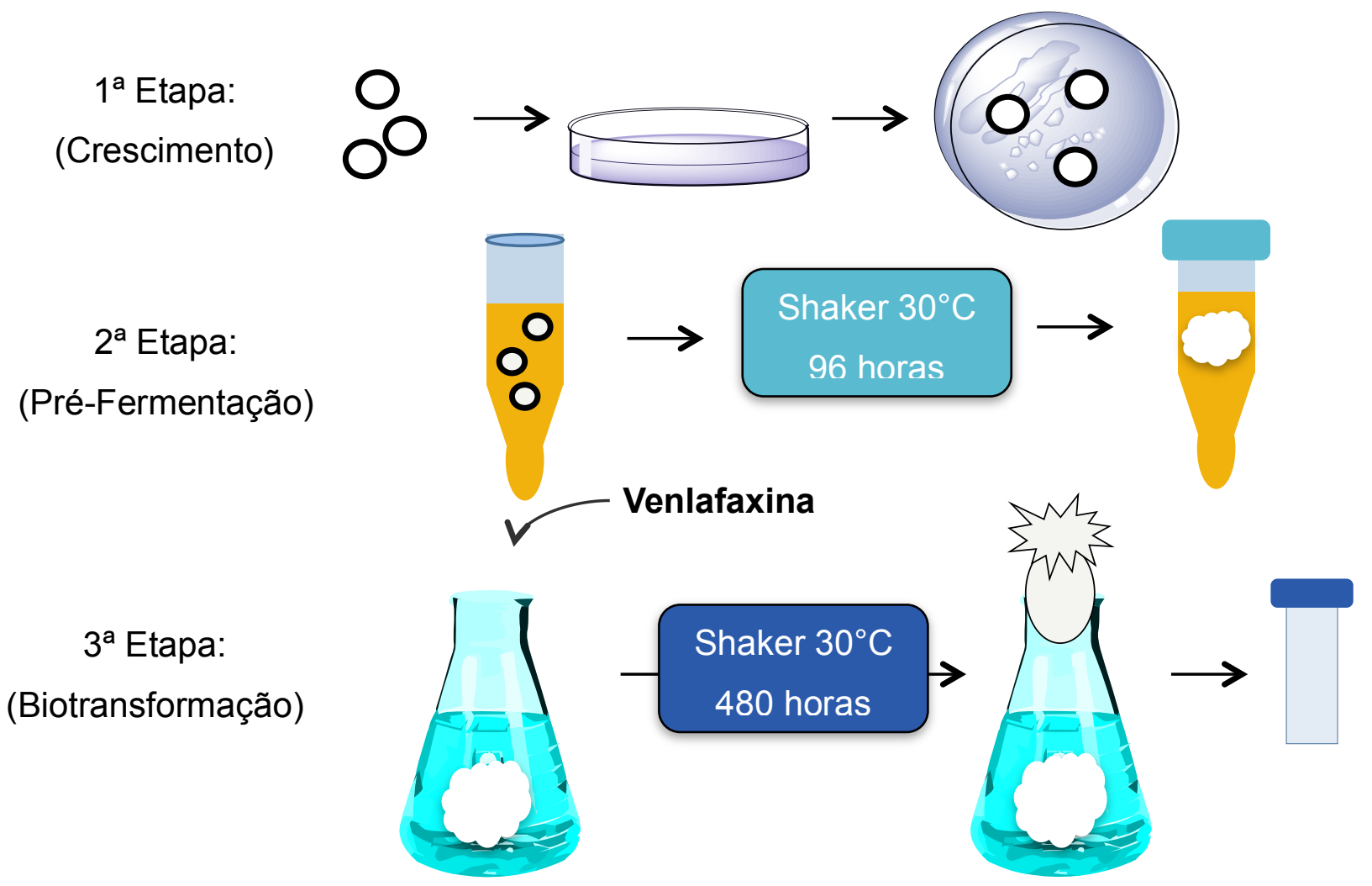

Figura 6- Esquema representativo do procedimento de biotransformação de fungos.

\subsubsection{Concentração inibitória mínima (MIC)}

Para avaliar a toxicidade da venlafaxina sobre os fungos em estudo, foi realizado o ensaio de concentração inibitória mínima, ou seja, a menor concentração do fármaco que é capaz de inibir o crescimento do fungo. As massas miceliais foram 
cultivadas em placa de Petri contendo meio PDA conforme descrito anteriormente. Posteriormente, $5 \mathrm{~mL}$ de meio de cultura líquido Czapek foram adicionados nas placas para raspagem e obtenção de uma suspensão de células miceliais (inóculo). Paralelamente, foram preparadas soluções de venlafaxina (800 $\left.\mu \mathrm{g} \mathrm{mL}^{-1}\right)$ e de antifúngico actidione ${ }^{\circledR}\left(800 \mu \mathrm{g} \mathrm{mL}^{-1}\right)$. Em uma placa com 96 poços, foram pipetados, em uma fileira completa, $100 \mu \mathrm{L}$ de meio Czapek. No primeiro poço também foi pipetado $100 \mu \mathrm{L}$ da solução de venlafaxina. A partir desse poço, foram feitas diluições seriadas de 1:1 até completar a fileira. Em seguida, foi adicionado em todos os poços da fileira, $80 \mu \mathrm{L}$ de meio Czapek e $20 \mu \mathrm{L}$ de inóculo, resultando um intervalo de concentração de $200 \mu \mathrm{g} \mathrm{mL}^{-1}$ a $97,7 \mathrm{ng} \mathrm{mL}^{-1}$. Na fileira seguinte foi feito o mesmo procedimento porém com adição do antifúngico no lugar do inóculo (controle negativo) (Quadro 1). Dessa forma, cada duas sequências de fileiras representava o teste de um determinado fungo em triplicata. Foram feitos também controles positivos e controles de esterilidade do meio de cultura Czapek. A placa foi incubada a $30{ }^{\circ} \mathrm{C}$ durante sete dias em estufa bacteriológica (Solab Científica, Brasil, SP) e a avaliação dos resultados foi feita visualmente.

\begin{tabular}{|c|c|c|c|}
\hline $\begin{array}{c}100 \mu \mathrm{L} \mathrm{M} \\
100 \mu \mathrm{LS} \\
+ \\
80 \mu \mathrm{L} \mathrm{M} \\
20 \mu \mathrm{L}\end{array}$ & $\begin{array}{c}100 \mu \mathrm{L} \mathrm{M} \\
100 \mu \mathrm{L} \text { D1 } \\
+ \\
80 \mu \mathrm{L} M \\
20 \mu \mathrm{L} I\end{array}$ & $\begin{array}{c}100 \mu \mathrm{L} \mathrm{M} \\
100 \mu \mathrm{L} \mathrm{D} 2 \\
+ \\
80 \mu \mathrm{L} M \\
20 \mu \mathrm{L}\end{array}$ & $\begin{array}{c}100 \mu \mathrm{L} \mathrm{M} \\
100 \mu \mathrm{L} 3 \\
+ \\
80 \mu \mathrm{L} \mathrm{M} \\
20 \mu \mathrm{L}\end{array}$ \\
\hline $\begin{array}{c}100 \mu \mathrm{L} \mathrm{M} \\
100 \mu \mathrm{L} \mathrm{S} \\
+ \\
80 \mu \mathrm{L} \mathrm{M} \\
20 \mu \mathrm{LAF}\end{array}$ & $\begin{array}{c}100 \mu \mathrm{L} \mathrm{M} \\
100 \mu \mathrm{L} \mathrm{D} 1 \\
+ \\
80 \mu \mathrm{L} M \\
20 \mu \mathrm{L} \mathrm{AF}\end{array}$ & $\begin{array}{c}100 \mu \mathrm{L} \mathrm{M} \\
100 \mu \mathrm{L} \mathrm{D} 2 \\
+ \\
80 \mu \mathrm{L} \mathrm{M} \\
20 \mu \mathrm{LAF}\end{array}$ & $\begin{array}{c}100 \mu \mathrm{L} \mathrm{M} \\
100 \mu \mathrm{L} 3 \\
+ \\
80 \mu \mathrm{L} \mathrm{M} \\
20 \mu \mathrm{L} \mathrm{AF}\end{array}$ \\
\hline
\end{tabular}

Quadro 1- Etapas no teste de concentração inibitória mínima (MIC). M: meio de cultura líquido Czapek; S: substrato venlafaxina; I: solução inóculo; D1,D2 e D3: diluições sucessivas; AF: Solução de antifúngico.

\subsubsection{Otimização do procedimento de biotransformação}

A fim de se obter a biotransformação da venlafaxina em seus foram feitas modificações no procedimento de biotransformação empregando o fungo Cunninghamella elegans (ATCC 10028B) devido aos resultados satisfatórios obtidos 
nos estudos preliminares de biotransformação. Foram avaliadas as seguintes modificações:

3.3.6.1. Substituição da fonte de carbono do meio de cultura líquido Czapek (a sacarose foi substituída pela glicose)

A fonte de carbono do meio de cultura líquido Czapek foi substituída para verificar possíveis melhoras na biotransformação da venlafaxina em seus metabólitos. Dessa forma, foi adicionado $30 \mathrm{~g} / \mathrm{L}$ de glicose como fonte de carbono ao meio de cultura.

3.3.6.2. Eliminação da fonte de carbono do meio de cultura líquido Czapek deixando apenas a venlafaxina como fonte de carbono

A eliminação da fonte de carbono do meio de cultura líquido Czapek foi feita para que a única fonte disponível para o fungo fosse a venlafaxina. Dessa forma, um procedimento de biotransformação foi realizado na ausência de sacarose no meio de cultura liquido.

\subsubsection{Eliminação da etapa de pré-fermentação em meio Malte}

Nesse procedimento, os plugs de fungos coletados em meio PDA foram adicionados diretamente ao meio de cultura líquido Czapek contendo a venlafaxina. Esse estudo foi realizado para uma tentativa de se obter a biotransformação na fase $\log$ de crescimento do micro-organismo e, com isso, otimizar a produção de metabólitos.

3.3.6.4. Adição da venlafaxina diretamente na etapa de pré-fermentação em meio de cultura líquido Malte

A biotransformação da venlafaxina foi realizada em meio de pré-fermentação de malte a fim de se obter a biotransformação na fase exponencial (log) de crescimento do fungo. 


\subsubsection{Adição de cofator NADPH no meio de cultura líquido Czapek}

A solução de cofator consiste em NADP ${ }^{+}\left(0,25 \mathrm{mmol} \mathrm{L}^{-1}\right)$, glicose-6-fosfato (5 mmol L $\left.{ }^{-1}\right)$ e glicose-6-fosfato desidrogenase (0,5 unidades), todos em solução tampão tris- $\mathrm{HCl}, \mathrm{pH} 7,4$. A partir desses componentes, ocorre a formação de NADPH (MOREIRA et al., 2013). O cofator fosfato de nicotinamida adeninadinucleotídeo (NADPH) é um importante componente nas biotransformações que envolvem reações de oxidação. O cofator NADPH doa um elétron ao grupo heme da enzima do $\mathrm{P} 450$ reduzindo o átomo de ferro $\left(\mathrm{Fe}^{3+}\right)$. $\mathrm{O}$ átomo de ferro reduzido $\left(\mathrm{Fe}^{2+}\right)$ pode se ligar a um átomo de oxigênio que depois será transferido ao substrato, conforme reação descrita abaixo (ZHANG; ZHU; HUMPHREYS, 2007). Dessa forma, a adição desse cofator ao meio de cultura Czapek foi realizada e a biotransformação avaliada.

$$
\text { Substrato }(\mathrm{RH})+\mathrm{O}_{2}+\mathrm{NADPH}+\mathrm{H}^{+} \rightarrow \text { Produto }(\mathrm{ROH})+\mathrm{H}_{2} \mathrm{O}+\mathrm{NADP}^{+}
$$

\subsection{VALIDAÇÃO ANALÍTICA}

A validação analítica foi realizada segundo as normas do European Medicines Agency (EMA) 2011 e Agência Nacional de Vigilância Sanitária (ANVISA) 2012. Os parâmetros analisados foram linearidade, limite inferior de quantificação (LLOQ), precisão e exatidão intra- e interdias, recuperação, estabilidade de bancada e de ciclos de congelamento e descongelamento. A validação do método analítico foi realizada utilizando o meio de cultura liquido Czapek como matriz e empregando a DLLME como técnica de preparação de amostras. A padronização interna foi realizada empregando o cetononazol (CLAE) e a risperidona (CE), ambos na concentração de $100 \mu \mathrm{g} \mathrm{mL}^{-1}$, como padrão interno. Devido a presença de um interferente no padrão analítico da $\mathrm{N}$-desmetilvenlafaxina, não foi possível a validação desse analito empregando CLAE. 


\subsubsection{Linearidade}

A linearidade do método analítico avalia a correlação linear entre duas variáveis dependente $(\mathrm{y})$ e independente (x) (TRIOLA, 2005). A linearidade do método foi avaliada utilizando a soma dos mínimos quadrados ponderada e coeficientes de correlação. A ponderação foi realizada empregando como peso $1 / x^{2}$ e as amostras analisadas em triplicatas $(n=3)$. A validade da regressão foi determinada empregando o teste da falta de ajuste linear (lack of fit test). O nível de significância ( $\alpha$ ) avaliado foi de 0,05\% em grau de confiança 95\%. Para a linearidade no método empregando CLAE a faixa linear foi avaliada entre $500-15.000 \mathrm{ng} \mathrm{mL}^{-1}$ para cada enantiômero da venlafaxina e 225-1875 $\mathrm{ng} \mathrm{mL}^{-1}$ para cada enantiômero da O-desmetilvenlafaxina. Para o método desenvolvido por eletroforese capilar a faixa linear avaliada foi de 500-15.000 $\mathrm{ng} \mathrm{mL}^{-1}$ para cada enantiômero da venlafaxina e 75-938 $\mathrm{ng} \mathrm{mL}^{-1}$ para cada enantiômero da O-desmetilvenlafaxina e $\mathrm{N}$ desmetilvenlafaxina.

\subsubsection{Limite de quantificação (LLOQ)}

O limite de quantificação é a menor concentração do analito que pode ser quantificada com precisão (determinada pela desvio padrão relativo, DPR\%) e exatidão (determinada pelo erro relativo, E\%) inferior a 20\% (ANVISA, 2012). Na validação empregando CLAE o limite de quantificação foi de $500 \mathrm{ng} \mathrm{mL}^{-1}$ para cada enantiômero da venlafaxina e $225 \mathrm{ng} \mathrm{\textrm {mL } ^ { - 1 }}$ para cada enantiômero da Odesmetilvenlafaxina. Já para na validação empregando a eletroforese capilar os limites de quantificação foram $500 \mathrm{ng} \mathrm{mL}^{-1}$ e $75 \mathrm{ng} \mathrm{mL}^{-1}$ para cada enantiômero da venlafaxina e seus metabólitos, respectivamente.

\subsubsection{Precisão e exatidão}

A exatidão determina se o valor obtido pelo método é próximo o suficiente do valor nominal da concentração dos analitos (ANVISA, 2012). Esse parâmetro pode ser representado pelo erro percentual (E\%) que deve ser menor que $15 \%(<20 \%$ para o LLOQ). O erro relativo é calculado pela Equação 1, abaixo: 


$$
E=\frac{\text { valor obtido-valor real }}{\text { valor real }} \times 100
$$

A precisão determina se a repetitividade dos experimentos têm variações aceitáveis (ANVISA, 2012). É representado pelo desvio padrão relativo que deve ser menor que $15 \%$ (< 20\% para o LLOQ) e é representado pela Equação 2, abaixo:

$$
D P R=\frac{S D}{\bar{X}} \times 100
$$

Onde SD é o desvio padrão absoluto e $\bar{X}$ é a média das replicatas

A precisão e exatidão devem ser avaliadas interdias e intra-dia empregando concentrações alta, média e baixa de cada analito, além do limite de quantificação todos em quintuplicata $(n=5)$. Nesse trabalho as concentrações empregadas, tanto no método por CLAE quanto no método por CE, foram 1500, 7500 e $12.000 \mathrm{ng} \mathrm{mL}^{-1}$ para os enantiômeros da venlafaxina. No método empregando CLAE foram utilizadas concentrações de 450, 937 e $1400 \mathrm{ng} \mathrm{mL}^{-1}$ para os enantiômeros da Odesmetilvenlafaxina e, no método empregando eletroforese capilar, foram utilizadas as concentrações 150,300 e $700 \mathrm{ng} \mathrm{mL}^{-1}$ para os enantiômeros da $\mathrm{N}$ desmetilvenlafaxina e O-desmetilvenlafaxina.

\subsubsection{Recuperação}

$\mathrm{Na}$ determinação da recuperação absoluta do procedimento de extração, alíquotas de $2 \mathrm{~mL}$ de meio de cultura liquido Czapek foram fortificadas com venlafaxina nas concentrações de 1500,7500 e $12.000 \mathrm{ng} \mathrm{mL}^{-1}$ para cada enantiômero $(n=3)$ e 450, 937 e $1400 \mathrm{ng} \mathrm{mL}^{-1}$ para cada enantiômero da Odesmetilvenlafaxina $(n=3)$ no método empregando CLAE. No método por eletroforese capilar, foram utilizadas as concentrações 150, 300 e $700 \mathrm{ng} \mathrm{mL}^{-1}$ para os enantiômeros da O-desmetilvenlafaxina e $N$-desmetilvenlafaxina $(n=3)$. Após, as amostras foram submetidas ao procedimento de DLLME. As áreas destas amostras 
foram comparadas com áreas obtidas por injeção direta de soluções-padrão, contendo a mesma quantidade de cada composto dissolvido em água. A recuperação foi expressa como porcentagem (\%) da quantidade extraída (Equação 3).

$$
\text { Recuperação }=\frac{\text { Conc.Calculada }}{\text { Conc.Nominal }} \times 100
$$

\subsubsection{Seletividade}

O método analítico deve ser capaz de diferenciar os analitos e padrão interno de possíveis interferentes da matriz biológica. Para isso, é necessário que não haja picos interferentes na matriz nos mesmos tempos de retenção/migração dos analitos. Um interferente será permitido se este apresentar menos de $20 \%$ do sinal do limite de quantificação (LLOQ) e menos de 5\% do sinal do padrão interno (ANVISA, 2012). A análise de seletividade foi realizada com o meio de cultura líquido Czapek puro e com o meio Czapek incubado com os fungos de estudo sem adição de venlafaxina.

\subsubsection{Estabilidade}

A estabilidade avalia se ocorreu alguma alteração na concentração dos analitos devido aos procedimentos de preparo de amostra e armazenamento. Esse parâmetro é realizado com as concentrações baixa e alta de cada analito em quintuplicata $(n=5)$.

\subsubsection{Estabilidade de bancada}

A estabilidade de bancada foi avaliada deixando os analitos em meio de cultura liquido Czapek e tampão borato $100 \mathrm{mmol} \mathrm{L}^{-1} \mathrm{pH} 10$ em bancada durante 8 horas. Após esse período de tempo as amostras foram extraídas e quantificadas empregando uma curva analítica recém-preparada. 
3.4.6.2. Estabilidade de ciclos de congelamento e descongelamento

As amostras foram submetidas a ciclos de congelamento e descongelamento de 12, 24 e 24 horas. Os analitos em meio de cultura liquido Czapek foram congelados em tubos de ensaio e, após 12 horas, descongeladas em temperatura ambiente. Assim que totalmente descongeladas, foram congelados novamente permanecendo durante $24 \mathrm{em}$ freezer apropriado. O procedimento foi realizado totalizando 3 ciclos de congelamento e descongelamento. Após esse período as amostras foram extraídas e quantificadas empregando uma curva analítica recémpreparada. 
RESULTADOS E DISCUSSÃO 


\section{RESULTADOS E DISCUSSÃO}

\subsection{SEPARAÇÃo ENANTIOSSELETIVA DA VENLAFAXINA E SEUS METABÓLITOS}

\subsubsection{Separação empregando CLAE}

A separação quiral da venlafaxina e seus metabólitos por CLAE foi avaliada empregando duas colunas quirais baseadas em amilose. Ambas as colunas apresentam o mesmo radical (3,5-dimetilfenilcarbamato). Essas colunas diferem em seus tamanhos de partículas e comprimento. A coluna Chiralpak AD-RH ${ }^{\circledR}$ apresenta tamanho de partícula de $5 \mu \mathrm{m}$ e $15 \mathrm{~cm}$ de comprimento e a coluna Chiralpak $A D^{\circledR}$ apresenta tamanho de partícula de $10 \mu \mathrm{m}$ e $25 \mathrm{~cm}$ de comprimento. De acordo com a equação de Van Deemter (Equação 4) quanto menor o tamanho da partícula maior é a eficiência observada na separação (SNYDER; KIRKLAND; GLAJCH, 1997). O tamanho de partícula influencia os termos $A$ e $C$ da equação de Van Deemter. $O$ termo A se refere aos caminhos múltiplos. Quanto menor o tamanho da partícula, mais homogêneo será o empacotamento da coluna e, portanto, menor a probabilidade das moléculas do analito percorrem caminhos distintos e dessa forma atingirem o detector em tempos diferentes. $O$ termo $C$ refere-se à resistência à transferência de massa. Quanto menor o tamanho da partícula, menor será também seus poros o que acarreta uma transferência de massa mais rápida. Diminuindo-se os termos $\mathrm{A}$ e $\mathrm{C}$, há uma diminuição na altura de pratos $(\mathrm{H})$ e consequentemente um aumento na eficiência da separação. Baseando-se, portanto na equação de Van Deemter temos que a coluna Chiralpak $\mathrm{AD}-\mathrm{RH}^{\circledR}$ seria mais adequada para a continuidade dos experimentos. Por outro lado, temos que o comprimento da coluna influencia também a eficiência na separação (Equação 5). Uma coluna de maior comprimento apresenta uma melhor eficiência (SNYDER; KIRKLAND; GLAJCH, 1997). Baseando-se nessa equação conclui-se que a coluna Chiralpak $A D^{\circledR}$ apresenta melhor eficiência e, portanto, torna-se difícil a escolha apenas pela análise do tamanho de partícula e comprimento da coluna. Utilizando a coluna Chiralpak $\mathrm{AD}-\mathrm{RH}^{\circledR}$ foram obtidos valores de resolução de 3,37 para os enantiômeros da venlafaxina, 2,48 para os enantiômeros da $\mathrm{N}$-desmetilvenlfaxina e 2,04 para os 
enantiômeros da O-desmetilvenlafaxina e um tempo total de análise de 20 minutos. Com a coluna Chiralpak $A D^{\circledR}$ foram obtidos valores de resolução aceitáveis apenas com o acoplamento de uma coluna aquiral C18 (150 mm x 4,6 mm, $5 \mu \mathrm{m}$ de partícula) anterior a coluna quiral. $\mathrm{Na}$ ausência da coluna C18 houve coeluição do segundo enantiômero da $\mathrm{N}$-desmetilvenlafaxina com o primeiro enantiômero da venlafaxina. As resoluções finais nessa condição foram 2,35; 1,58 e 1,60 para os enantiômeros da venlafaxina, $\mathrm{N}$-desmetilvenlafaxina e O-desmetilvenlafaxina, respectivamente, em 25 minutos de análise. Como pode ser visto na Figura 7, a coluna Chiralpak $\mathrm{AD}-\mathrm{RH}^{\circledR}$ apresentou melhores resultados em termos de simetria de picos e tempo de análise. Dessa forma, nesse caso, o menor tamanho de partícula da coluna resultou em uma melhor resolução dos analitos. Portanto essa coluna foi escolhida para a continuidade dos estudos e posterior validação do método. $O$ mecanismo de interação quiral não é completamente conhecido. As moléculas quirais podem interagir com o grupamento tris (3,5-dimetilfenilcarbamato) dessa coluna através de ligações de hidrogênio com os grupamentos amina e carboxila e interações dipolo-dipolo com os grupamentos carboxila. Os grupamentos aromáticos podem também interagir com os grupos fenil da fase estacionária, principalmente quando fase reversa é empregada (LOURENÇO; CASSIANO; CASS, 2010; BONATO; JABOR; GAITANI, 2005). A fase móvel utilizada foi metanol: acetonitrila: água (80: 13: $7 \mathrm{~V} / \mathrm{V} / \mathrm{V}$ ) com adição de $0,15 \%$ de trietilamina como modificador orgânico o que minimiza a interação de analitos com característica básica com os silanóis residuais. Além disso, a trietilamina ajuda a manter os analitos em sua forma não ionizada permitindo uma melhor interação com a fase estacionária.

$$
H=A+\frac{B}{\mu}+C \cdot \mu
$$

Onde, $\mathrm{H}=$ altura de pratos $(\mathrm{cm}) ; \mathrm{A}=$ coeficiente do efeito dos caminhos múltiplos (difusão turbilhonar); $B$ = coeficiente de difusão longitudinal; $C=$ coeficiente de transferência de massa e $\mu=$ velocidade linear da fase móvel $\left(\mathrm{cm} . \mathrm{s}^{-1}\right)$. 


$$
N=\frac{L}{H}
$$

Onde, $N=$ número de pratos; $L=$ comprimento da coluna cromatográfica $(\mathrm{cm})$ e $\mathrm{H}=$ altura de pratos $(\mathrm{cm})$.

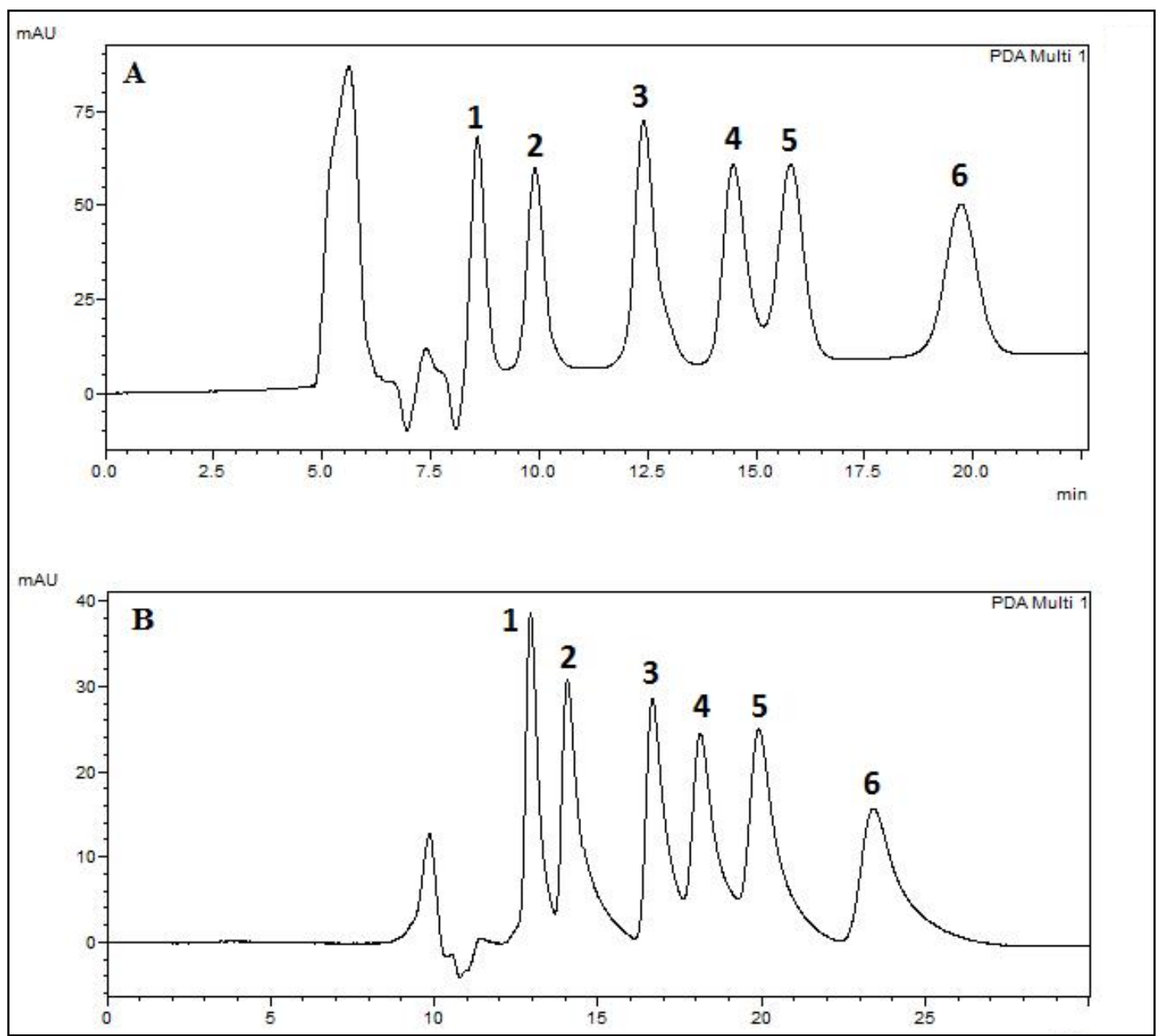

Figura 7- Cromatogramas da separação quiral da Vx e metabólitos. (A)-coluna Chiralpak AD-RH ${ }^{\circledR}$; (B)-coluna Chiralpak $A D^{\circledR}$ acoplada a uma coluna aquiral C18. (1)-(2) enantiômeros da ODV; (3)-(4)enantiômeros da NDV; (5)-(6) enantiômeros da Vx. Fase móvel: metanol: acetonitrila: água (80: 13: 7 $v / v / v)$ com $0,15 \%$ de trietilamina, temperatura de análise $23 \pm 2^{\circ} \mathrm{C}$ e vazão de $0,3 \mathrm{~mL} \mathrm{~min}^{-1}$.

\subsubsection{Separação empregando eletroforese capilar}

As condições para separação dos enantiômeros da venlafaxina e seus metabólitos por eletroforese capilar foram obtidas utilizando um capilar de sílica fundida com comprimento total de $40 \mathrm{~cm}$ (30 cm efetivo) e $75 \mu \mathrm{m}$ de diâmetro interno. As injeções foram realizadas pelo modo hidrodinâmico, aplicando 0,5 psi 
durante 8 segundos. Os analitos foram monitorados no comprimento de onda 204 $\mathrm{nm}$.

\subsubsection{Otimização da concentração e pH da solução tampão de análise}

Em eletroforese capilar é importante que os analitos estejam em sua forma ionizada para que possam migrar sob a influência de um campo elétrico. $\mathrm{O} \mathrm{pH}$ de análise, além de influenciar o grau de ionização das moléculas também tem influencia na formação do fluxo eletrosmótico. Quanto maior o $\mathrm{pH}$, maior o potencial Zeta dos grupamentos silanóis da parede do capilar e, portanto, maior o fluxo eletrosmótico (WEINBERGER, 1999). A venlafaxina e seus metabólitos são compostos básicos e apresentam-se ionizados em pHs abaixo de seus pkas $(\approx 9,4)$ (RUDAZ et al., 2000). Dentre os pHs analisados, apenas conseguiu-se uma separação enantiomérica dos analitos em $\mathrm{pH}$ 2,0. Nesse $\mathrm{pH}$ não há fluxo eletrosmótico considerável sendo a migração eletroforética do analito o único fator responsável pela migração dos analitos até o detector (Equação 6). Quanto maior for a concentração da solução tampão, menor será a migração dos analitos devido à influência dos contra-íons presentes em solução e também pelo aumento da viscosidade do meio (WEINBERGER, 1999).

$$
\mu_{e f}=\left(\frac{q}{6 \pi \eta \mathrm{r}}\right)
$$

Onde q é o número de cargas, $\eta$ é a viscosidade do meio e r é o raio aquoso do íon.

Fixando o pH do eletrólito de análise em 2,0, foram avaliadas as seguintes concentrações da solução tampão fosfato de sódio: 50, 60, 70, 80, 90 e 100 mmol L'

1 (Tabela 5). Nessa etapa foi utilizada uma tensão de $+20 \mathrm{kV}$ e temperatura do capilar de $20^{\circ} \mathrm{C}$. Como seletor quiral foi empregado a mistura de ciclodextrinas $\alpha-C D$ (10 mmol L ${ }^{-1}$ ) e CM-ß-CD (1\%) (RUDAZ; VEUTHEY; DESIDERIO; FANALI, 1999). Os melhores valores de resoluções foram obtidos empregando a solução com concentração de $50 \mathrm{mmol} \mathrm{L}^{-1}$. A diminuição da resolução observada com o emprego 
de soluções mais concentradas pode estar relacionada ao efeito Joule, pois um aumento na concentração da solução tampão leva a um aumento da corrente gerada e consequentemente um aumento da temperatura do meio com diminuição da resolução (WEINBERGER, 1999).

Tabela 5- Valores de resolução obtidos com diferentes concentrações de solução tampão fosfato de sódio.

\begin{tabular}{ccccccc}
\hline Analitos & \multicolumn{3}{c}{ Concentração da solução tampão $\left(\mathbf{m m o l ~ L ~}^{-1}\right.$ ) } \\
\hline & 50 & 60 & 70 & 80 & 90 & 100 \\
\cline { 2 - 7 } & 2,39 & 1,56 & 1,45 & 1,42 & 1,38 & 1,32 \\
Resolução dos enantiômeros da Vx & 2,67 & 1,86 & 1,84 & 1,88 & 1,87 & 1,77 \\
Resolução dos enantiômeros da NDV & 2,58 & 2,23 & 1,99 & 1,93 & 1,85 & 1,75 \\
Resolução dos enantiômeros da ODV & & & & & &
\end{tabular}

\subsubsection{Otimização da tensão aplicada}

A tensão aplicada exerce influência na eficiência de separação, resolução e também no tempo de migração dos analitos. Isso porque influencia na temperatura de análise, na viscosidade do eletrólito de análise e velocidade de migração dos analitos (WEINBERGER, 1999). Utilizando a solução tampão fosfato de sódio 50 mmol L-1 $\mathrm{pH} 2,0$, temperatura do capilar de $20^{\circ} \mathrm{C}$ e a mistura de ciclodextrinas descrita no item 4.1.2.1, foram avaliados os seguintes valores de tensão aplicada: $+15,+20$ e +25 kV (Tabela 6). Como pode ser observado, a variação na tensão aplicada influenciou pouco os valores de resolução dos analitos tendo mais influencia na resolução dos enantiômeros da ODV. Dessa forma, foi estabelecido o emprego de $+20 \mathrm{kV}$ para as análises posteriores, pois nesse valor de corrente todos os valores de resolução são aceitáveis e o tempo de análise é relativamente curto ( 15 minutos).

Tabela 6- Valores de resolução obtidos após aplicação de diferentes valores de tensão aplicada.

\begin{tabular}{lccc}
\hline \multicolumn{1}{c}{ Analitos } & \multicolumn{3}{c}{ Tensão Aplicada (kV) } \\
\hline & +15 & +20 & +25 \\
\cline { 2 - 4 } Resolução dos enantiômeros da Vx & 2,29 & 2,39 & 2,09 \\
Resolução dos enantiômeros da NDV & 2,63 & 2,67 & 2,33 \\
Resolução dos enantiômeros da ODV & 2,94 & 2,58 & 2,58 \\
\hline
\end{tabular}




\subsubsection{Otimização da temperatura do capilar}

A passagem de corrente elétrica em uma solução eletrolítica gera calor pela fricção dos íons em solução com as moléculas do eletrólito de análise podendo acarretar no efeito Joule (WEINBERGER, 1999). O efeito Joule pode levar à perda de eficiência e de resolução na separação dos analitos. Além disso, a temperatura do capilar influencia a viscosidade da solução, o que leva à modificações no tempo de migração e resolução dos analitos (WEINBERGER, 1999). Utilizando a solução tampão fosfato $50 \mathrm{mmol} \mathrm{L}^{-1} \mathrm{pH}$ 2,0 com a mistura de CDs descritas no item 4.1.2.1 e a aplicação de $+20 \mathrm{kV}$ de tensão, foram avaliadas as seguintes temperaturas do capilar: 15,18 e $20^{\circ} \mathrm{C}$ (Tabela 7). Os melhores valores de resolução foram obtidos com a temperatura de $20{ }^{\circ} \mathrm{C}$. Para os analitos Vx e NDV, com o aumento da temperatura houve um ligeiro aumento nos valores de resolução. Esse fato pode ser explicado pela diminuição na velocidade de formação do complexo de inclusão entre o analito e a CDs diminuindo, portanto a eficiência na separação. Os valores de resolução do analito ODV foram poucos alterados com a variação da temperatura do capilar.

Tabela 7. Valores de resolução obtidos empregando diferentes temperaturas do capilar.

\begin{tabular}{lccc}
\hline \multicolumn{1}{c}{ Analitos } & \multicolumn{3}{c}{ Temperatura do capilar $\left({ }^{\circ} \mathbf{C}\right)$} \\
\hline & 15 & 18 & 20 \\
\cline { 2 - 4 } Resolução dos enantiômeros da Vx & 1,97 & 1,90 & 2,39 \\
Resolução dos enantiômeros da NDV & 2,34 & 2,25 & 2,67 \\
Resolução dos enantiômeros da ODV & 2,64 & 2,48 & 2,58 \\
\hline
\end{tabular}

Posteriormente, após determinar a temperatura do capilar e a tensão aplicada, um experimento foi realizado variando os valores de tensão aplicada e monitorando os valores de corrente gerados (gráfico de Ohm, Figura 8). O gráfico de Ohm é importante para verificar se a tensão escolhida para análise pode levar ao efeito joule devido o gradiente de temperatura gerado. Para isso, valores crescentes de tensão são aplicados e a respectiva corrente gerada é avaliada. Idealmente, a resposta deve permanecer linear durante todo intervalo avaliado (WEINBERGER, 1999). Verifica-se, a partir do gráfico abaixo, que a resposta permanece linear até um valor de tensão de $+18 \mathrm{kV}$. Em valores maiores de tensão há uma leve 
inclinação da reta, indicando uma possível ocorrência de efeito Joule. Apesar desse comportamento, optou-se por utilizar $+20 \mathrm{kV}$ pois nessa condição observou-se um melhor valor de resolução (Tabela 7) e um tempo de análise mais curto.

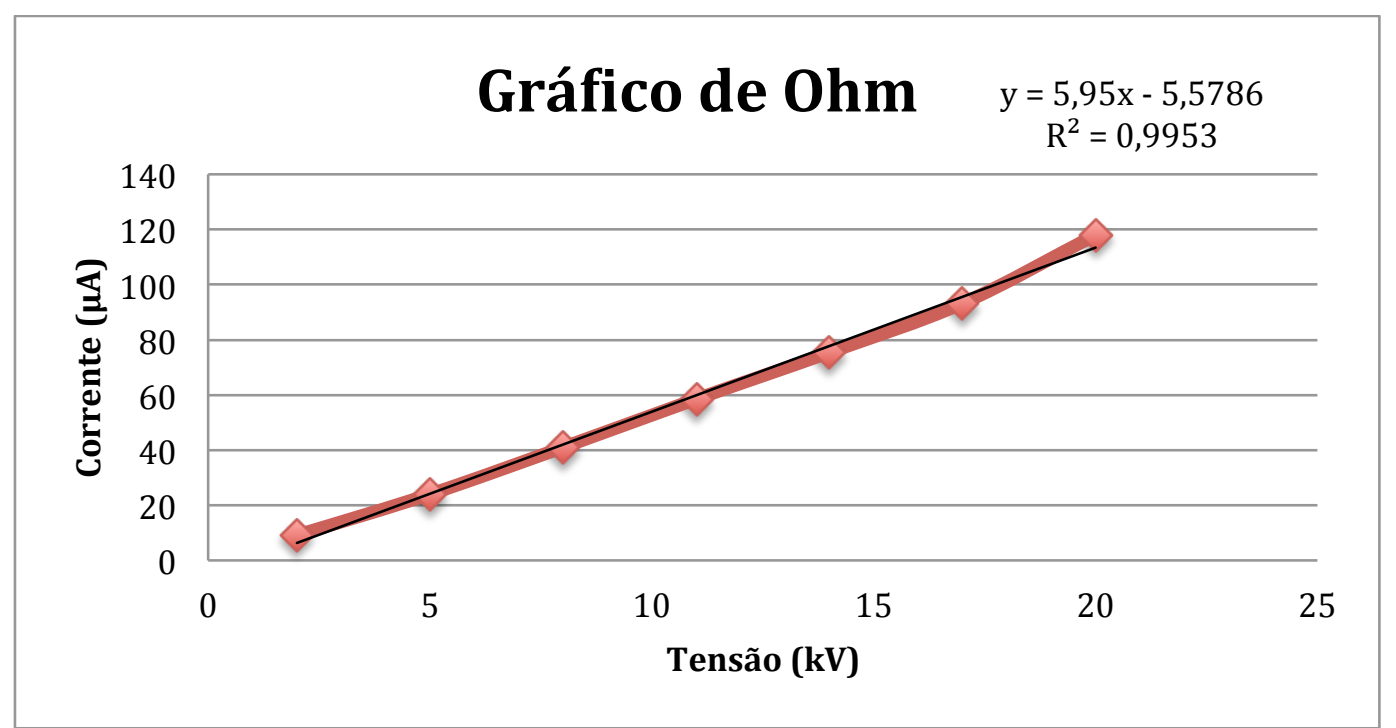

Figura 8- Gráfico de Ohm. Condições de análise: solução tampão fosfato $50 \mathrm{mmol} \mathrm{L^{-1 }} \mathrm{pH} 2,0$ contendo $C M-\beta-C D(1 \%)$ e $\alpha-C D\left(10 \mathrm{mmol} \mathrm{L}^{-1}\right)$, temperatura de análise $20^{\circ} \mathrm{C}$.

\subsubsection{Otimização da concentração de ciclodextrinas}

A resolução quiral empregando ciclodextrinas ocorre devido a formação de complexos diasteroisoméricos transitórios que apresentam diferentes tempos de migração em um campo elétrico permitindo, assim, a separação enantiomérica (EECKHAUT; MICHOTTE, 2009). Nesse trabalho, a separação enantiomérica foi realizada empregando uma mistura das ciclodextrinas $\alpha-C D$ e CM- $\beta-C D$ ambas com características neutras em pH 2,0. Utilizando a solução tampão fosfato de sódio 50 mmol L ${ }^{-1} \mathrm{pH} 2,0$, temperatura do capilar de $20^{\circ} \mathrm{C}$ e aplicação de tensão $+20 \mathrm{kV}$, a variação da concentração dessas ciclodextrinas foi realizada. Fixando a concentração de CM- $\beta$-CD em $1 \%$ foram analisadas as seguintes concentrações de a-CD: $5 \mathrm{mmol} \mathrm{L}^{-1}, 8 \mathrm{mmol} \mathrm{L}{ }^{-1}, 10 \mathrm{mmol} \mathrm{L}^{-1}$ e $15 \mathrm{mmol} \mathrm{L}^{-1}$ (Tabela 8). Posteriormente, após otimizada a concentração da $\alpha-C D$, a concentração de $C M-\beta-C D$ foi avaliada no intervalo de 0,5\%-1,5\% (Tabela 9). As melhores resoluções para os metabólitos foram obtidas empregando $10 \mathrm{mmol} \mathrm{L}^{-1}$ de $\alpha-C D$ e $1 \%$ de CM- $\beta-C D$. Porém, foram escolhidas as concentrações de $8 \mathrm{mmol} \mathrm{L}^{-1}$ de $\alpha-C D$ para continuidade do trabalho pois a maior resolução dos enantiômeros da venlafaxina foi essencial para a 
validação de uma faixa relativamente mais concentrada desses enantiômeros. Misturas de ciclodextrinas são frequentemente utilizadas nas separações quirais. Geralmente, a mistura é constituída de uma ciclodextrina neutra e uma ciclodextrina carregada, que proporciona ao meio uma mobilidade eletroforética aparente permitindo, então, a separação quiral. Porém, no presente trabalho, ambas as ciclodextrinas encontram-se neutras em pH 2,0. Nesse caso, a resolução poderia ser obtida com a concentração ótima de uma das ciclodextrinas. Entretanto, essa concentração ótima é geralmente muito alta, o que inviabiliza o método. Não é sempre possível explicar o aumento de seletividade com o uso de mistura de ciclodextrinas. Um mecanismo de antagonismo ou sinergismo pode ocorrer acarretando a separação enantiomérica (FILLET; HUBERT; CROMMEN, 2000).

Tabela 8. Valores de resolução obtidos com diferentes concentrações a-CD.

\begin{tabular}{ccccc}
\hline Analitos & \multicolumn{4}{c}{ Concentração da $\boldsymbol{\alpha}$-CD $\left(\mathbf{m m o l ~ L}^{-1}\right)$} \\
\hline & 5 & 8 & 10 & 15 \\
\cline { 2 - 5 } Resolução dos enantiômeros da Vx & 2,82 & 2,68 & 2,19 & 2,41 \\
Resolução dos enantiômeros da NDV & 1,91 & 2,36 & 2,54 & 0 \\
Resolução dos enantiômeros da ODV & 1,68 & 1,80 & 3,04 & 3,19 \\
\hline
\end{tabular}

Tabela 9. Valores de resolução obtidos com diferentes concentrações CM- $\beta$-CD.

\section{Analitos}

\begin{tabular}{ccccc}
\hline & 0,50 & 0,80 & 1,0 & 1,5 \\
\cline { 2 - 5 } Resolução dos enantiômeros da Vx & 1,37 & 2,09 & 2,19 & 0 \\
Resolução dos enantiômeros da NDV & 1,96 & 2,61 & 2,54 & 0 \\
Resolução dos enantiômeros da ODV & 1,76 & 3,09 & 3,04 & 0 \\
\hline
\end{tabular}

Concentração da CM- $\beta-C D(\%)$

\subsubsection{Condições finais de separação}

As condições otimizadas para separação enantiomérica da venlafaxina e seus metabólitos por CE foram: solução tampão fosfato de sódio $50 \mathrm{mmol} \mathrm{L}^{-1}, \mathrm{pH} \mathrm{2,0}$ contendo $8 \mathrm{mmol} \mathrm{L}^{-1}$ de $\alpha-C D$ e $1,0 \%$ de $C M-\beta-C D$. A tensão aplicada foi de $+20 \mathrm{kV}$ e a temperatura do capilar foi mantida em $20{ }^{\circ} \mathrm{C}$. Nessas condições, o tempo de 
análise foi inferior a 15 minutos com valores de resolução superior a 1,5 para todos os analitos (Figura 9).

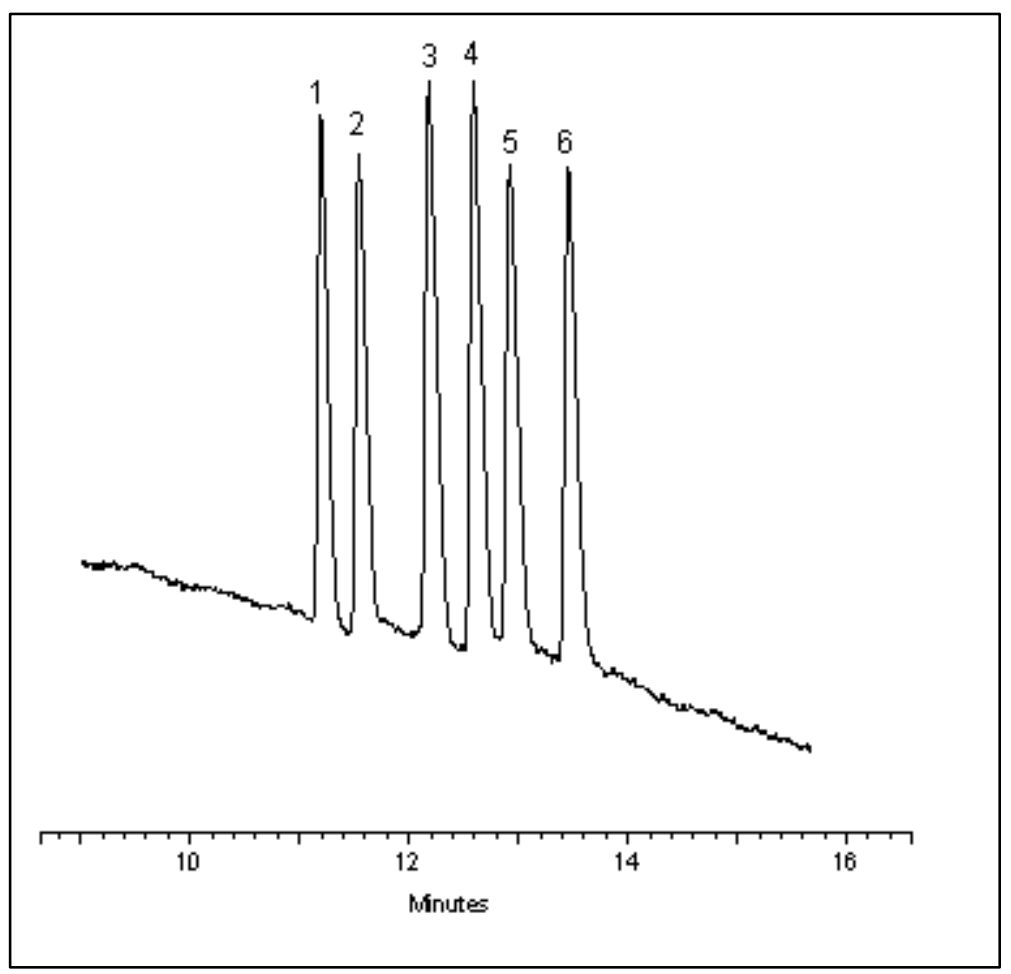

Figura 9- Eletroferograma da separação enantiosseletiva da venlafaxina e seus metabólitos. (1)-(2)enantiômeros da Vx; (3)-(4)-enantiômeros da NDV; (5)-(6)-enantiômeros da ODV. Condições de análise: solução tampão fosfato de sódio $50 \mathrm{mmol} \mathrm{L}^{-1}, \mathrm{pH} 2,0$ contendo $\mathrm{CM}-\beta-\mathrm{CD}$ (1\%) e $\alpha-C D(8$ $\mathrm{mmol} \mathrm{\textrm {L } ^ { - 1 }}$ ), tensão aplicada $+20 \mathrm{kV}$ e temperatura de análise $20^{\circ} \mathrm{C}$.

\subsection{DETERMINAÇÃO DA ORDEM DE ELUIÇÃO DOS ENANTIÔMEROS}

A determinação da ordem de eluição dos enantiômeros da venlafaxina e seus metabólitos foi realizada após isolamento dos enantiômeros desses analitos empregando a metodologia descrita por Da FONSECA et al., 2010. Nesse método, a separação dos enantiômeros foi realizada por CLAE empregando a coluna quiral Chiralpak $\mathrm{AD}^{\circledR}$ (250 mm x 4,6 mm x $10 \mu \mathrm{m}$ de partícula) e fase móvel composta por hexano: isopropanol $(95: 5 \mathrm{v} / \mathrm{v})+0,025 \%$ de dietilamina e vazão de 1,0 $\mathrm{mL} \mathrm{min}^{-1}$. As resoluções dos enantiômeros foram obtidas à temperatura de $23 \pm 2^{\circ} \mathrm{C}$. Os picos referentes aos enantiômeros foram coletados separadamente, e após evaporação da fase móvel sob fluxo ar comprimido, o resíduo foi solubilizado em metanol e armazenado em freezer $\left(-20^{\circ} \mathrm{C}\right)$ para posterior análise. A determinação da ordem de 
eluição/migração foi realizado por comparação com a ordem de eluição descrita por Da FONSECA et al., 2010.

\subsubsection{Determinação da ordem de eluição dos enantiômeros por CLAE}

Para determinação da ordem de eluição dos enantiômeros por CLAE, $500 \mu \mathrm{L}$ da solução contendo cada enantiômero foi transferida para um tudo de ensaio e evaporada sob fluxo de ar comprimido. Posteriormente, o resíduo foi solubilizado em $50 \mu \mathrm{L}$ de fase móvel e analisado nas condições estabelecida nesse trabalho. Além dos enantiômeros puros, foram injetadas também amostras do racemato fortificadas com cada enantiômero puro para confirmação. As Figuras 10, 11 e 12 apresentam os resultados referentes a essas análises. Dessa forma, em CLAE, a ordem de eluição dos enantiômeros ficou estabelecida como: (+)-(S)-O-desmetilvenlfaxina (pico 1), (-)-(R)-O-desmetilvenlafaxina (pico 2), (+)-(S)-N-desmetilvenlafaxina (pico 3), (-)-(R)-N-desmetilvenlafaxina (pico 4), (+)-(S)-venlafaxina (pico 5) e (-)-(R)venlafaxina (pico 6) referentes à Figura 7.

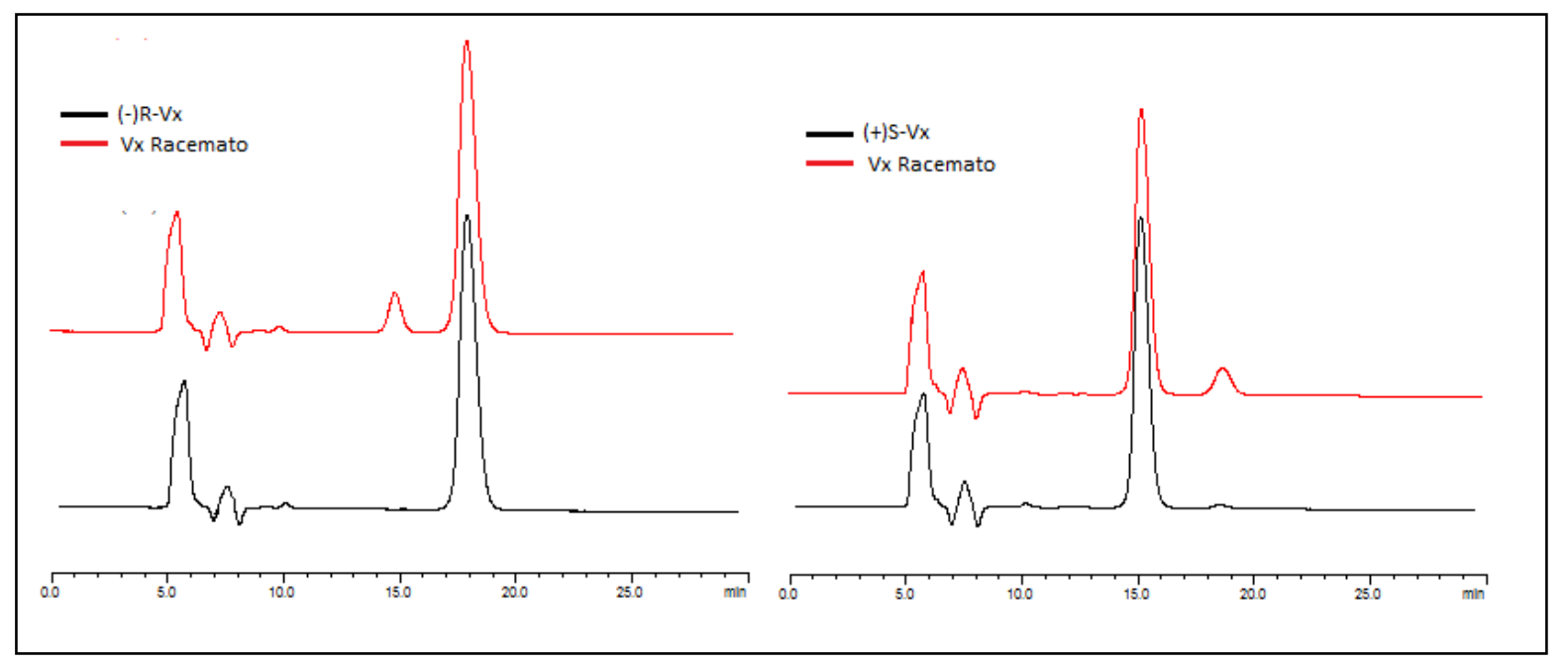

Figura 10- Cromatogramas referentes a análise dos enantiômeros (-)-R-Vx e (+)-S-Vx puros e fortificados em uma mistura racêmica. Condições cromatográficas: coluna Chiralpak $A D-R H^{\circledR}$, fase móvel: metanol: acetonitrila: água $(80: 13: 7 \mathrm{v} / \mathrm{v} / \mathrm{V})+0,15 \%$ de trietilamina, temperatura de análise 23 $\pm 2^{\circ} \mathrm{C}$ e vazão de $0,3 \mathrm{~mL} \mathrm{~min}^{-1}$. 


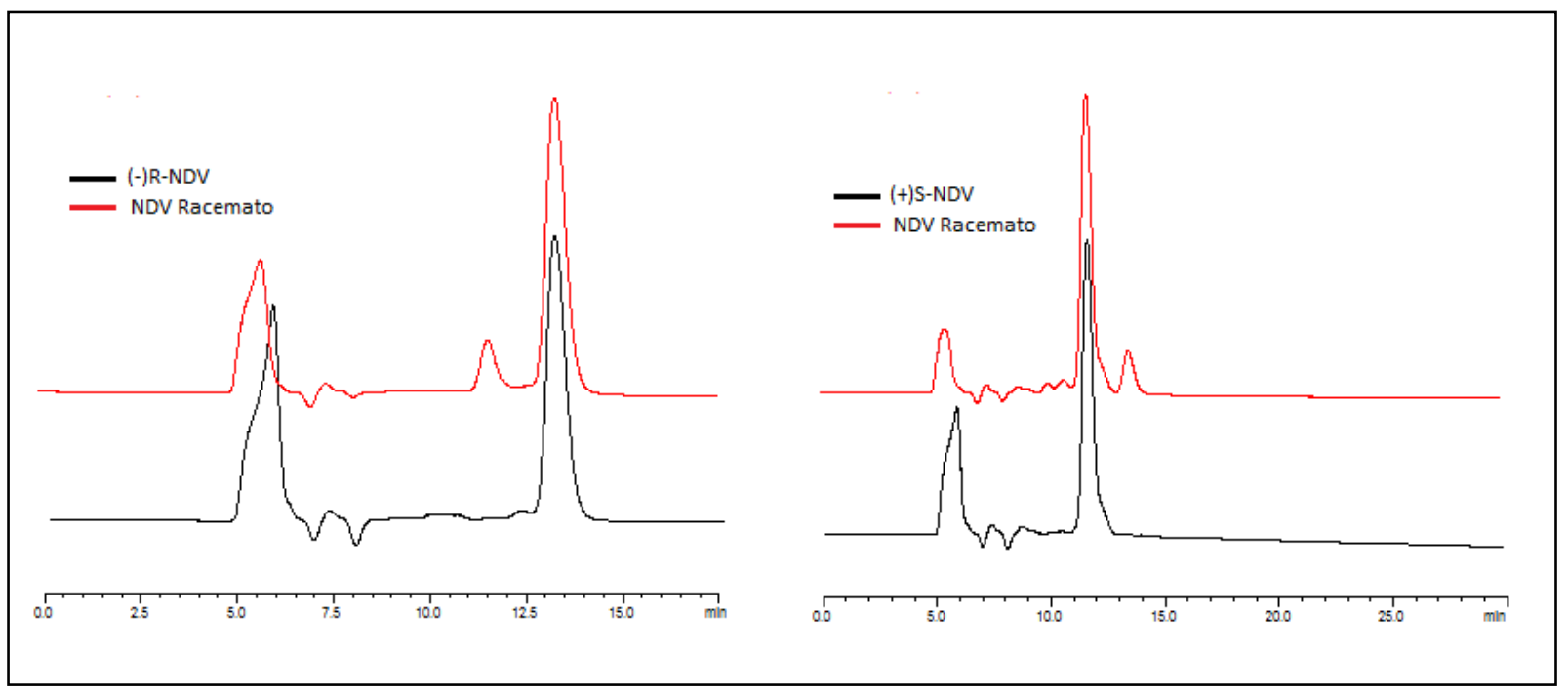

Figura 11- Cromatogramas referentes a análise dos enantiômeros (-)-R-NDV e (+)-S-NDV puros e fortificados em uma mistura racêmica. Condições cromatográficas: coluna Chiralpak $A D-R H^{\circledR}$, fase móvel: metanol:acetonitrila:água $(80: 13: 7 \mathrm{v} / \mathrm{V} / \mathrm{V})+0,15 \%$ de trietilamina temperatura de análise $23 \pm$ $2^{\circ} \mathrm{C}$ e vazão de $0,3 \mathrm{~mL} \mathrm{~min}^{-1}$.

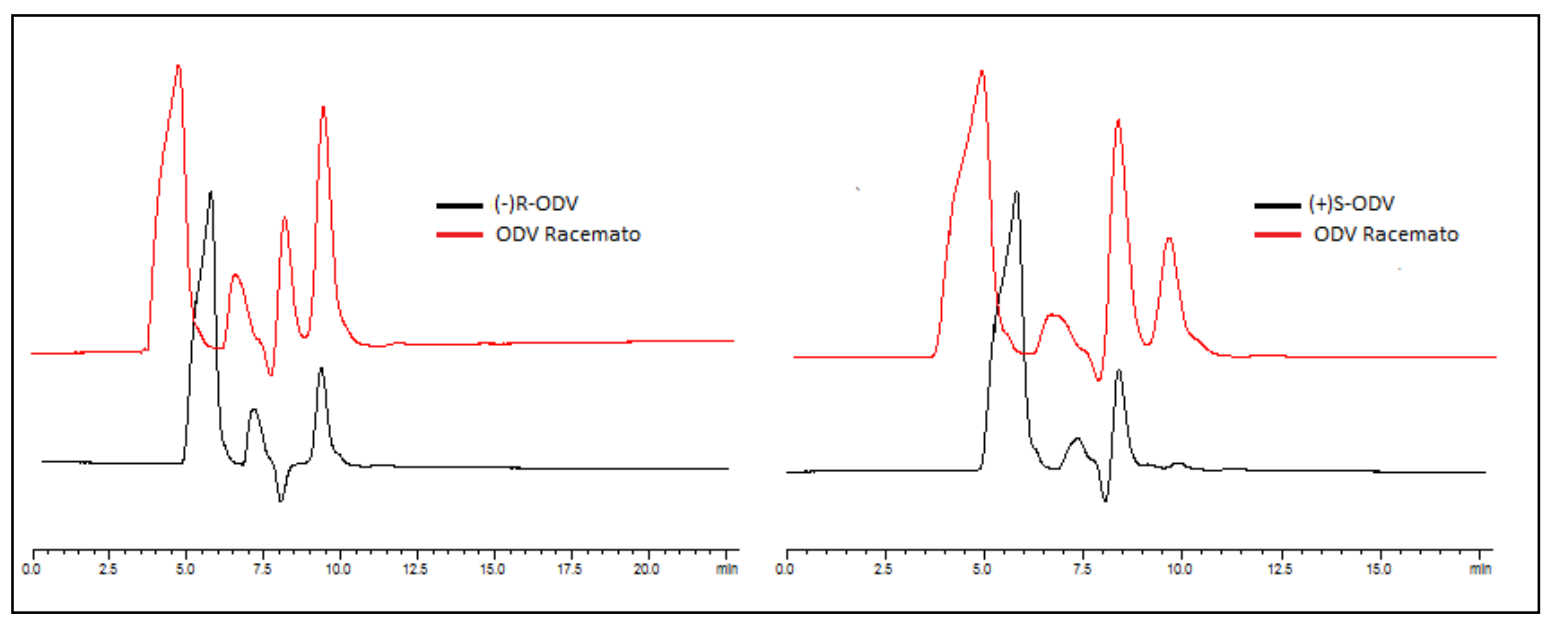

Figura 12- Cromatogramas referentes a análise dos enantiômeros (-)-R-ODV e (+)-S-ODV puros e fortificados em uma mistura racêmica. Condições cromatográficas: coluna Chiralpak $A D-R H^{\circledR}$, fase móvel: metanol: acetonitrila: água (80: 13: $7 \mathrm{v} / \mathrm{v} / \mathrm{v})+0,15 \%$ de trietilamina, temperatura de análise 23 $\pm 2^{\circ} \mathrm{C}$ e vazão de $0,3 \mathrm{~mL} \mathrm{~min}^{-1}$.

\subsubsection{Determinação da ordem de migração dos enantiômeros por EC}

Para determinação da ordem de eluição dos enantiômeros empregando o método desenvolvido por CE, $500 \mu \mathrm{L}$ da solução contendo cada enantiômero foi transferida para um tudo de ensaio e evaporada sob fluxo de ar comprimido. Posteriormente, o resíduo foi solubilizado em $50 \mu \mathrm{L}$ de água e analisada por CE empregando as condições definidas nesse trabalho. Assim como descrito para as 
análises por CLAE, além dos enantiômeros puros, foram injetadas também amostras do racemato fortificadas com cada enantiômero puro para confirmação. As Figuras 13, 14 e 15 apresentam os resultados referentes a essas análises. Dessa forma, em $\mathrm{CE}$, a ordem de migração dos enantiômeros ficou estabelecida como: (+)-(S)venlafaxina (pico 1) e (-)-(R)-venlafaxina (pico 2), (+)-(S)-N-desmetilvenlafaxina (pico 3), (-)-(R)-N-desmetilvenlafaxina (pico 4), (+)-(S)-O-desmetilvenlfaxina (pico 5), $(-)-(\mathrm{R})$-O-desmetilvenlafaxina (pico 6$)$ referentes à Figura 9.

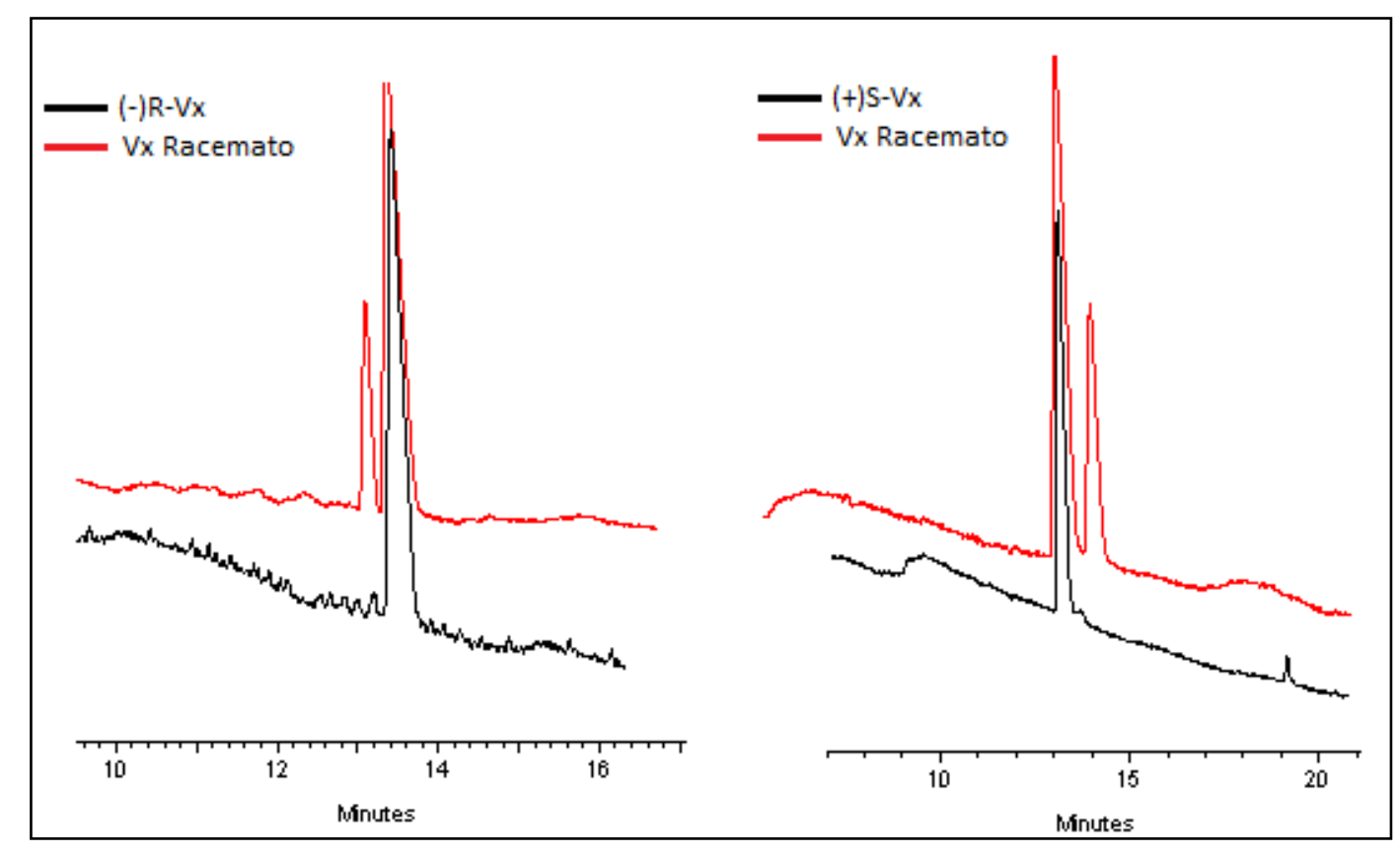

Figura 13- Eletroferogramas referentes a análise dos enantiômeros (+)-S- $V x$ e (-)-R-Vx puros e fortificados em uma mistura racêmica. Condições de análise: solução tampão fosfato de sódio 50 mmol L ${ }^{-1} \mathrm{pH} 2,0$ contendo $\mathrm{CM}-\beta-\mathrm{CD}(1 \%)$ e $\alpha-\mathrm{CD}\left(8 \mathrm{mmol} \mathrm{L}^{-1}\right)$, tensão aplicada $+20 \mathrm{kV}$, temperatura do capilar $20^{\circ} \mathrm{C}$. 


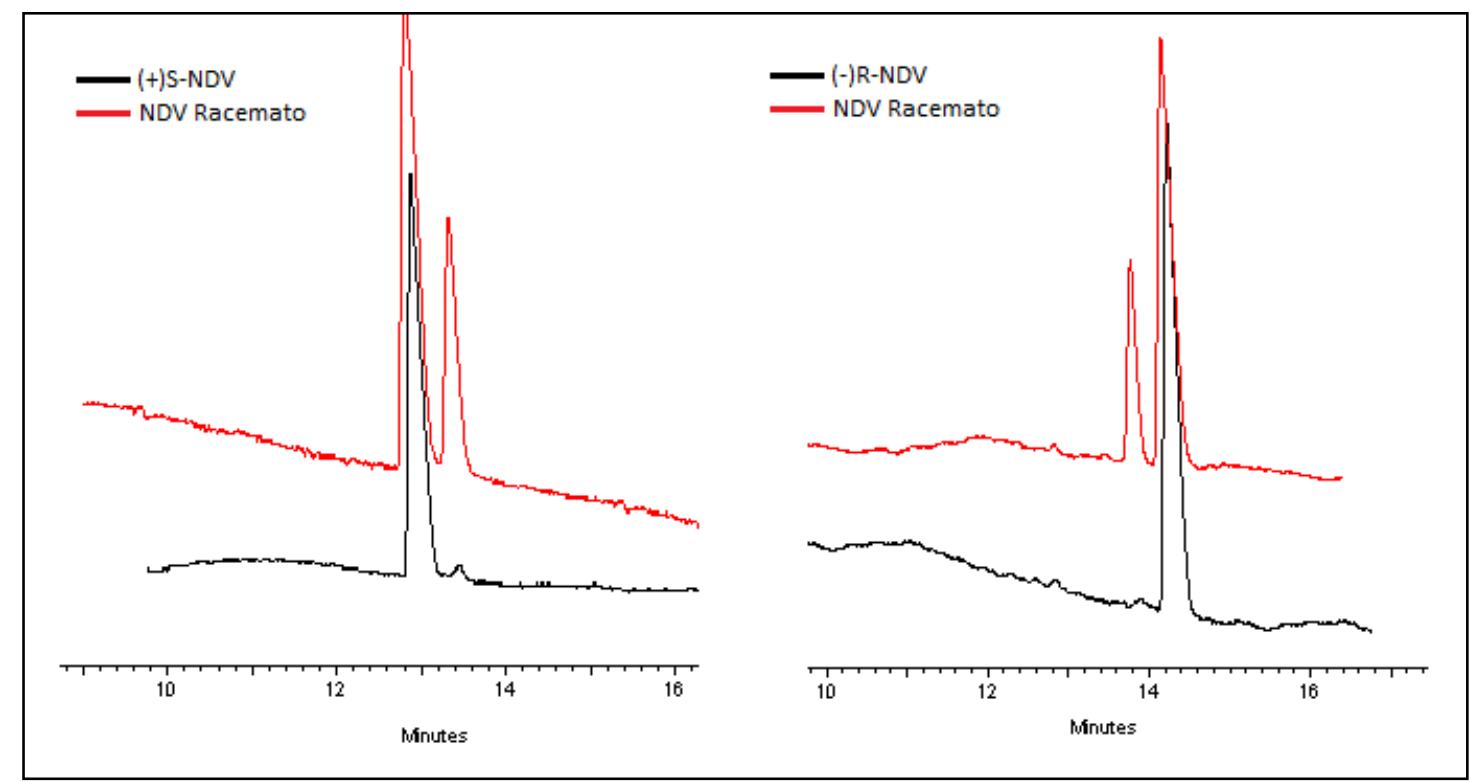

Figura 14- Eletroferogramas referentes a análise dos enantiômeros (+)-S-NDV e (-)-NDV puros e fortificados em uma mistura racêmica. Condições de análise: solução tampão fosfato de sódio 50 mmol L $\mathrm{L}^{-1} \mathrm{pH} 2,0$ contendo CM- $\beta$-CD (1\%) e $\alpha-\mathrm{CD}\left(8 \mathrm{mmol} \mathrm{L}^{-1}\right)$, tensão aplicada $+20 \mathrm{kV}$, temperatura do capilar $20^{\circ} \mathrm{C}$.

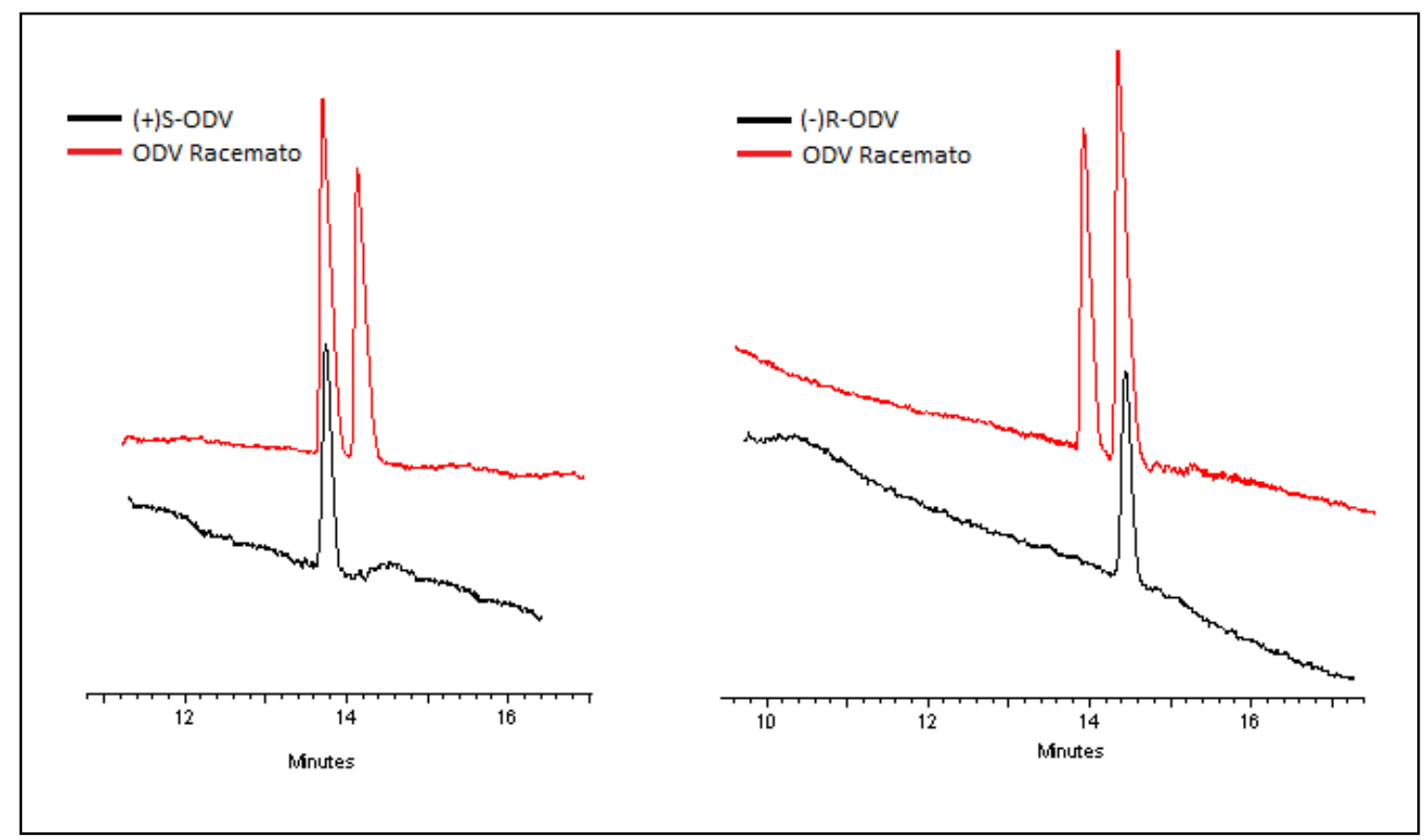

Figura 15- Eletroferogramas referentes a análise dos enantiômeros (+)-S-ODV e (-)-R-ODV puros e fortificados em uma mistura racêmica. Condições de análise: solução tampão fosfato de sódio 50 $\mathrm{mmol} \mathrm{L}^{-1} \mathrm{pH} 2,0$ contendo CM- $\beta$-CD $(1 \%)$ e $\alpha-\mathrm{CD}\left(8 \mathrm{mmol} \mathrm{L}^{-1}\right)$, tensão aplicada $+20 \mathrm{kV}$, temperatura do capilar $20^{\circ} \mathrm{C}$. 


\subsection{MICROEXTRAÇÃO LIQUIDO-LIQUIDO DISPERSIVA (DLLME)}

A técnica de preparo de amostra DLLME consiste na dispersão de uma mistura de solventes extrator e dispersor feita rapidamente em uma matriz aquosa com o auxilio de uma microsseringa. Após injeção dos solventes ocorre a formação de uma solução turva (ponto nuvem) formada por gotículas contendo o analito no solvente extrator. A centrifugação é realizada para sedimentação da fase orgânica que é posteriormente coletada e analisada (REZAEE et al., 2006; MENG et al., 2011; CALDAS; GONÇALVEZ; PRIMEL, 2011; ZGOTA-GRZESKOWIAK; GRZESKOWIAK, 2011; REZAEE; YAMINI; FARAJI, 2010; XIAO-HUAN et al., 2009). Os analitos devem estar em sua forma não ionizada para permitir a partição na fase orgânica. Portanto, é necessário o controle do $\mathrm{pH}$ da amostra. A venlafaxina e seus metabólitos apresentam características básicas e valores de pKa em torno de 9,4 (RUDAZ et al., 2000). Dessa forma, decidiu-se controlar o pH da matriz empregando uma solução tampão borato de sódio $100 \mathrm{mmol} \mathrm{L}^{-1} \mathrm{pH}$ 10. Os parâmetros otimizados foram: (i) volume e tipo de solvente dispersor, (ii) volume e tipo de solvente extrator e (iii) tempo de agitação das amostras antes da centrifugação (DLLME assistida) (MENG et al., 2011). Toda a otimização foi realizada empregando $2 \mathrm{~mL}$ de meio de cultura líquido Czapek fortificados com $25 \mu \mathrm{L}$ de venlafaxina e seus metabólitos na concentração de $100 \mu \mathrm{g} \mathrm{mL}^{-1}$. Na otimização da DLLME optou-se por estabelecer as condições que melhor extraísse o metabólito ativo ODV e todo procedimento foi realizado empregando as condições estabelecidas para análise por CLAE. Todos os experimentos foram realizados em temperatura ambiente $\left(23 \pm 2^{\circ} \mathrm{C}\right)$ em quintuplicata.

\subsubsection{Otimização do tipo de solvente dispersor}

O tipo de solvente dispersor foi otimizado fixando-se um volume de $100 \mu \mathrm{L}$ de clorofórmio (solvente extrator) e $500 \mu \mathrm{L}$ de solventes dispersores (acetona, isopropanol, acetonitrila, metanol e etanol). Como pode ser observado na Figura 16, o isopropanol foi o melhor solvente para extração do metabólito ativo ODV. O solvente dispersor deve ser solúvel no solvente extrator e também solúvel em água. Ao ser injetado na solução amostra, juntamente com o solvente extrator, ele proporciona uma enorme superfície de contato entre o extrator e o analito, 
permitindo a extração com grande eficiência (REZAEE et al., 2006; MENG et al., 2011; CALDAS; GONÇALVEZ; PRIMEL, 2011; ZGOTA-GRZESKOWIAK; GRZESKOWIAK, 2011; REZAEE; YAMINI; FARAJI, 2010; XIAO-HUAN et al., 2009). Dessa forma, o isopropanol foi escolhido para continuação dos experimentos.

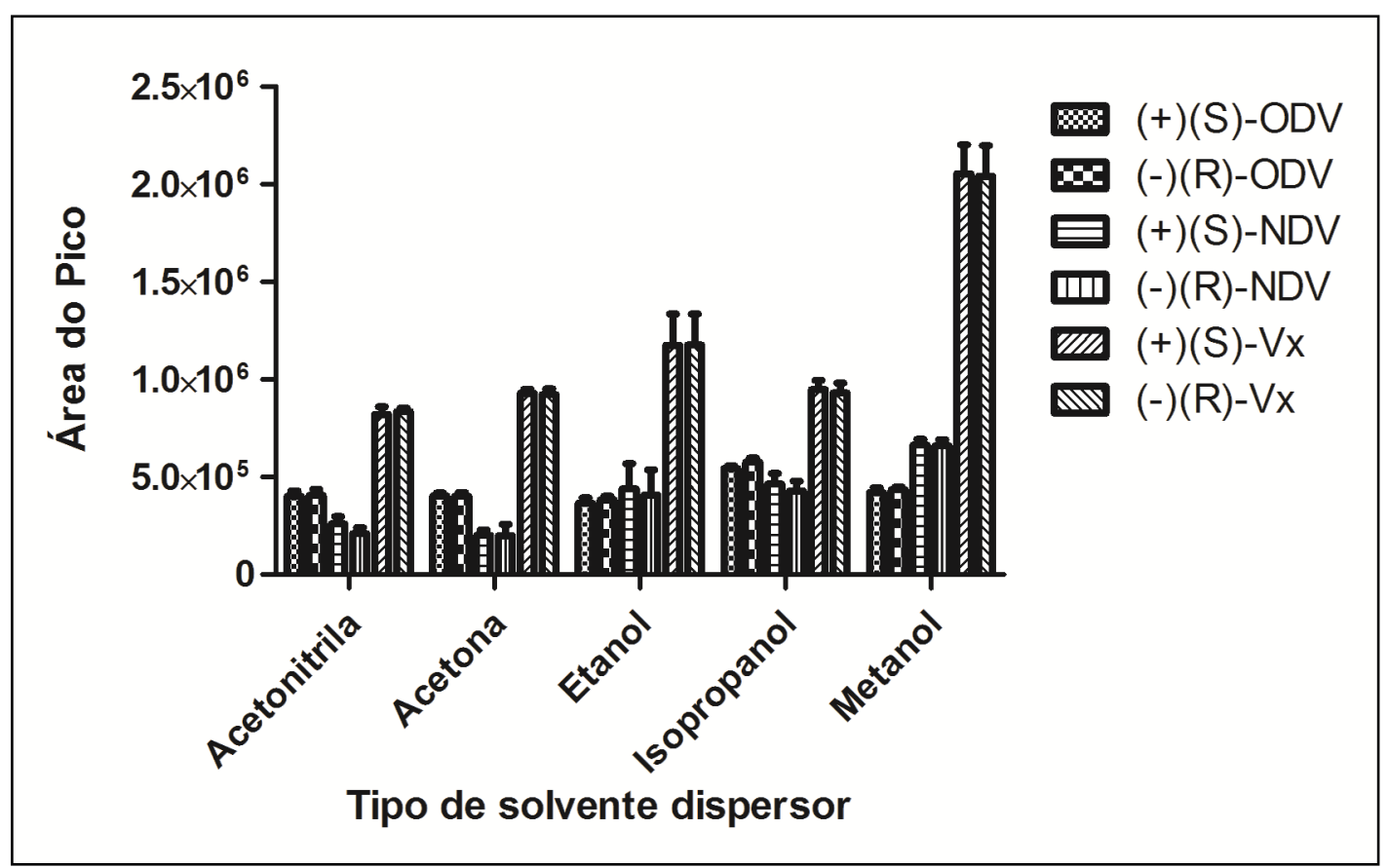

Figura 16- Otimização do tipo de solvente dispersor. Condições extração: $100 \mu \mathrm{L}$ de clorofórmio e $500 \mu \mathrm{L}$ de solvente dispersor. Amostra: $2 \mathrm{~mL}$ de meio de cultura liquido Czapek fortificado com $2 \mathrm{~mL}$ de solução tampão borato de sódio $100 \mathrm{mmol} \mathrm{L}^{-1} \mathrm{pH} 10$. Condições cromatográficas: coluna Chiralpak $A D-R H^{\circledR}$, fase móvel: metanol: acetonitrila: água $(80: 13: 7 \mathrm{~V} / \mathrm{V} / \mathrm{V})+0,15 \%$ de trietilamina, temperatura de análise $23 \pm 2^{\circ} \mathrm{C}$ e vazão de $0,3 \mathrm{~mL} \mathrm{~min}^{-1}$.

\subsubsection{Otimização do tipo de solvente extrator}

O otimização do tipo de solvente extrator foi realizada empregando a mesma estratégia descrita anteriormente. Fixou-se o tipo solvente dispersor (500 $\mu \mathrm{L}$ de isopropanol) e variou-se diversos solventes extratores: clorofórmio, diclorometano, dicloroetano e tetracloreto de carbono (100 $\mu \mathrm{L}$ de cada). Como pode ser observado na Figura 17, o melhor solvente para extração do metabólito ativo ODV foi o clorofórmio e, portanto esse solvente foi escolhido para os demais experimentos. $O$ solvente extrator, além da capacidade de extrair os analitos, deve ser solúvel no solvente dispersor e insolúvel em água (matriz). Também, deve ser mais denso que a água para ser coletado após centrifugação. Geralmente, essas características são encontradas em solventes clorados. 


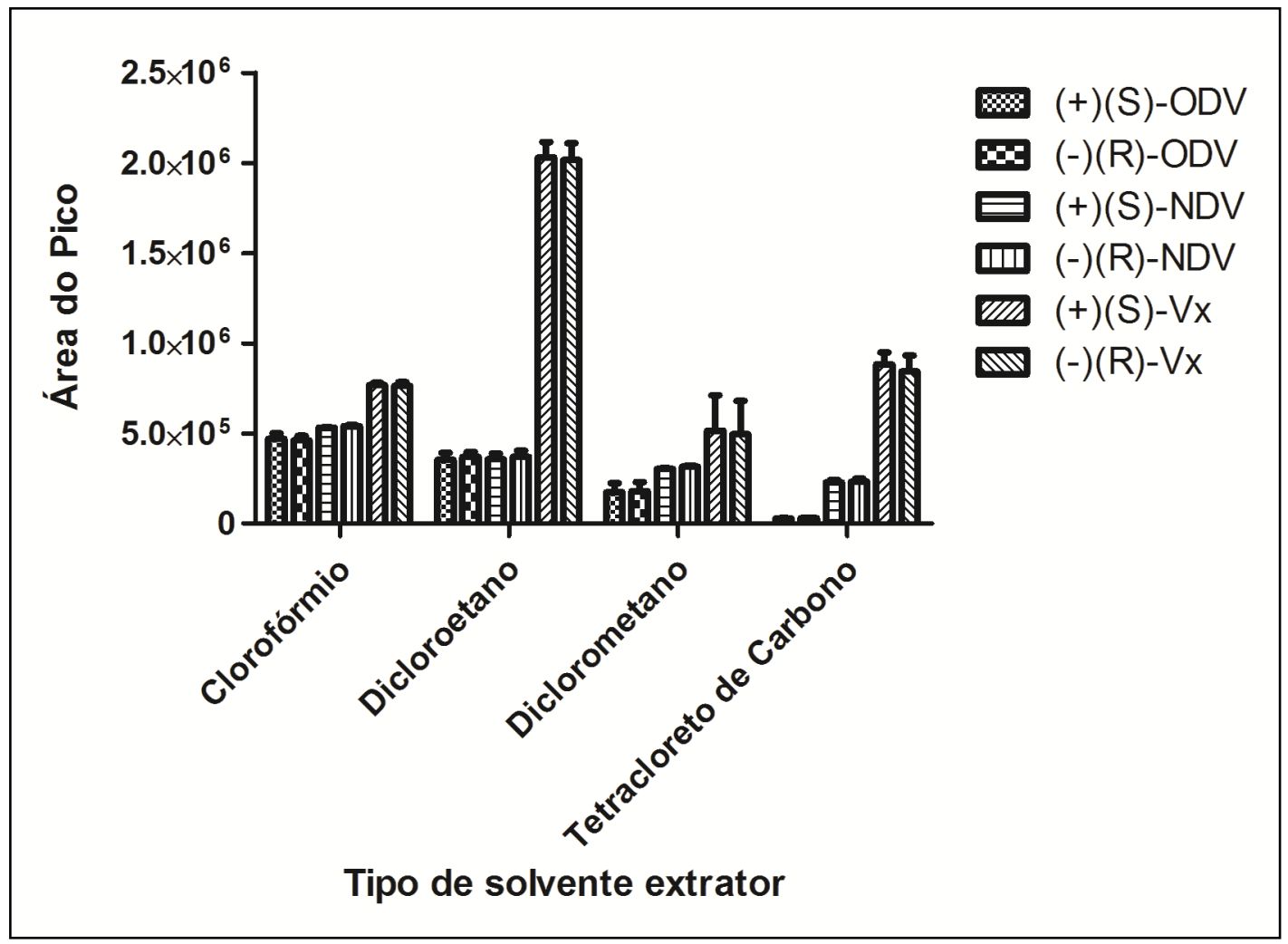

Figura 17- Otimização do tipo de solvente extrator. Condições extração: $100 \mu \mathrm{L}$ de solvente extrator e $500 \mu \mathrm{L}$ de isopropanol. Amostra: $2 \mathrm{~mL}$ de meio de cultura liquido Czapek fortificado com $2 \mathrm{~mL}$ de solução tampão borato de sódio $100 \mathrm{mmol} \mathrm{L}^{-1} \mathrm{pH} 10$. Condições cromatográficas: coluna Chiralpak $\mathrm{AD}-\mathrm{RH}^{\circledR}$, fase móvel: metanol: acetonitrila: água $(80: 13: 7 \mathrm{v} / \mathrm{v} / \mathrm{V})+0,15 \%$ de trietilamina, temperatura de análise $23 \pm 2^{\circ} \mathrm{C}$ e vazão de $0,3 \mathrm{~mL} \mathrm{~min}^{-1}$.

\subsubsection{Otimização dos volumes de solventes dispersor e extrator}

Para otimização do volume de solvente dispersor fixou-se $100 \mu \mathrm{L}$ de clorofórmio e o volume de isopropanol foi variado $(300 \mu \mathrm{L}, 400 \mu \mathrm{L}, 500 \mu \mathrm{L}, 600 \mu \mathrm{L}$ e $700 \mu \mathrm{L}$ ). A melhor eficiência foi obtida com $300 \mu \mathrm{L}$ de isopropanol conforme pode ser obervado na Figura 18. Volumes maiores de isopropanol levaram à uma diminuição na extração dos analitos. Esse efeito é explicado pela polaridade do solvente dispersor. O aumento do volume de isopropanol leva à uma redução de polaridade da fase aquosa o que acarreta à menores recuperações dos analitos (REZAEE et al., 2006). Esse efeito é mais pronunciado para a venlafaxina devido à sua menor polaridade comparada aos metabólitos. 


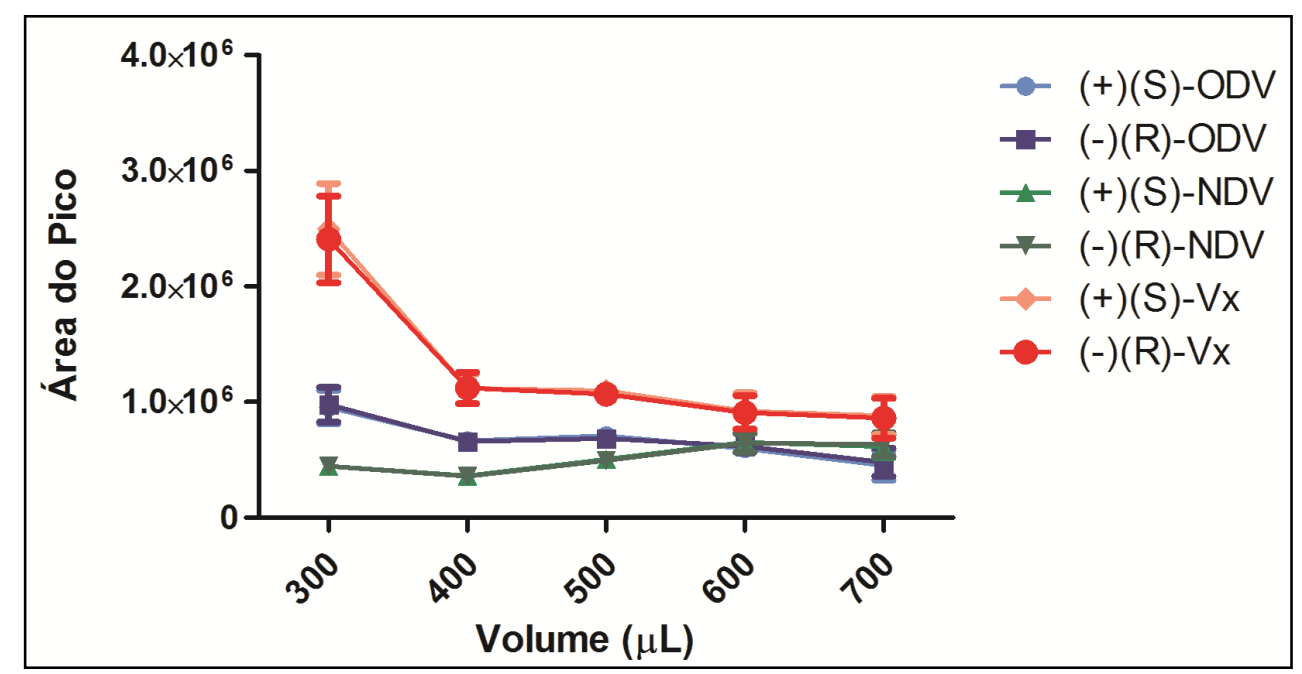

Figura 18- Otimização do volume de solvente dispersor. Condições extração: $100 \mu \mathrm{L}$ de solvente clorofórmio e volume de solvente extrator variável. Amostra: $2 \mathrm{~mL}$ de meio de cultura liquido Czapek fortificado com $2 \mathrm{~mL}$ de solução tampão borato de sódio $100 \mathrm{mmol} \mathrm{L}{ }^{-1}, \mathrm{pH} 10$. Condições cromatográficas: coluna Chiralpak $A D-\mathrm{RH}^{\circledR}$, fase móvel: metanol: acetonitrila: água (80: 13: $\left.7 \mathrm{v} / \mathrm{v} / \mathrm{V}\right)+$ $0,15 \%$ de trietilamina, temperatura de análise $23 \pm 2^{\circ} \mathrm{C}$ e vazão de $0,3 \mathrm{~mL} \mathrm{~min}^{-1}$.

A escolha do volume de solvente extrator foi feita fixando em $300 \mu \mathrm{L}$ o volume de isopropanol e variando os volumes de clorofórmio no intervalo de 70 a $400 \mu \mathrm{L}$. O melhor resultado foi obtido com $200 \mu \mathrm{L}$ de clorofórmio (Figura 19). Como mostrado pela Figura 16, a recuperação dos analitos aumenta com o aumento de volume de solvente extrator até um ponto ótimo e começa a diminuir com volumes maiores. Isso ocorre provavelmente pela dificuldade de formação do ponto nuvem com volumes maiores de clorofórmio devido à sua alta densidade (REZAEE et al., 2006). 


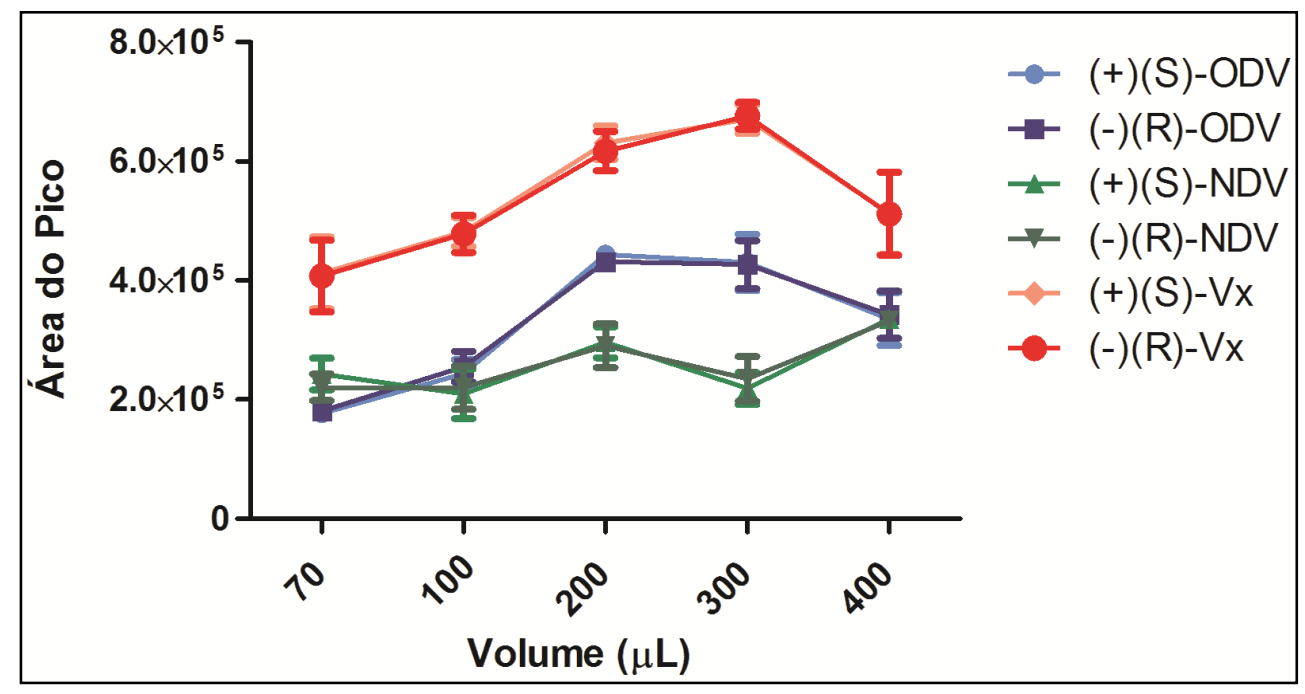

Figura 19- Otimização do volume de solvente extrator. Condições extração: $300 \mu \mathrm{L}$ de solvente de isopropanol e volume de solvente extrator variável. Amostra: $2 \mathrm{~mL}$ de meio de cultura liquido Czapek fortificado com $2 \mathrm{~mL}$ de solução tampão borato de sódio $100 \mathrm{mmol} \mathrm{L}^{-1}, \mathrm{pH} 10$. Condições cromatográficas: coluna Chiralpak $A D-\mathrm{RH}^{\circledR}$, fase móvel: metanol: acetonitrila: água (80: 13: $\left.7 \mathrm{v} / \mathrm{v} / \mathrm{V}\right)+$ $0,15 \%$ de trietilamina, temperatura de análise $23 \pm 2^{\circ} \mathrm{C}$ e vazão de $0,3 \mathrm{~mL} \mathrm{~min}^{-1}$.

\subsubsection{Otimização do tempo de agitação das amostras (DLLME assistida)}

A otimização do tempo de agitação das amostras é feita para verificar se a formação do ponto nuvem é suficiente para atingir o equilíbrio de extração (CALDAS; GONÇALVEZ; PRIMEL, 2011). Observou-se que, com o aumento do tempo de agitação das amostras, a recuperação aumenta (Figura 20). Porém, a fim de se obter um método de extração rápido não foram otimizados tempos maiores, sendo, portanto, escolhido como tempo de extração, 30 segundos. 


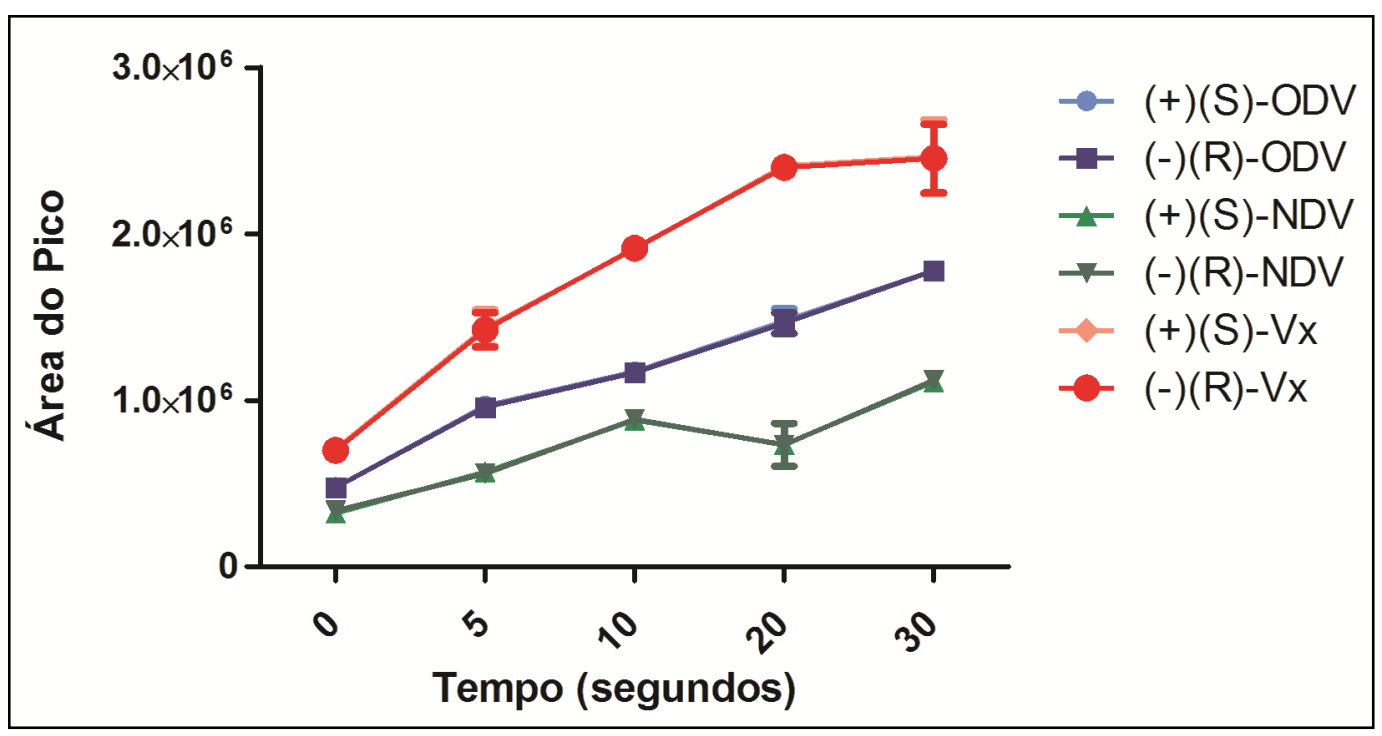

Figura 20- Otimização do tempo de agitação das amostras. Condições de extração: $200 \mu \mathrm{L}$ de clorofórmio e $300 \mu \mathrm{L}$ de isopropanol. Amostra: $2 \mathrm{~mL}$ de meio de cultura liquido Czapek fortificado com $2 \mathrm{~mL}$ de solução tampão borato de sódio $100 \mathrm{mmol} \mathrm{L}^{-1} \mathrm{pH} 10$. Condições cromatográficas: coluna Chiralpak $A D-\mathrm{RH}^{\circledR}$, fase móvel: metanol: acetonitrila: água $(80: 13: 7 \mathrm{v} / \mathrm{v} / \mathrm{v})+0,15 \%$ de trietilamina, temperatura de análise $23 \pm 2^{\circ} \mathrm{C}$ e vazão de $0,3 \mathrm{~mL} \mathrm{~min}^{-1}$.

Após otimização, as condições finais de extração dos analitos por DLLME foram: meio de cultura líquido Czapek $(2 \mathrm{~mL})$ adicionado de solução tampão borato de sódio $100 \mathrm{mmol} \mathrm{L}^{-1} \mathrm{pH}$ 10,0 (2 mL); isopropanol (300 $\left.\mu \mathrm{L}\right)$ como solvente dispersor e clorofórmio $(200 \mu \mathrm{L})$ como solvente extrator. Após formação de ponto nuvem as amostras foram agitadas por 30 segundos em vórtex e centrifugadas por 5 minutos a 3000 rpm. Posteriormente a fase orgânica foi sedimentada, coletada e analisada.

\subsection{VALIDAÇÃO ANALÍTICA}

\subsubsection{Validação do método analítico empregando CLAE}

A validação analítica empregando CLAE foi realizada pelo método de padronização interna utilizando o fármaco cetoconazol (Figura 21) como padrão interno. Essa molécula apresenta valores de pKa de 2,94 e 6,51 (DE ANTONIO, 2007). O log $P$ dessa molécula é de 3,84 semelhante ao da venlafaxina $(3,28)$, apresentando, portanto, características físico-químicas semelhantes aos analitos de interesse. Na validação analítica empregando CLAE o metabólito NDV não foi incluído nos ensaios devido a presença de um interferente no padrão analítico, na qual baixas concentrações impossibilitaram a análise desse analito. 


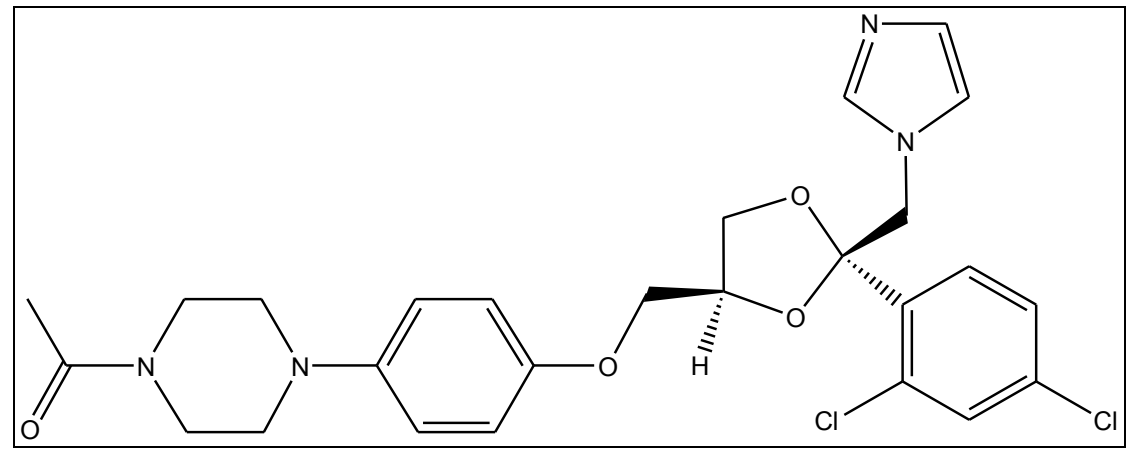

Figura 21- Estrutura química do cetoconazol.

\subsubsection{Linearidade}

A linearidade foi realizada em triplicata $(n=3)$ aplicando o método dos mínimos quadrados e ponderação empregando como peso $1 / x^{2}$. Além disso, a linearidade foi avaliada pelo emprego do teste de falta de ajuste e ANOVA. A faixa de concentração utilizada para os enantiômeros da $V x$ foi de 500 a $15000 \mathrm{ng} \mathrm{mL}^{-1} \mathrm{e}$ para os enantiômeros da ODV de 225 a $1875 \mathrm{ng} \mathrm{mL}^{-1}$. Como pode ser observado nas Tabelas 10 e 11, os dados obtidos comprovam que o método apresenta uma linearidade adequada para quantificação dos analitos em meio de cultura liquido por CLAE. Os valores de $F$ calculados para a validade da regressão foram todos maiores que o valor crítico $(2,85)$ e os valores de $p$ menores que $0,05(\alpha=0,05 \%)$. Para o teste de falta de ajuste, os valores de $\mathrm{F}$ calculados foram menores que o $\mathrm{F}$ crítico $(2,85)$ e os valores de $p$ todos maiores que $0,05(\alpha=0,05 \%)$.

Tabela 10- Linearidade do método para análise dos enantiômeros da $V x$ e ODV.

Analitos Intervalo (ng mL ${ }^{-1}$ )

Equação Linear

$r^{a}$

\begin{tabular}{cccc}
\hline$(-)-(R)-O D V$ & $225-1875$ & $y=0,0004 x-0,0332$ & 0,9957 \\
$(+)-(S)-O D V$ & $225-1875$ & $y=0,0004 x-0,0334$ & 0,9952 \\
$(+)-(S)-V x$ & $500-15000$ & $y=0,0005 x+0,0602$ & 0,9918 \\
$(-)-(R)-V x$ & $500-15000$ & $y=0,0005 x+0,0472$ & 0,9936
\end{tabular}

a) coeficiente de correlação 
Tabela 11- Análise de variância e falta de ajuste (ANOVA) para análise dos enantiômeros da $V x$ e ODV.

\begin{tabular}{ccccc}
\hline $\begin{array}{c}\text { Análise de Variância } \\
\text { ANOVA }\end{array}$ & \multicolumn{2}{c}{ Validade da Regressão } & \multicolumn{2}{c}{ Falta de Ajuste } \\
Valor de $\mathbf{F}$ & Valor de $\mathbf{p}$ & Valor de F & Valor de $\mathbf{p}$ \\
\hline$(+)-(\mathrm{S})-\mathrm{ODV}$ & 940,70 & 0,000 & 2,29 & 0,174 \\
$(-)-(\mathrm{R})-\mathrm{ODV}$ & 423,28 & 0,000 & 2,17 & 0,171 \\
$(+)-(\mathrm{S})-\mathrm{Vx}$ & 1197,35 & 0,000 & 2,25 & 0,160 \\
$(-)-(\mathrm{R})-\mathrm{Vx}$ & 436,53 & 0,000 & 2,77 & 0,108 \\
\hline
\end{tabular}

4.4.1.2. Limite de quantificação (LLOQ)

O limite de quantificação foi realizado com a menor concentração da curva analítica de cada analito, sendo de $225 \mathrm{ng} \mathrm{mL}^{-1}$ para os enantiômeros da ODV e de $500 \mathrm{ng} \mathrm{mL}^{-1}$ para os enantiômeros da $\mathrm{Vx}$. As concentrações obtidas foram todas próximas às concentrações nominais, com valores de erro $(E \%)$ e desvio padrão relativo (DPR\%) menores que $20 \%$ (Tabela 12).

Tabela 12- Limite de quantificação para análise dos enantiômeros da Vx e ODV

\begin{tabular}{|c|c|c|c|c|}
\hline Analitos & $\begin{array}{c}\text { Concentração } \\
\text { Nominal }\left(n g \mathrm{~mL}^{-1}\right)\end{array}$ & $\begin{array}{l}\text { Concentração obtida } \\
\text { (ng mL }{ }^{-1} \text { ) }\end{array}$ & $\begin{array}{c}E \\
(\%)\end{array}$ & $\begin{array}{l}\text { DPR } \\
(\%)\end{array}$ \\
\hline 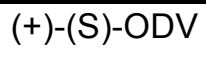 & 225 & 218 & -3 & 4 \\
\hline$(-)-(R)-O D V$ & 225 & 219 & -3 & 4 \\
\hline$(+)-(S)-V x$ & 500 & 484 & -3 & 4 \\
\hline$(-)-(R)-V x$ & 500 & 493 & -2 & 3 \\
\hline
\end{tabular}

\subsubsection{Precisão e Exatidão interdia}

A precisão e exatidão interdia foi realizada empregando concentrações alta, média e baixa de cada analito sendo essas: 450,937 e $1400 \mathrm{ng} \mathrm{mL}^{-1}$ para os enantiômeros da ODV e 1500, 7500 e $12.000 \mathrm{ng} \mathrm{mL}^{-1}$ para os enantiômeros da Vx. As concentrações obtidas foram todas próximas às concentrações nominais, com valores de erro (E\%) e desvio padrão relativo (DPR\%) menores que $15 \%$ (Tabela 13). 
Tabela 13- Precisão e exatidão inter-dia para análise dos enantiômeros da Vx e ODV.

\begin{tabular}{ccccc}
\hline Analitos & $\begin{array}{c}\text { Concentração nominal } \\
\left(\mathbf{n g ~ m L}^{-1}\right)\end{array}$ & $\begin{array}{c}\text { Concentração obtida } \\
\left(\mathbf{n g ~ m L}^{-1}\right)\end{array}$ & $\begin{array}{c}\text { E } \\
\text { (\%) }\end{array}$ & $\begin{array}{c}\text { DPR } \\
\text { (\%) }\end{array}$ \\
\hline$(+)-(\mathrm{S})-\mathrm{ODV}$ & $450 / 937 / 1400$ & $479 / 970 / 1359$ & $+3 /+3 /-2$ & $6 / 5 / 2$ \\
$(-)-(\mathrm{R})-\mathrm{ODV}$ & $450 / 937 / 1400$ & $445 / 979 / 1353$ & $-3 /+4 /-2$ & $1 / 4 / 2$ \\
$(+)-(\mathrm{S})-\mathrm{Vx}$ & $1500 / 7500 / 12000$ & $1492 / 7968 / 11315$ & $-1 /+8 /-7$ & $5 / 4 / 3$ \\
$(-)-(\mathrm{R})-\mathrm{Vx}$ & $1500 / 7500 / 12000$ & $1491 / 8000 / 11328$ & $-1 /+6 /-6$ & $3 / 4 / 1$ \\
\hline
\end{tabular}

\subsubsection{Precisão e Exatidão intradia}

A precisão e exatidão intradia foi também realizada com as concentrações alta, média e baixa de cada analito conforme descrito anteriormente. As concentrações obtidas próximas às concentrações nominais e valores de erro $(E \%)$ e desvio padrão relativo (DPR\%) menores que 15\% (Tabela 14).

Tabela 14: Precisão e exatidão intradia para análise dos enantiômeros da Vx e ODV.

\begin{tabular}{ccccc}
\hline Analitos & $\begin{array}{c}\text { Concentração nominal } \\
\left(\mathbf{n g ~ m L} \mathbf{~ m}^{-1}\right)\end{array}$ & $\begin{array}{c}\text { Concentração obtida } \\
(\mathbf{n g ~ m L}\end{array}$ & $\begin{array}{c}\text { E } \\
\mathbf{( \% )}\end{array}$ & $\begin{array}{c}\text { DPR } \\
\mathbf{( \% )}\end{array}$ \\
\hline$(+)-(\mathrm{S})-\mathrm{ODV}$ & $450 / 937 / 1400$ & $447 / 956 / 1378$ & $-1 /+2 /-2$ & $4 / 3 / 10$ \\
$(-)-(\mathrm{R})-\mathrm{ODV}$ & $450 / 937 / 1400$ & $445 / 983 / 1348$ & $-1 /+5 /-4$ & $6 / 5 / 10$ \\
$(+)-(\mathrm{S})-\mathrm{Vx}$ & $1500 / 7500 / 12000$ & $1494 / 7839 / 11504$ & $-0,4 . /+5 /-4$ & $7 / 7 / 5$ \\
$(-)-(\mathrm{R})-\mathrm{Vx}$ & $1500 / 7500 / 12000$ & $1496 / 7752 / 11539$ & $-0,3 /+3 /-4$ & $6 / 5 / 2$ \\
\hline
\end{tabular}

\subsubsection{Recuperação}

O ensaio de recuperação foi realizado em triplicata empregando soluções com concentrações alta, média e baixa de cada analito, conforme descrito anteriormente. Foi obtido uma média de $70 \%$ e $88 \%$ de recuperação para os enantiômeros da ODV e Vx, respectivamente. Todos os valores de coeficiente de variação foram menores que $15 \%$.

4.4.1.6. Estabilidade de bancada e ciclos de congelamento e descongelamento

Conforme pode ser observado na Tabela 15, as amostras mantiveram-se estáveis ao permanecer 8 horas sob a bancada e após ciclos de congelamento e 
descongelamento. Isso indica que durante o preparo das amostras e durante seu armazenamento os analitos se mantém estáveis.

Tabela 15- Estabilidade de bancada e ciclos de congelamento e descongelamento para análise dos enantiômeros da Vx e ODV.

Estabilidade em ciclos de congelamento e descongelamento

\begin{tabular}{|c|c|c|c|}
\hline Analitos & $\begin{array}{l}\text { Concentração } \\
\left(\text { ng mL }{ }^{-1}\right)\end{array}$ & $\begin{array}{l}\text { Exatidão } \\
(\mathrm{E} \%)\end{array}$ & $\begin{array}{c}\text { Precisão } \\
\text { (DPR\%) }\end{array}$ \\
\hline$(+)-(\mathrm{S})-\mathrm{ODV}$ & $450 / 1400$ & $6 /-12$ & $7 / 1$ \\
\hline$(-)-(\mathrm{R})-\mathrm{ODV}$ & $450 / 1400$ & $9 /-13$ & $5 / 1$ \\
\hline$(+)-(S)-V x$ & $1500 / 12000$ & $5 /-2$ & $2 / 11$ \\
\hline$(-)-(R)-V x$ & $1500 / 12000$ & $2 / 1$ & $3 / 12$ \\
\hline \multicolumn{4}{|c|}{ Estabilidade de Bancada } \\
\hline Analitos & $\begin{array}{l}\text { Concentração } \\
\left(\text { (ng mL }{ }^{-1}\right)\end{array}$ & $\begin{array}{l}\text { Exatidão } \\
\text { (E\%) }\end{array}$ & $\begin{array}{c}\text { Precisão } \\
\text { (DPR\%) }\end{array}$ \\
\hline$(+)-(\mathrm{S})-\mathrm{ODV}$ & $450 / 1400$ & $11 / 7$ & $4 / 2$ \\
\hline$(-)-(\mathrm{R})-\mathrm{ODV}$ & $450 / 1400$ & $11 / 7$ & $2 / 2$ \\
\hline$(+)-(S)-V x$ & $1500 / 12000$ & $6 / 7$ & $1 / 1$ \\
\hline$(-)-(R)-V x$ & $1500 / 12000$ & $5 / 8$ & $2 / 1$ \\
\hline
\end{tabular}

\subsubsection{Validação do método analítico empregando eletroforese capilar}

A validação analítica empregando $\mathrm{CE}$ foi realizada pelo método de padronização interna utilizando o fármaco risperidona (Figura 22) como padrão interno. Essa molécula apresenta pKa de 7,8 e seu log P é 2,7 (BOCATO, 2012) próximo ao log $\mathrm{P}$ da venlafaxina $(3,28)$. Na validação do método para análise por $\mathrm{CE}$ foi possível incluir o analito NDV, pois nesse método o interferente presente no padrão analítico não causou prejuízos na resolução dos analitos. 


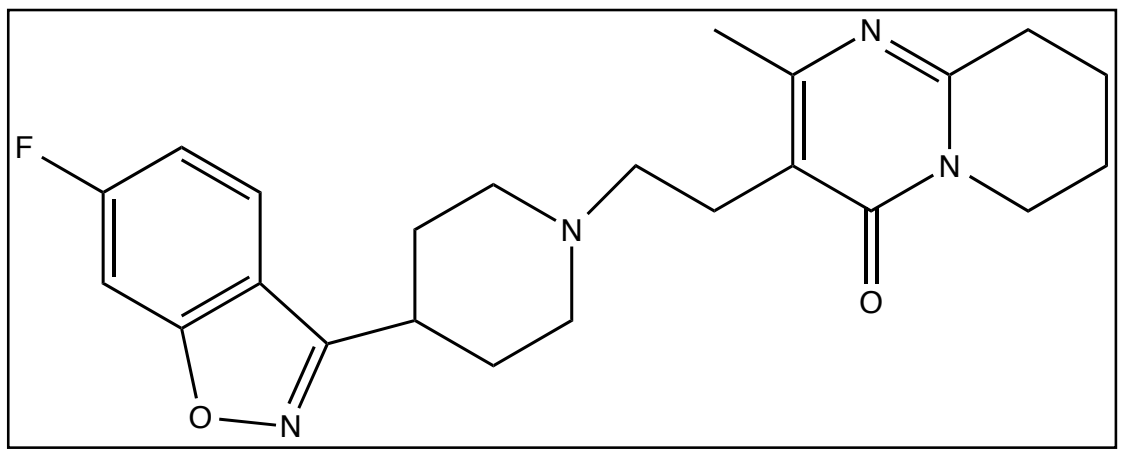

Figura 22- Estrutura química da risperidona.

\subsubsection{Linearidade}

A linearidade foi realizada em triplicata $(n=3)$ para cada ponto da curva empregando o método dos mínimos quadrados com ponderação usando o peso de $1 / x^{2}$. Além disso, a linearidade foi avaliada pelo emprego do teste de falta de ajuste e ANOVA. A faixa de concentração utilizada para os enantiômeros da $V x$ foi de 500 a $15000 \mathrm{ng} \mathrm{mL} \mathrm{mL}^{-1}$ e para os enantiômeros da ODV e NDV foi de 75 a $938 \mathrm{ng} \mathrm{mL} \mathrm{mL}^{-1}$. Como pode ser observado nas Tabelas 16 e 17 os dados obtidos comprovam que o método apresenta uma linearidade adequada para quantificação dos analitos em meio de cultura por $\mathrm{CE}$. Os valores de $\mathrm{F}$ calculados para a validade da regressão foram todos maiores que o valor crítico $(2,85)$ e os valores de $p$ menores que 0,05 ( $\alpha$ $=0,05 \%)$. Para o teste de falta de ajuste, os valores de $\mathrm{F}$ calculados foram menores que o F crítico $(2,85)$ e os valores de $p$ todos maiores que 0,05 ( $\alpha=0,05 \%)$.

Tabela 16- Linearidade do método para análise dos enantiômeros da $V x$ e seus metabólitos.

\begin{tabular}{cccc}
\hline Analitos & Intervalo $\left(\mathbf{n g} \mathbf{~ m L}^{-1}\right)$ & Equação Linear & $\mathbf{r}^{\mathbf{a}}$ \\
\hline$(-)-(\mathrm{R})-\mathrm{ODV}$ & $75-938$ & $\mathrm{y}=0,000956 \mathrm{x}-0,0527$ & 0,9909 \\
$(+)-(\mathrm{S})-\mathrm{ODV}$ & $75-938$ & $\mathrm{y}=0,000974 \mathrm{x}-0,0424$ & 0,9948 \\
$(-)-(\mathrm{R})-\mathrm{NDV}$ & $75-938$ & $\mathrm{y}=0,001236 \mathrm{x}+0,0044$ & 0,9975 \\
$(+)-(\mathrm{S})-\mathrm{NDV}$ & $75-938$ & $\mathrm{y}=0,001268 \mathrm{x}+0,0013$ & 0,9971 \\
$(+)-(\mathrm{S})-\mathrm{Vx}$ & $500-15000$ & $\mathrm{y}=0,001061 \mathrm{x}+0,3042$ & 0,9973 \\
$(-)-(\mathrm{R})-\mathrm{V} \mathrm{C}$ & $500-15000$ & $\mathrm{y}=0,001051 \mathrm{x}+0,3751$ & 0,9973 \\
\hline
\end{tabular}


Tabela 17- Análise de variância e falta de ajuste (ANOVA) para análise dos enantiômeros da Vx e seus metabólitos.

\begin{tabular}{ccccc}
\hline $\begin{array}{c}\text { Análise de Variância } \\
\text { ANOVA }\end{array}$ & \multicolumn{2}{c}{ Validade da Regressão } & \multicolumn{2}{c}{ Falta de Ajuste } \\
Valor de $\mathbf{F}$ & Valor de $\boldsymbol{p}$ & Valor de $\mathbf{F}$ & Valor de $\boldsymbol{p}$ \\
\hline (+)-(S)-ODV & 473,33 & 0,00 & 1,46 & 0,313 \\
$(-)-(\mathrm{R})-$ ODV & 402,14 & 0,00 & 2,28 & 0,157 \\
$(+)-(\mathrm{S})-$ NDV & 527,79 & 0,00 & 0,86 & 0,551 \\
$(-)-(\mathrm{R})-\mathrm{NDV}$ & 354,41 & 0,00 & 0,55 & 0,736 \\
$(+)-(\mathrm{S})-\mathrm{Vx}$ & 1102,34 & 0,00 & 1,06 & 0,455 \\
$(-)-(\mathrm{R})-\mathrm{Vx}$ & 1243,98 & 0,00 & 2,31 & 0,152 \\
\hline
\end{tabular}

4.4.2.2. Limite de quantificação (LLOQ)

O limite de quantificação foi realizado utilizando para tanto o primeiro ponto da curva analítica. Dessa forma, foi empregado a concentração de $75 \mathrm{ng} \mathrm{mL}^{-1}$ para cada enantiômero da ODV e NDV e $500 \mathrm{ng} \mathrm{mL}^{-1}$ para cada enantiômero da Vx. As concentrações obtidas foram todas próximas às concentrações nominais, com valores de erro (E\%) e desvio padrão relativo (CV\%) menores que 20\% (Tabela 18).

Tabela 18- Limite de quantificação do método para análise dos enantiômeros da $V x$ e seus metabólitos.

\begin{tabular}{|c|c|c|c|c|}
\hline Analitos & $\begin{array}{c}\text { Concentração } \\
\left.\text { Nominal (ng mL }{ }^{-1}\right)\end{array}$ & $\begin{array}{l}\text { Concentração obtida } \\
\left.\text { (ng mL }{ }^{-1}\right)\end{array}$ & $\begin{array}{c}E \\
(\%)\end{array}$ & $\begin{array}{c}\text { DPR } \\
(\%)\end{array}$ \\
\hline$(+)-(\mathrm{S})-\mathrm{ODV}$ & 75 & 76 & 2 & 5 \\
\hline$(-)-(\mathrm{R})-\mathrm{ODV}$ & 75 & 77 & 3 & 7 \\
\hline$(+)-(S)-N D V$ & 75 & 70 & -6 & 6 \\
\hline$(-)-(R)-N D V$ & 75 & 71 & -5 & 12 \\
\hline$(+)-(S)-V x$ & 500 & 512 & 2 & 7 \\
\hline$(-)-(R)-V x$ & 500 & 513 & 2 & 5 \\
\hline
\end{tabular}

\subsubsection{Precisão e exatidão interdia}

A precisão e exatidão interdia foi realizada empregando os valores de concentrações alta, média e baixa de cada analito sendo de 150,300 e $700 \mathrm{ng} \mathrm{mL}^{-1}$ para cada enantiômero da ODV e da NDV e 1500, 7500 e $12000 \mathrm{ng} \mathrm{mL}^{-1}$ para cada enantiômero da $\mathrm{Vx}$. As concentrações obtidas foram todas próximas às concentrações nominais, com valores de erro (E\%) e desvio padrão relativo (DPR\%) menores que $15 \%$ (Tabela 19). 
Tabela 19- Precisão e exatidão inter-dia para análise dos enantiômeros da Vx e seus metabólitos.

\begin{tabular}{|c|c|c|c|c|}
\hline Analitos & $\begin{array}{c}\text { Concentração nominal } \\
\left.\text { (ng mL }{ }^{-1}\right)\end{array}$ & $\begin{array}{l}\text { Concentração obtida } \\
\qquad\left(\mathrm{ng} \mathrm{mL} \mathrm{m}^{-1}\right)\end{array}$ & $\begin{array}{c}E \\
(\%)\end{array}$ & $\begin{array}{l}\text { DPR } \\
(\%)\end{array}$ \\
\hline$(+)-(\mathrm{S})-\mathrm{ODV}$ & $150 / 300 / 700$ & $143 / 332$ / 653 & $-5 / 10 /-7$ & $5 / 1 / 3$ \\
\hline$(-)-(R)-O D V$ & $150 / 300 / 700$ & $148 / 311 / 683$ & $4 /-2 /-2$ & $2 / 4 / 6$ \\
\hline$(+)-(S)-N D V$ & $150 / 300 / 700$ & $147 / 316 / 675$ & $-2 / 5 /-3$ & $6 / 1 / 9$ \\
\hline$(-)-(R)-N D V$ & $150 / 300 / 700$ & 144 / 333 / 650 & $-4 / 11 /-7$ & $2 / 1 / 2$ \\
\hline$(+)-(S)-V x$ & $1500 / 7500 / 12000$ & 1502 / 7404 / 12140 & $0 /-1 / 1$ & $2 / 4 / 5$ \\
\hline$(-)-(R)-V x$ & $1500 / 7500 / 12000$ & $1510 / 6859 / 13316$ & $1 /-8 / 10$ & $2 / 4 / 1$ \\
\hline
\end{tabular}

4.4.2.4. Precisão e exatidão intradia

Da mesma forma, a precisão e exatidão intradia foi realizada com os valores de concentrações alta, média e baixa de cada analito, conforme descrito anteriormente. As concentrações obtidas foram todas próximas às concentrações nominais, com valores de erro $(\mathrm{E} \%)$ e desvio padrão relativo $(\mathrm{CV} \%)$ menores que 15\% (Tabela 20).

Tabela 20- Precisão e exatidão intradia para análise dos enantiômeros da $V x$ e seus metabólitos.

\begin{tabular}{|c|c|c|c|c|}
\hline Analitos & $\begin{array}{c}\text { Concentração nominal } \\
\left.\text { (ng mL }{ }^{-1}\right)\end{array}$ & $\begin{array}{l}\text { Concentração obtida } \\
\qquad\left(\text { ng mL }{ }^{-1}\right)\end{array}$ & $\begin{array}{c}E \\
(\%)\end{array}$ & $\begin{array}{l}\text { DPR } \\
(\%)\end{array}$ \\
\hline$(+)-(\mathrm{S})-\mathrm{ODV}$ & $150 / 300 / 700$ & $135 / 328 / 701$ & $-9 / 9 / 4$ & $6 / 5 / 5$ \\
\hline$(-)-(R)-O D V$ & $150 / 300 / 700$ & $133 / 332$ / 699 & $-10 / 11 / 4$ & $2 / 2 / 4$ \\
\hline$(+)-(S)-N D V$ & $150 / 300 / 700$ & $165 / 315 / 665$ & $10 / 5 /-1$ & $5 / 6 / 6$ \\
\hline$(-)-(R)-N D V$ & $150 / 300 / 700$ & $157 / 281 / 628$ & $5 / 9 /-7$ & $7 / 8 / 2$ \\
\hline$(+)-(S)-V x$ & $1500 / 7500 / 12000$ & $1398 / 7168 / 13351$ & $-7 /-4 / 11$ & $2 / 2 / 1$ \\
\hline$(-)-(R)-V x$ & $1500 / 7500 / 12000$ & 1402 / 7524 / 12313 & $-6 / 0 / 3$ & $2 / 4 / 7$ \\
\hline
\end{tabular}

\subsubsection{Recuperação}

A recuperação foi realizada somente para análise da NDV, pois para $\mathrm{Vx}$ e ODV, os valores já foram descritos anteriormente. Dessa forma, foi possível obter uma recuperação média de $76 \%$ para os enantiômeros da NDV com valor de desvio padrão relativo menor que $15 \%$. 
4.4.2.6. Estabilidade de bancada e ciclos de congelamento e descongelamento dos enantiômeros da Vx e metabólitos

Como foi mencionado no ensaio de recuperação, a estabilidade foi avaliada somente para os enantiômeros da NDV. O ensaio de estabilidade foi realizado em triplicata $(n=3)$ empregando os valor de concentração baixo (150 ng mL $\left.{ }^{-1}\right)$ e alto (700 ng mL $\mathrm{m}^{-1}$ ) da curva analítica. Como pode ser observado na Tabela 21 os enantiômeros se mantém estáveis durante o preparo da amostra e durante o armazenamento.

Tabela 21- Estabilidade de bancada e ciclos de congelamento e descongelamento para análise dos enantiômeros da $\vee x$ e seus metabólitos.

Estabilidade em ciclos de congelamento e descongelamento

\begin{tabular}{cccc}
\hline Analito & Concentração $\left(\mathrm{ng} \mathrm{mL}^{-1}\right)$ & $\mathrm{E} \%$ & DPR\% \\
\hline$(+)-(\mathrm{S})-\mathrm{NDV}$ & $150 / 700$ & $8 /-1$ & $12 / 6$ \\
$(-)-(\mathrm{R})-\mathrm{NDV}$ & $150 / 700$ & $-3 / 4$ & $6 / 8$ \\
\hline
\end{tabular}

Estabilidade de Bancada

\begin{tabular}{cccc}
\hline Analito & Concentração $\left(\mathrm{ng} \mathrm{mL}^{-1}\right)$ & E\% & DPR\% \\
\hline$(+)-(\mathrm{S})-\mathrm{NDV}$ & $150 / 700$ & $1 / 2$ & $8 / 3$ \\
$(-)-(\mathrm{R})-\mathrm{NDV}$ & $150 / 700$ & $6 / 8$ & $4 / 3$ \\
\hline
\end{tabular}

\subsection{ESTUDOS DE BIOTRANSFORMAÇÃO}

\subsubsection{Concentração inibitória mínima (MIC)}

O ensaio de concentração inibitória mínima foi realizado para todas as espécies de fungos em estudo. Não houve indícios de inibição em nenhuma das espécies de fungos empregadas neste estudo. Apenas para a espécie Cunninghamella echinulata ocorreu inibição do crescimento em concentrações mais altas que a de estudo $\left(30 \mu \mathrm{gL}^{-1}\right)$. 


\subsubsection{Estudos de biotransformação}

Os fungos Chaetomiun globosun (VR10), Glomerela cingulata (VA1), Cunninghamella echinulata (ATCC 8688A), Cunninghamella elegans (ATCC 10028B), Mucor rouxii, Beuveria bassiana (ATCC 7159) e Phomopsis sp (TD2) foram submetidos ao processo de biotransformação conforme descrito no item 3.3.4. Apenas uma espécie, Cunninghamella elegans, apresentou potencial de biotransformar a venlafaxina em seus metabólitos O-desmetilvenlafaxina e $N$ desmetilvenlafaxina na condição avaliada nesse estudo.

4.5.2.1. Biotransformação pelo fungo Cunninghamella elegans e análise por CLAE

A análise da biotransformação pelo fungo Cunninghamella elegans foi realizada na condição cromatográfica e de preparação de amostras otimizadas e após validação da metodologia. Após 480 horas de incubação as amostras foram coletadas e analisadas. Como pode ser observado na Figura 23 dois picos (7 e 8) apresentaram tempos de retenção semelhantes aos picos 2, representando 0 enantiômero (-)-(R)-ODV e ao pico 3 representando o enantiômero (+)-(S)-NDV. Na tentativa de confirmar se tais picos tratavam-se desses metabólitos, uma análise do espectro de absorção desses picos foi realizada e comparada com os espectros de absorção das soluções padrão desses analitos. Após análise conclui-se que o espectro de absorção referente ao pico 7 não representa o metabólito (-)-(R)-Odesmetilvenlafaxina como esperado devido à diferenças nos espectros de absorção. Porém, como pode ser observado na Figura 24, o espectro de absorção referente ao pico 8 apresentou significativa semelhança ao espectro de absorção do analito (+)(S)-N-desmetilvenlafaxina (Figura 23). Contudo a quantificação desse analito não foi possível devido à impossibilidade de incluir o metabólito NDV na validação da metodologia empregando CLAE. 


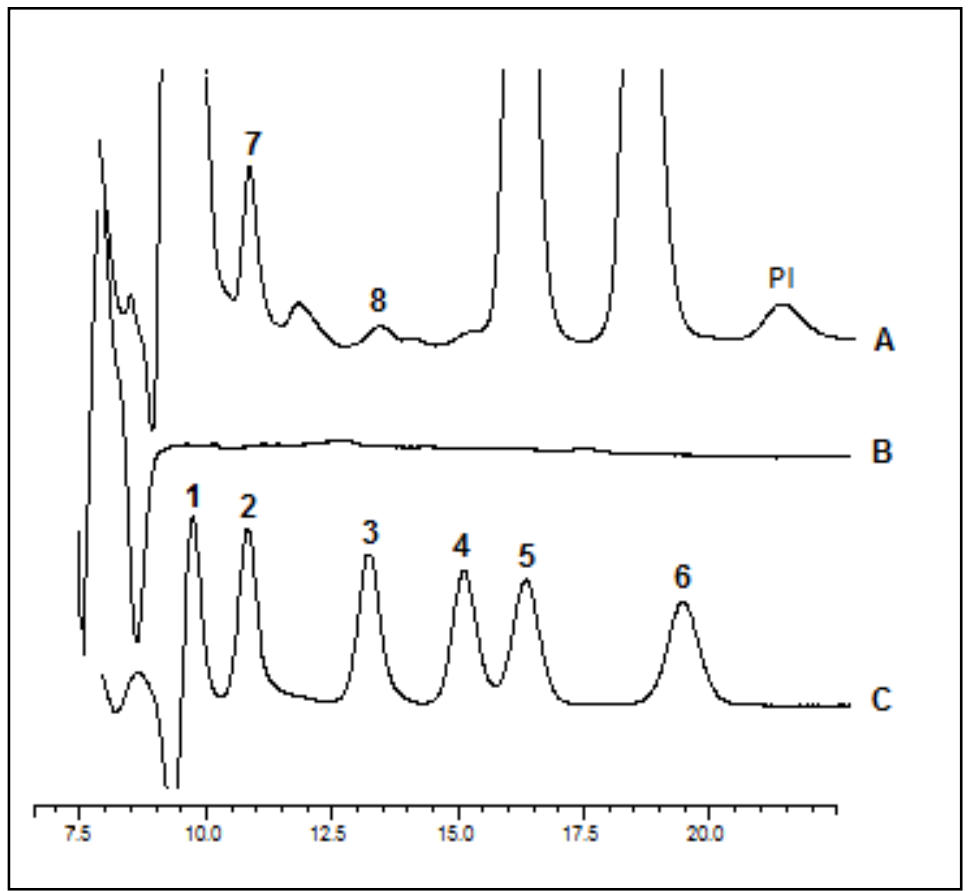

Figura 23- A- Cromatograma referente a biotransformação da venlafaxina pelo fungo Cunninghamella elegans após 480 horas de incubação. B- Amostra controle "branco do fungo" Cunninghamella elegans. C- Cromatograma referente a injeção das soluções padrão da venlafaxina e seus metabólitos. Condições cromatográficas: coluna Chiralpak $\mathrm{AD}-\mathrm{RH}^{\circ}$, fase móvel: metanol: acetonitrila: água (80: 13: $7 \mathrm{v} / \mathrm{V} / \mathrm{V})+0,15 \%$ de trietilamina e vazão de $0,3 \mathrm{~mL} \mathrm{~min}{ }^{-1}$. (1)- (+)-(S)- ODV; (2)- (-)-(R)ODV; (3)-(+)-(S)-NDV; (4)-(-)-(R)-NDV; (5)-(+)-(S)-Vx $\quad(6)-(-)(\mathrm{R})-\mathrm{Vx} ; \quad$ (7)-(8)-produtos de biotransformação do fungo. (PI)-Padrão interno cetoconazol.

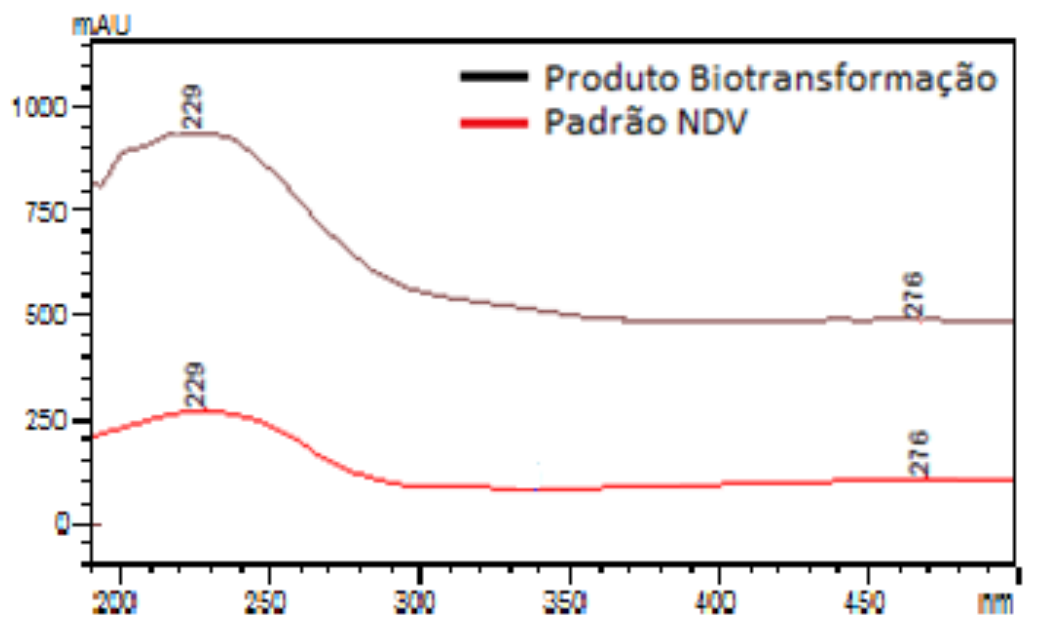

Figura 24- Espectros de absorção dos picos 8 (produto de biotransformação) e $3(+)(S)-N$ desmetilvenlafaxina representados na figura 23. 
4.5.2.2. Biotransformação pelo fungo Cunninghamella elegans e análise por $E C$

A análise da biotransformação pelo fungo Cunninghamella elegans também foi realizada por CE empregando as condições de separação e extração previamente otimizadas. Conforme descrito anteriormente, essa análise foi realizada após 20 dias de incubação. Houve evidências de formação do analito (+)-(S)-Odesmetilvenlafaxina devido à semelhança nos tempos de retenção (picos 8 e 5 da Figura 25). Porém, uma análise dos espectros de absorção mostrou que, provavelmente, o pico 8 representa um produto do metabolismo secundário do fungo. O pico 7 representa a (+)-(S)-N-desmetilvenlafaxina, conforme descrita anteriormente. Contudo nesse caso, a quantificação da (+)-(S)-NDV foi possível, pois o método desenvolvido por CE apresentou seletividade suficiente o que possibilitou a inclusão desse analito na validação da metodologia. Após 20 dias de incubação, a concentração encontrada de (+)-(S)-NDV foi de $191 \mathrm{ng} \mathrm{mL}{ }^{-1}$. Não houve indícios da presença de (+)-(S)-N-desmetilvenlafaxina em tempos inferiores de biotransformação.

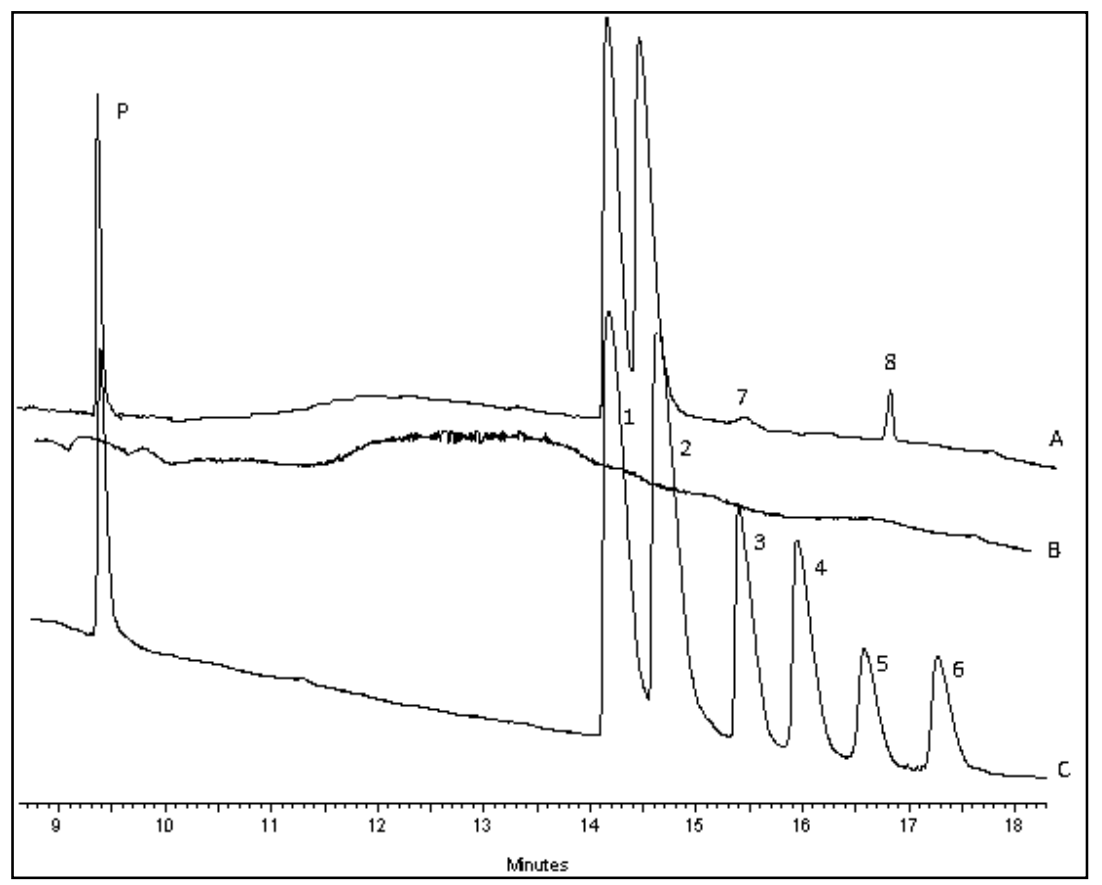

Figura 25- A-Eletroferograma referente a biotransformação da venlafaxina pelo fungo Cunninghamella elegans após 480 horas de biotransformação. B- Amostra controle "branco do fungo" Cunninghamella elegans. C- Eletroferograma referente a análise dos padrões de venlafaxina e seus metabólitos. Condições de análise: solução tampão fosfato de sódio $50 \mathrm{mmol} \mathrm{L}{ }^{-1} \mathrm{pH} 2,0$ contendo CM- $\beta$-CD (1\%) e $\alpha-C D\left(8\right.$ mmol L $\left.{ }^{-1}\right)$, tensão aplicada $+20 \mathrm{kV}$, temperatura de análise $20^{\circ} \mathrm{C}$. (1)-(+)(S)-Vx; (2)-(-)-(R)-Vx; (3)-(+)-(S)-NDV; (4)-(-)-(R)-NDV; (5)-(+)-(S)-ODV (6)-(-)-(R)-ODV; (7), (8)produtos de biotransformação do fungo. (PI)-Padrão interno risperidona. 


\subsubsection{Otimização dos estudos de biotransformação}

Na tentativa de aumentar o rendimento da biotransformação, foram realizadas modificações no meio de cultura e no procedimento anteriormente descrito. As análises foram realizadas por CLAE e também por CE, contudo somente as análises por CE serão descritas, pois nesse método foi também possível a quantificação do metabólito NDV, o qual foi formado em diversas condições. Nessa etapa também foi empregado como tempo de incubação de 480 horas.

4.5.3.1. Substituição da fonte de carbono do meio de cultura líquido Czapek (a sacarose foi substituída pela glicose);

Ao realizar essa modificação, notou-se que houve um aumento na formação da (+)-(S)-N-desmetilvenlafaxina (pico 3) e formação de produtos de metabolismo secundário do fungo nos mesmos tempos de migração dos enantiômeros (-)-(R)NDV (pico 4) e da (+)-(S)-ODV (pico 5). Tais condições podem ser vistas na Figura 26. Esses produtos do metabolismo secundário do fungo apresentaram espectros de absorção diferente do espectro de absorção da solução padrão dos analitos. A

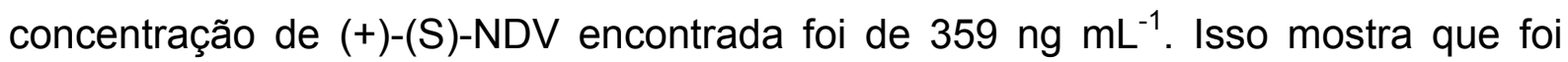
possível obter uma melhora na formação desse analito ao se substituir a sacarose pela glicose no meio de cultura líquido Czapek.

A glicose é um monossacarídeo enquanto a sacarose é um dissacarídeo formado por uma molécula de glicose e uma molécula de frutose. A sacarose é, geralmente, rapidamente hidrolisada em meio biológico. A glicose é prontamente usada pelo micro-organismo em seu metabolismo, o que usualmente, leva a formação de uma quantidade maior de produtos relacionados ao metabolismo secundário dos fungos, como foi observado nesse estudo. 


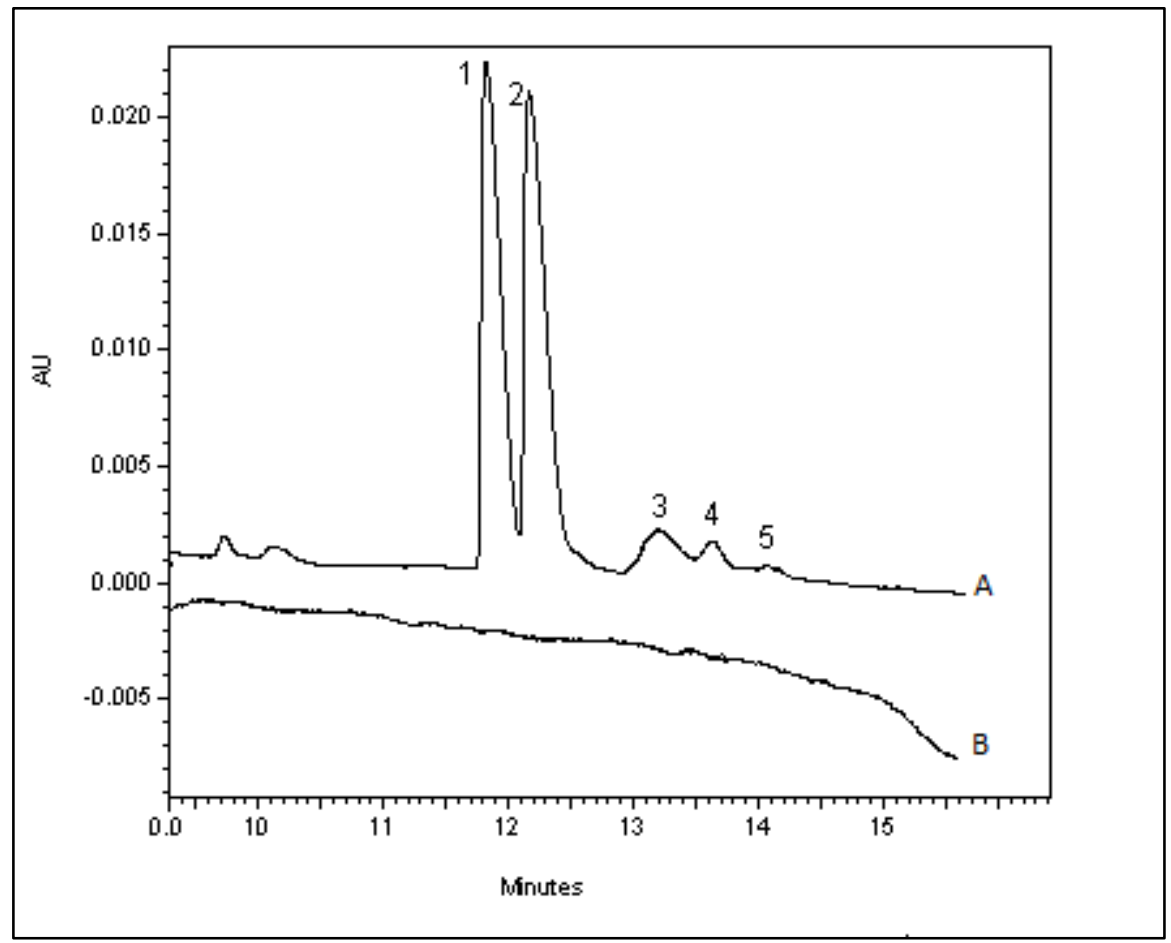

Figura 26- Eletroferograma referente a biotransformação da venlafaxina pelo fungo Cunninghamella elegans em meio de cultura liquido Czapek contendo glicose como fonte de carbono. Aeletroferograma referente a biotransformação da venlafaxina após 480 horas de incubação; BAmostra controle "branco de fungo". Condições de análise: solução tampão fosfato de sódio $50 \mathrm{mmol}$ $\mathrm{L}^{-1} \mathrm{pH} 2,0$ contendo $\mathrm{CM}-\beta-\mathrm{CD}(1 \%)$ e $\alpha-\mathrm{CD}\left(8 \mathrm{mmol} \mathrm{L}^{-1}\right)$, tensão aplicada $+20 \mathrm{kV}$, temperatura de análise $20^{\circ} \mathrm{C}$.

4.5.3.2. Eliminação da fonte de carbono do meio de cultura líquido Czapek deixando apenas a venlafaxina como fonte de carbono;

A eliminação da fonte de carbono do meio de cultura líquido Czapek apresentou uma drástica redução da concentração de venlafaxina, porém não houve o aparecimento de nenhum metabólito da venlafaxina (Figura 27). A quantificação dos enantiômeros da venlafaxina foi realizada apresentando concentrações de 1523 $n g \mathrm{~mL}^{-1}$ e $1516 \mathrm{ng} \mathrm{mL}^{-1}$ para os enantiômeros (+)-(S)-venlafaxina (pico 1) e (-)-(R)venlafaxina (pico 2), respectivamente, o que representa uma diminuição de $95 \%$ da quantidade inicial. Provavelmente, a falta de uma "fonte de alimento" no meio levou a um consumo rápido de toda a venlafaxina pelo fungo assim como os metabólitos produzidos. Nesse caso, uma análise de tempos menores de biotransformação poderia revelar se algum metabólito da venlafaxina foi produzido. 


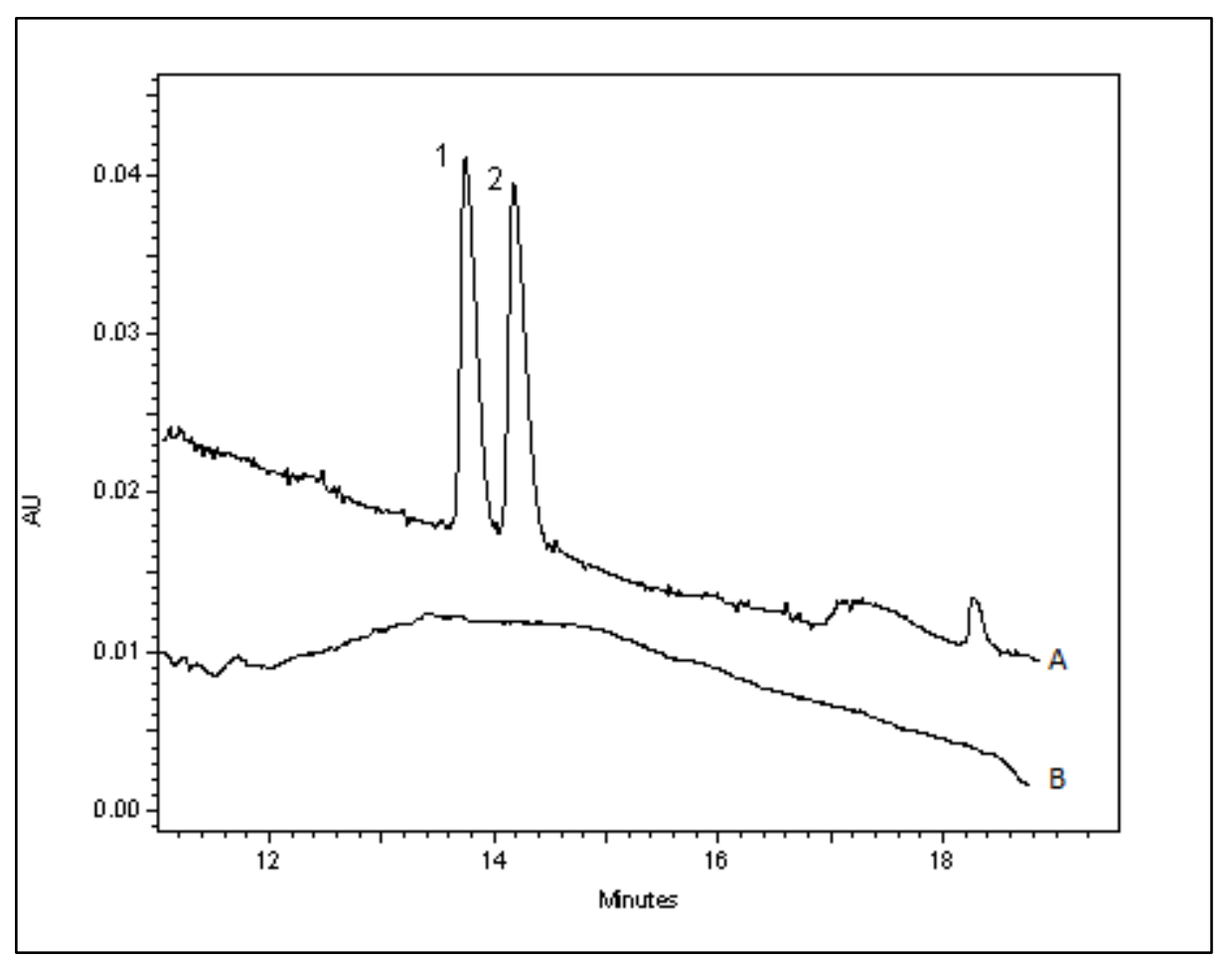

Figura 27. Eletroferograma referente a biotransformação da venlafaxina pelo fungo Cunninghamella elegans em meio de cultura liquido Czapek na ausência de fonte de carbono. A- eletroferograma referente a biotransformação da venlafaxina após 480 horas de incubação; B- Amostra controle "branco de fungo". Condições de análise: solução tampão fosfato de sódio $50 \mathrm{mmol} \mathrm{L}^{-1} \mathrm{pH} 2,0$ contendo $C M-\beta-C D(1 \%)$ e $\alpha-C D\left(8 \mathrm{mmol} \mathrm{L}^{-1}\right)$, tensão aplicada $+20 \mathrm{kV}$, temperatura de análise $20^{\circ} \mathrm{C}$.

4.5.3.3. Eliminação da etapa de pré-fermentação em meio de cultura líquido Malte;

Nessa etapa houve um aumento relativo da biotransformação da venlafaxina em (+)-(S)-N-desmetilvenlafaxina de forma enantiosseletiva (Figura 28). Nessas condições, a concentração encontrada de (+)-(S)-NDV (pico 3) foi de $761 \mathrm{ng} \mathrm{mL}{ }^{-1}$. A etapa de pré-fermentação representa, possivelmente, a fase log do crescimento microbiano. Provavelmente, a eliminação da etapa de pré-fermentação, pode ter levado a fase log para a etapa de meio de cultura líquido Czapek contendo venlafaxina. $\mathrm{Na}$ fase de rápido crescimento microbiano acredita-se que há formação de enzimas que não estão presentes em outras fases (BORGES; BORGES; PUPO; BONATO, 2009), podendo ter influenciado na eficiência de biotransformação. 


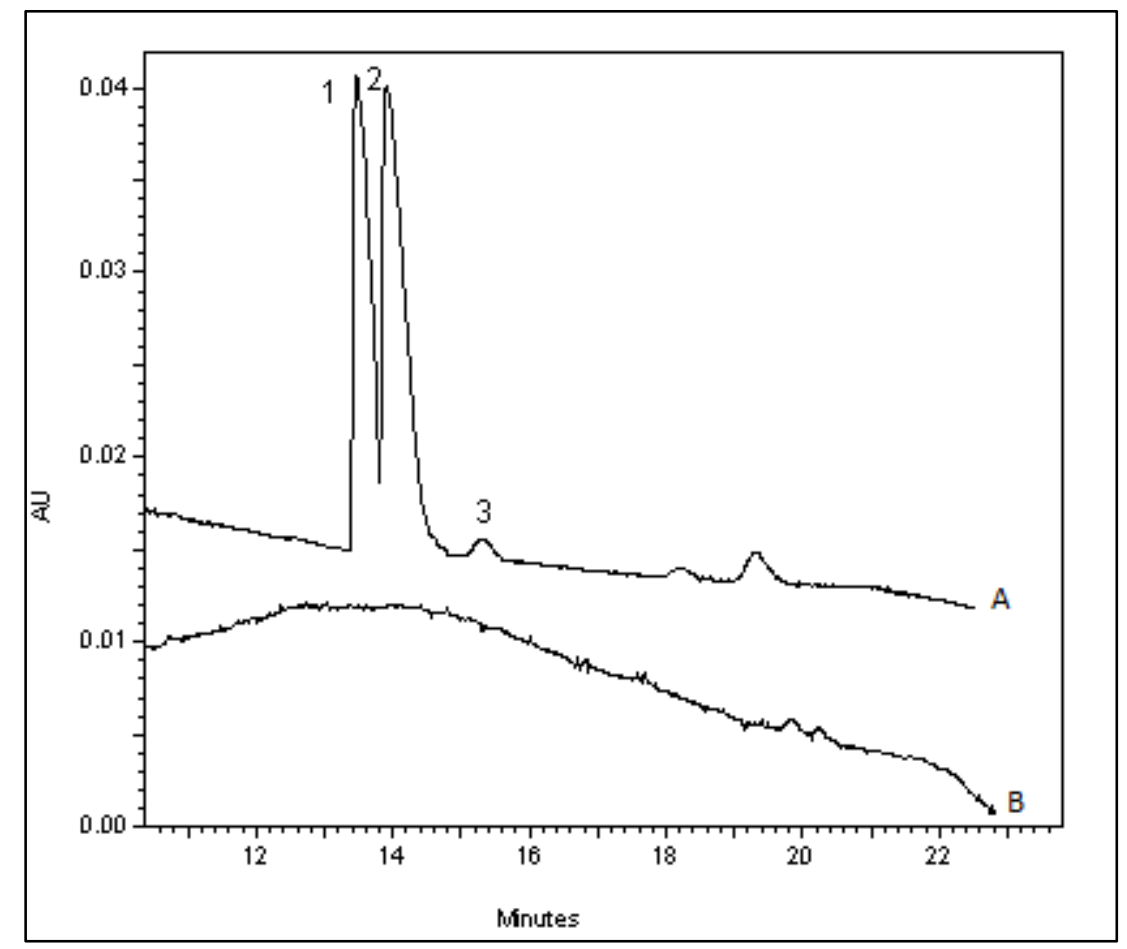

Figura 28- Eletroferograma referente a biotransformação da venlafaxina pelo fungo Cunninghamella elegans em meio de cultura liquido Czapek sem a etapa de pré-fermentação. A- eletroferograma referente a biotransformação da venlafaxina após 480 horas de incubação; B- Amostra controle "branco de fungo". Condições de análise: solução tampão fosfato $50 \mathrm{mmol} \mathrm{L}^{-1} \mathrm{pH} 2,0$ contendo CM- $\beta$ $\mathrm{CD}(1 \%)$ e $\alpha-C D\left(8 \mathrm{mmol} \mathrm{L}^{-1}\right)$, tensão aplicada $+20 \mathrm{kV}$, temperatura de análise $20^{\circ} \mathrm{C}$.

4.5.3.4. Adição da venlafaxina diretamente na etapa de pré-fermentação em meio de cultura líquido Malte (troca de meio de cultura de biotransformação);

Na avaliação desse parâmetro, houve a detecção de um pico com o mesmo tempo de retenção que a (+)-(S)-ODV (pico 4) (Figura 29). Porém, esse produto de biotransformação apresentou espectro de absorção diferente do espectro de absorção da solução do padrão analítico. A biotransformação da venlafaxina em (+)(S)-NDV (pico 3) também apresentou uma melhora significativa, sendo a melhor condição avaliada para a $\mathrm{N}$-desmetilação da venlafaxina. A concentração encontrada foi de $838 \mathrm{ng} \mathrm{mL}^{-1}$.

Assim como foi dito no procedimento anterior, a etapa de pré-fermentação é, possivelmente, representativa da fase log de crescimento microbiano. Portanto, a adição da venlafaxina nessa etapa favorece a biotransformação pela possível presença de enzimas não presentes em outras fases. 


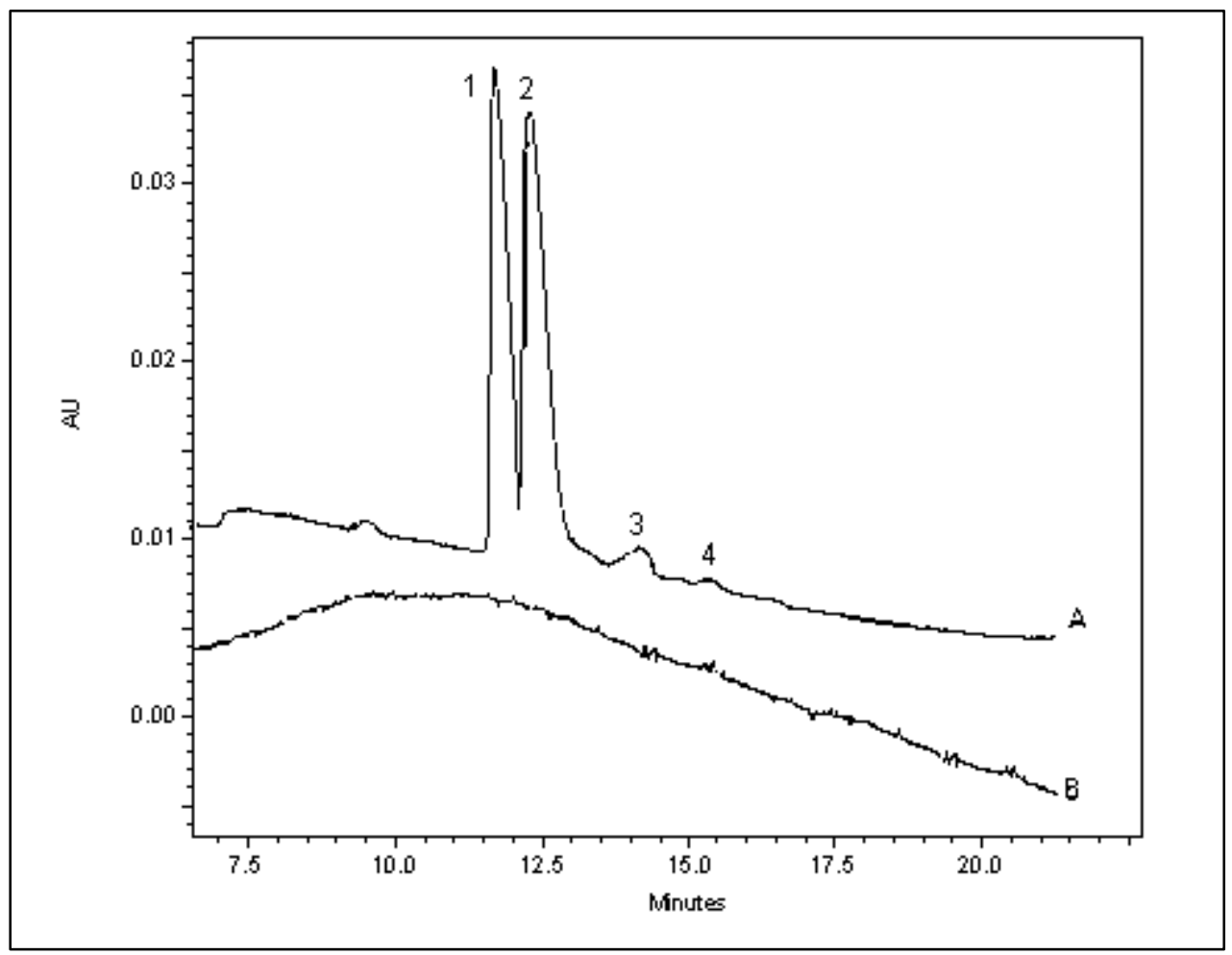

Figura 29. Eletroferograma referente a biotransformação da venlafaxina pelo fungo Cunninghamella elegans em meio de cultura pré-fermentativo malte. A- eletroferograma referente a biotransformação da venlafaxina após 480 horas de incubação; B- Amostra controle "branco de fungo". Condições de análise: solução tampão fosfato $50 \mathrm{mmol} \mathrm{L}^{-1} \mathrm{pH} 2,0$ contendo $C M-\beta-C D(1 \%)$ e $\alpha-C D\left(8 \mathrm{mmol} \mathrm{L} \mathrm{L}^{-1}\right)$, tensão aplicada $+20 \mathrm{kV}$, temperatura de análise $20^{\circ} \mathrm{C}$.

\subsubsection{Adição de cofator NADPH no meio de cultura líquido Czapek.}

A análise da amostra referente a biotransformação em meio de cultura liquido Czapek após a adição do cofator NADPH não apresentou a formação de qualquer metabólito da venlafaxina assim como a presença de interferentes diversos, os quais apresentaram espectros de absorção diferentes dos padrões. Dessa forma, nas condições de biotransformação empregada em nosso trabalho, a presença do cofator não promoveu a biotransformação da venlafaxina em seus metabólitos. 
CONCLUSÕES 


\section{5- CONCLUSÕES}

Esse trabalho apresentou pela primeira vez o estudo enantiosseletivo de biotransformação da venlafaxina empregando fungos. Para isso, foram desenvolvidos métodos de separação quiral da venlafaxina e de seus metabólitos empregando CLAE e eletroforese capilar. Como não foi possível validar o método para análise dos enantiômeros da NDV por CLAE, o método desenvolvido por CE mostrou-se mais seletivo e sensível. A técnica de preparo de amostra empregada, microextração líquido-líquido dispersiva (DLLME), mostrou-se simples, eficiente e seletiva para os analitos de estudo. Além disso, apresentou pouco consumo de solventes orgânicos e altos valores de recuperação (>70\%). Os estudos de biotransformação mostraram que somente fungo Cunninghamella elegans mostrou potencial para a formação de metabólitos da venlafaxina nas condições empregadas nesse estudo. Dessa, empregando esse fungo, algumas modificações no procedimento de biotransformação foram realizadas a fim de se obter uma melhor produção dos metabólitos da venlafaxina. Entre as diversas modificações avaliadas, houve uma significativa melhora somente na produção de NDV, e de maneira enantiosseletiva, a adição da venlafaxina no meio de cultura líquido pré-fermentativo malte e não no meio de cultura liquido Czapek. Provavelmente devido à alteração na fase de crescimento microbiano em que se iniciou a biotransformação, que pode ter levado à produção de enzimas diferentes e ocasionado diferentes estímulos ao fungo. 
REFERÊNCIAS BIBLIOGRÁFICAS 


\section{REFERÊNCIAS BIBLIOGRÁFICAS}

ANVISA - AGÊNCIA NACIONAL DE VIGILÂNCIA SANITÁRIA. Guia para validação de métodos analíticos e bioanalíticos RE. $N^{\circ} .899$, de 29 de Maio de 2003, Brasília, DF, 2003. Disponível em http://www.anvisa.gov.br/legis/resol/2003/re/899_03re.htm. Acesso em 10 de maio de 2012.

BARTH, T.; PUPO, M. T.; BORGES, K.B.; OKANO, L. T.; BONATO, P. S. Stereoselective determination of midodrine and desglymidodrine in culture medium: Application to a biotransformation study emplying endophytic fungi. Electrophoresis, v.31, p.1521-1528, 2010.

BLANCO, M.; VALVERDE, I. Choice of chiral selector for enantioseparation by capillary electrophoresis. Trends in Analytical Chemistry, v. 22, p. 428-439, 2003.

BOCATO M.Z.; SIMÕES R.A.; CALIXTO L.A.; GAITANI C.M.; PUPO M.T.; DE OLIVEIRA A.R.M. Solid phase microextraction and LC-MS/MS for the determination of paliperidone after stereoselective fungal biotransformation of risperidone. Analytica Chimica Acta, v.742, p. 80-89, 2012.

BONATO, P. S.; JABOR, V. A. P.; GAITANI C.M. Análise enantiosseletiva de fármacos: contribuições da cromatografia líquida de alta eficiência e eletroforese capilar. Quimica Nova, v.28, p. 683-691, 2005.

BORGES, K.B.; BORGES, W.D.; PUPO, M. T.; BONATO, P. S. Stereoselective analysis of thioridazine-2-sulfoxide and thioridazine-5-sulfoxide: An investigation of rac-thioridazine biotransformation by some endophytic fungi. Journal of Pharmaceutical and Biomedical Analysis, v.46, p. 945-952, 2008.

BORGES, K. B.; BORGES, W. D.; PUPO, M. T.; BONATO, P. S. Endophytic fungi: natural products, enzymes and biotransformation reactions. Current Organic Chemistry, v.13, p. 1137-1163, 2009b. 
BRUICE,Y.P. Estereoquímica: arranjo dos átomos no espaço; estereoquímica de reações de adição. In: Química Orgânica. 4.Ed, v.1, São Paulo: Pearson, 2006. Capítulo 5, p.180-234.

CALDAS, S.S.; GONÇALVEZ, F. F.; PRIMEL, E.G. Principais técnicas de preparo de amostras para a determinação de resíduos de agrotóxicos em água por cromatografia líquida com detecção por arranjo de diodos e por espectrometria de massas. Química Nova, v.34, p. 1604-1617, 2011.

CARRÃO, D.B.; BORGES, K.B.; BARTH, T.; PUPO, M.T.; BONATO, P.S.; DE OLIVEIRA, A.R.M. Capillary electrophoresis and hollow fiber liquid-phase microextraction for the enantioselective determination of albendazole sulfoxide after biotransformation of albendazole by an endophytic fungus. Electrophoresis, ,v.32, p. 2746-2756, 2011.

COLLINS, H.C.; BRAGA, G.L.; BONATO, P.S. Cromatografia Líquida de Alta Eficiência. In: . Fundamentos de Cromatografia.1.Ed. Campinas: Editora Unicamp, 2006. Capítulo 9, p. 273-398.

DA FONSECA, P.; BONATO, P. S. Chiral HPLC analysis of venlafaxine metabolites in rat liver microsomal preparations after LPME extraction and application to an in vitro biotransformation study. Analytical and Bioanalytical Chemistry. v.396, p. 817-824, 2010.

DE ANTONIO, M.C.O. Permeação cutânea in vitro como ferramenta auxiliar para o estudo de formulações semi-sólidas de cetononazol para aplicações tópicas. 2007. 147 f. Dissertação (Mestrado em Ciências Farmacêuticas), Universidade Federal do Paraná, Curitiba, 2007.

DE JESUS, L.I.; ALBURQUERQUE, N.C.; BORGES, K.B.; SIMÕES, R.A.; CALIXTO, L.A.; FURTADO, N.A.J.C; GAITANI, C.M.; PUPO, M.T.; DE OLIVEIRA, A.R.M. Enantioselective fungal biotransformation of risperidone in liquid culture medium by capillary electrophoresis and hollow fiber liquid-phase 
microextraction. Electrophoresis, v.32, p. 2765-2775, 2011.

EECKHAUT, A.V.; MICHOTTE, Y. Factors influencing ciclodextrin-mediated chiral separations. In: Chiral Separations by capillary electrophoresis. $1 \mathrm{Ed}$, vol. 100. New York: CRC Press, 2009. Capítulo 4, p. 87-107.

ELIEZER, J.B.; FRAGA,C.A.M. A importância do conhecimento do mecanismo molecular de ação dos fármacos. In: . Química Medicinal: As bases moleculares da ação dos fármacos. 2.Ed. Porto Alegre: Editora Artmed, 2008. Capítulo 4, p. 133-160.

EMA - EUROPEAN MEDICINES AGENCY GUIDELINES. Guia para validação de métodos bioanalíticos. 21 de Julho de 2011, Londres, UK, 2011. Disponível em:

http://www.ema.europa.eu/docs/en_GB/document_library/Scientific_guideline/201 1/08/WC500109686.pdf.

FANALI, S. Enantioselective determination by capillary electrophoresis with ciclodextrins as chiral selectors. Journal of Chromatography A, v.875, p. 89122, 2000.

FANALI, S.; RUDAZ, S.; VEUTHEY, J. L.; DESIDERIO, C. Use of vancomycin silica stationary phase in packed capillary electrochromatography II. Enantiomer separation of venlafaxine and O-desmethylvenlafaxine in human plasma. Journal of Chromatography A, v. 919, p. 195-203, 2001.

FILLET, M.; HUBERT, P.H.; CROMMEN, J. Enantiomeric separations of drugs using mixtures of charged and neutral ciclodextrins. Journal of Chromatography A, v. 875 , p. $123-134,2000$.

FORTES, S.S.; BARTH, T.; FURTADO, N.A.J.C; PUPO, M.T.; GAITANI, C.M.; DE OLIVEIRA, A.R.M. Application of dispersive liquid-liquid microextraction and capillary electrophoresis for the stereoselective determination of cetirizine after 
fungal biotransformation of hydroxyzine. Talanta, v.116, p. 743-752, 2013.

GHAMBARI, H.; HADJMOHAMMADI, M. Low-density solvent-based dispersive liquid-liquid microextraction followed by high performance liquid chromatography for determination of warfarin in human plasma. Journal of Chromatogrphy B, v. 899, p. 66-71, 2012.

HILARIO, V. C.; CARRÃO, D.B.; BARTH, T.; BORGES, K.B.; FURTADO, N.A.J.C.; PUPO, M.T.; DE OLIVEIRA, A.R.M. Assessment of the stereoselective fungal biotransformation of albendazole and its analysis by HPLC in polar organic mode. Journal of Pharmaceutical and Biomedical Analysis, v. 61, p. 100-107, 2012.

HOLLIDAY, S. M.; BENFIELD, P. Venlafaxine: a review of its pharmacology and therapeutic potential in depression. Drugs, v. 49, p. 280-294, 1995.

KINGBÄCK, M.; JOSEFSSON, M.; KALRSSON, L.; AHLNER, J.; BENGTSSON, F.; KUGELBERG, F. C.; CARLSSON, B. Stereoselective determination of venlafaxine and its three demethylated metabolites in human plasma and whole blood by liquid chromatography with electrospray tandem mass spectrometric detection and solid phase extraction. Journal of Pharmaceutical and Biomedical Analysis, v. 53, p. 583-590, 2010.

KOHLER, I.; SCHAPPLER, J.; SIERRO, T.; RUDAZ, S. Dispersive liquid-liquid microextraction combined with capillary electrophoresis and time-of-flight mass spectrometry for urine analysis. Journal of Pharmaceutical and Biomedical Analysis, v.73, p. 82-89, 2013.

LOURENÇO, T. C.; CASSIANO, N. M.; CASS, Q. B. Fases estacionárias quirais para cromatografia líquida de alta eficiência. Química Nova, v. 33, p. 2155-2164, 2010. 
MASHAYEKHI, H.A.; ABROOMAND-AZAR, P.; SABER-TEHRANI, M.; HUSAIN, S. W. Rapid determination of carbamazepine in human urine, plasma samples and water using DLLME followed by RP-LC. Chromatographia, v. 71, p. 517$521,2010$.

MENG, L.; WANG, B.; LUO, F.; SHEN, G.; WANG, Z.; GUO. M. Application of dispersive liquid-liquid microextraction and CE with UV detection for the chiral separation and determination of the multiple illicit drugs on forensic samples. Forensic Science International, v. 209, p. 42-47, 2011.

MOREIRA, F.L.; DE SOUZA, G.B.; RODRIGUES, I.V.; LOPES, N.P.; DE OLIVEIRA, A.R.M. A non-michaelian behavior of the in vitro metabolism of the pentacyclic triterpene alfa and beta amyrins by employing rat liver microsomes. Journal of Pharmaceutical and Biomedical Analysis, v. 84, p. 14-19, 2013.

PELCZAR, M.J.; CHAN, E.C.S.; KRIEG, N.R. Introdução à microbiologia. In: Microbiologia: conceitos e aplicações. 2.Ed, vol.1, São Paulo: Pearson Makron Books, 1996. Capítulo 1, p. 3-58.

PERRY, R.; CASSAGNOL, M. Desvenlafaxine: a new serotonin-norepinephrine reuptake inhibitor for the treatment of adults with major depressive disorder. Clinical Therapeutics, v. 31, p. 1374-1404, 2009.

PUPO, M. T.; BORGES, K. B.; BORGES, W. S.; BONATO, P. S. Fungal Biotransformations: a Powerful Tool in Drug Metabolism Studies. In: Ratul Saikai; Rajib L. Bezbaruah; Tarun Ch. Bora. (Org.)., New Delhi: New India Publishing Agency. 2008, p. 47-66.

REZAEE, M.; ASSADI, Y.; HOSSEINI, M.M.; AGHAEE, E.; AHMADI, F.; BERIJANI, S. Determination of organic compounds in water using dispersive liquid-liquid microextraction. Journal of Chromatography A, v. 1116, p. 1-9, 2006. 
REZAEE, M.; YAMINI, Y.; FARAJI, M. Evolution of dispersive liquid-liquid microextraction method. Journal of Chromatography A. v. 1217, p. 2342-2357, 2010.

RUDAZ, S.; STELLA, C.; BALANT-GORGIA, A. E.; FANALI, S.; VEUTHEY, J. L. Simultaneous stereoselective analysis of venlafaxine and $O$ desmethylvenlafaxine enantiomers in clinical samples by capillary electrophoresis using charged ciclodextrins. Journal of Pharmaceutical and Biomedical Analysis, v. 23, p. 107-115, 2000.

RUDAZ, S.; VEUTHEY, J.-L.; DESIDERIO, C.; FANALI,S. Enantioseparation of venlafaxine and $O$-desmethylvenlafaxine by capillary electrophoresis with mixed cyclodextrins. Chromatographia, v. 50, p. 369-372, 1999.

SNYDER, L.R.; KIRKLAND, J. J.; GLAJCH, J. L. Basics of Separations. In:

Pratical HPLC Method Development. 2.Ed. California: Wiley Interscience,1997. Capítulo 2, p. 23-54.

SPINA, E.; SANTORO, V.; D'ARRIGO, C. Clinically relevant pharmacokinetic drug interations with second-generation antidepressants: an update. Clinical Therapeutics, v. 30, p. 1206-1227, 2008.

SUH, J.H.; LEE, Y.Y.; LEE, H.J.; KANGA, M.; HURA, Y.; LEEA, S.N.; YANGA, D.; HANA, S.B. Dispersive liquid-liquid microextraction based on solidification of floating organic droplets followed by high performance liquid chromatography for the determination of duloxetine in human plasma. Journal of Pharmaceutical and Biomedical Analysis, v. 75 , p. 214-219, 2013.

TESTA, B.T. Oxidations catalyzed by various oxidases and monoxygenases. In:__. The metabolism of drugs and other xenobiotics. San Diego: Academic Press, 1995. Capítulo 3, p. 323-334.

TRIOLA,M.F. Correlação e Regressão. In: . Introducão à Estatística. 9 Ed. Rio de Janeiro: Editora LTC, 2005. Capítulo 10, p. 414-458. 
WEINBERGER, R. Capillary zone electrophoresis: Basics concepts. In:

Practical Capillary Electrophoresis. 2 Ed. New York: Academic Press, 1999. Capítulo 2, p. 25-71.

WEN, L; CAI, H; LI, H. High performance liquid chromatography-electrospray ionization mass spectrometry (HPLC-MS/ESI) method for simultaneous determination of venlafaxine and its three metabolites in human plasma. Journal of Chromatography B, v. 850, p. 405-411, 2007.

XIAO-HUAN, Z.; QIU-HUA, W.; MEI-YUE, Z.; GUO-HONG, X.; ZHI, W. Developments of dispersive liquid-liquid microextraction technique. Chinese Journal of Analytical Chemistry, v. 37, p. 161-168, 2009.

ZGOTA-GRZESKOWIAK, A; GRZESKOWIAK, T. Dispersive liquid-liquid microextraction. Trends in Analytical Chemistry, v. 30, p. 1382-1399, 2011.

ZHANG, D; ZHU, M; HUMPHREYS, W. Oxidative, reductive and hydrolytic metabolism of drugs. In:__. Drug metabolism in drug design and development. 1 Ed. New Jersey: Wiley Interscience, 2007. Capítulo 2, p. 15-35. 